MLM--3245-Add. 1

DE88 001510

\title{
DOE EVALUATION DOCUMENT FOR DOT 7A TYPE A PACKAGING
}

Don A. Edling, Daniel R. Hopkins, and Russell L. Williams

March 1987

Monsanto

\section{MOUND}

Miamisburg. Ohio 45342

\section{operated by}

MONSANTO RESEARCH CORPORATION

a subsidiary of Monsarito Company

for the

U. S. DEPARTMENT OF ENERGY

Contract No. DE-ACO4-76-DPODO53 


\section{DISCLAIMER}

This report was prepared as an account of work sponsored by an agency of the United States Government. Neither the United States Government nor any agency Thereof, nor any of their employees, makes any warranty, express or implied, or assumes any legal liability or responsibility for the accuracy, completeness, or usefulness of any information, apparatus, product, or process disclosed, or represents that its use would not infringe privately owned rights. Reference herein to any specific commercial product, process, or service by trade name, trademark, manufacturer, or otherwise does not necessarily constitute or imply its endorsement, recommendation, or favoring by the United States Government or any agency thereof. The views and opinions of authors expressed herein do not necessarily state or reflect those of the United States Government or any agency thereof. 


\section{DISCLAIMER}

Portions of this document may be illegible in electronic image products. Images are produced from the best available original document. 
INTRODUCTION . . . . . . . . . . . . . . . . . . . . . . . I I

173.24 - STANDARD REQUIREMENTS FOR ALL PACKAGES

Stee1 Drums... . . . . . . . . . . . . . . . . A-1

Steel Boxes... . . . . . . . . . . . . . . A-7

Wooden Boxes . . . . . . . . . . . . . . . . . A-13

Fiberboard Containers . . . . . . . . . . . . . . . A-19

UF-6 Cylinders . . . . . . . . . . . . . . . . . . A-25

Liquids and Gases . . . . . . . . . . . . . . . . . A-31

Miscellaneous . . . . . . . . . . . . . . . . . . A-37

173.411 - GENERAL DESIGN REQUIREMENTS

Steel Drums . . . . . . . . . . . . . . . . . B-1

Steel Boxes . . . . . . . . . . . . . . . . . . . . . B-4

Wooden Boxes .. . . . . . . . . . . . . . . . . B-7

Fiberboard Containers... . . . . . . . . . . . . B-10

UF-6 Cylinders . . . . . . . . . . . . . . . . . . . . . . B-14

Liquids and Gases . . . . . . . . . . . . . . . . B-17

Miscellaneous... . . . . . . . . . . . . . B-20

173.412 - ADDITIONAL DESIGN REQUIREMENTS FOR TYPE A PACKAGES

Stee1 Drums . . . . . . . . . . . . . . . . . . . C-1

Steel Boxes.... . . . . . . . . . . . . . . C 12

Wooden Boxes . . . . . . . . . . . . . . . . . . . C-21

Fiberboard Containers . . . . . . . . . . . . . . . C-30

UF-6 Cylinders . . . . . . . . . . . . . . . . . . . . . . C-35

Liquids and Gases . . . . . . . . . . . . . . . . . . . . C-40

Miscellaneous . . . . . . . . . . . . . . . . . . . . . C-49

173.465 - TYPE A PACKAGING TESTS

Water Spray Test

Steel Drums . . . . . . . . . . . . . . D-3

Steel Boxes . . . . . . . . . . . . . . D 5

Wooden Boxes . . . . . . . . . . . . . . . . . D-7

Fiberboard Containers . . . . . . . . . . . . D-12

UF-6 Cylinders. . . . . . . . . . . . . . . . . . . . D-13

Liquids and Gases . . . . . . . . . . . . . . . . D-14

Miscellaneous . . . . . . . . . . . . . D-16

DISTRIBUTIOH OF THIS DOCUMEHT IS UALIMITER 
Free Drop Test (Four- and Thirty-Feet)

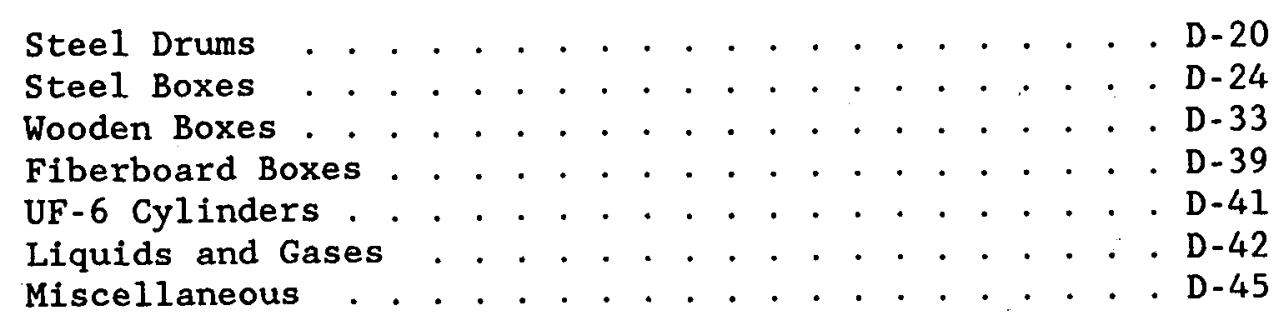

Free Drop Test (Corner)

Steel Drums ............... . Not Required Steel Boxes .. . . . . . . . . . . . . Not Required Wooden Boxes . . . . . . . . . . . . . . . . D-46 Fiberboard Boxes... . . . . . . . . . . . . . D-48 UF-6 Cylinders . . . . . . . . . . . . . . . Not Required Liquids and Gases . . . . . . . . . . . . . . . D-48 Miscellaneous . . . . . . . . . . . . Not Required

Compression Test

Steel Drums . . . . . . . . . . . . . . D-51

Steel Boxes .. . . . . . . . . . . . . . D-53

Wooden Boxes... . . . . . . . . . . . . D-57

Fiberboard Boxes... . . . . . . . . . . . D-62

UF-6 Cylinders . . . . . . . . . . . . . . . . . D-65

Liquids and Gases . . . . . . . . . . . . . D-66

Miscellaneous . . . . . . . . . . . . . . . D-69

Penetration Test

Steel Drums . . . . . . . . . . . . . . . D-71

Steel Boxes . . . . . . . . . . . . . . . . D-74

Wooden Boxes . . . . . . . . . . . . . . . . . . . D-80

Fiberboard Boxes . . . . . . . . . . . . . . D-86

UF-6 Cylinders . . . . . . . . . . . . . . . . . . D-89

Liquids and Gases . . . . . . . . . . . . . . . D-90

Miscellaneous . . . . . . . . . . . . . . D-92 
INTRODUCTION

This document is a support document for the DOE Evaluation Document for DOT 7A Type A Packaging, MLM-3245, March 1987.

Provided herein are details concerning the performance requirements specified in 178.350 Specification 7A, General Packaging, Type A.

MLM-3245 references appropriate sections in this document.

This document does not by itself meet the documentation requirements specified in 49 CFR 173.415 and has compliance value only when used in conjunction with MLM-3245.

\section{DISCLAIMER}

This report was prepared as an account of wort

Government. Neither the United States of work sponsored employees, makes any warranty States Government nor any an agency of the United States bility for the accuracy, completeness, or implied, or assumes any thereof, nor any of their process disclosed, or represents that or usefulness of any informatiogal liability or responsience herein to any specific commertial use would not infringe privately apparatus, product, or manufacturer, or otherwise does not product, process, or service by trawned rights. Refermendation, or favoring by does not necessarily conss, or service by trade name, trademarkand opinions of aung by the United States Governmte or imply its endorsement, United States Government expressed herein do not necest or any agency thereof. The recom.

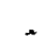


173.24 - STANDARD REQUIREMENTS FOR AIL PACKAGES

(a) Each package used for shipping hazardous material under this subchapter shall be so designed and constructed, and its contents so limited, that under conditions normally incident to transportation:

(1) There will be no significant release of the hazardous materials to the enviroment;

(2) The effectiveness of the packaging will not be substantially reduced; and

(3) There will be no mixture of gases or vapors in the package which could, through any credible spontaneous increase of heat or pressure or through an explosion, significantly reduce the effectiveness of the packaging.

(b) Materials for which detailed specifications for packaging are not set forth in this part must be securely packaged in strong, tight packages meeting the requirements of this section.

\section{ACIION REOUIRED/BY WHOM}

\section{PACKAGTIG CATEGORY}

$$
\text { STEEL DRUMS }
$$

To be considered during package design evaluation. Shipper responsibility to ensure.

To be considered during package design evaluation. Shipper responsibility to ensure. one aspect for strong consideration is effect of contents on packaging effectiveness.

Shipper responsibility to ensure.

Does not apply. MIM-3245 and this addendum.
All packagings met the intent of this requirement as demonstrated by meeting the more severe Type A packaging requirements of $173.411, .412$, .465 , and/or .466 as demonstrated in MIM-3245 and this addendum.

All packagings met the intent of this requirement as demonstrated by meeting the more severe Type A packaging requirements of $173.411, .412$, .465 , and/or .466 as demonstrated in

NOTE: Shipper responsibility to consider and evaluate, if necessary, the effect of the contents.

Shipper responsibility to ensure. 
(c) Packaging used for the shipment of hazardous matrials under this subchapter shall, unless otherwise specified or exempted therein, meet all of the following design and construction criteria:

(1) Each specification container must be marked as follows:

(i) In an unobstructed area with letters and numerals identifying the container specification (e.g., DOT-1A, DOT-17E-304HT, DOT-23G40) . see 178.0-2 of this subchapter.

(ii) The name and address or symbol of person making the mark specified in paragraph (c) (1) (i) of this section. Symbol letters, if used, must be registered with the Director, OHMT. Duplicate symbols are not authorized.

(iii) The markings must be stamped, embossed, burned, printed, or otherwise marked on the packaging to provide adequate accessibility, permanency, and contrast so as to be readily apparent and understood.

(iv) Unless otherwise specified, letters and numerals must be at least $1 / 2$ in. high.
Package must be marked "DOT 7A TYpe A." Shipper responsibility to ensure.

Shipper responsibility to ensure.

Shipper responsibility to ensure.

Shipper responsibility to ensure.
Shipper responsibility to ensure.

Shipper responsibility to ensure.

Shipper responsibility to ensure. 
(v) Packaging which does not comply with the applicable specification listed in parts 178 and 179 of this subchapter must not be marked to indicate such compliance (see 178.0-2 and 179.1 of this subchapter).

(2) Steel used shall be low-carbon commercial quality steel. Stainless, open hearth, electric, basic oxygen, or other similar quality steels are acceptable. Steel sheets of specified gauges shall comply with the following:

\begin{tabular}{|c|c|c|}
\hline $\begin{array}{l}\text { Gauge } \\
\text { No. }\end{array}$ & $\begin{array}{l}\text { Normal } \\
\text { Thickness } \\
\text { (in.) }\end{array}$ & $\begin{array}{l}\text { Minimm } \\
\text { Thickmess } \\
\text { (in.) }\end{array}$ \\
\hline 12 & 0.1046 & 0.0946 \\
\hline 13 & 0.0897 & 0.0817 \\
\hline 14 & 0.0747 & 0.0677 \\
\hline 15 & 0.0673 & 0.0603 \\
\hline 16 & 0.0598 & 0.0533 \\
\hline 17 & 0.0538 & 0.0478 \\
\hline 18 & 0.0478 & 0.0428 \\
\hline 19 & 0.0418 & 0.0378 \\
\hline 20 & 0.0359 & 0.0324 \\
\hline 22 & 0.0299 & 0.0269 \\
\hline 23 & 0.0269 & 0.0239 \\
\hline 24 & 0.0239 & 0.0209 \\
\hline 26 & 0.0179 & 0.0159 \\
\hline 28 & 0.0149 & 0.0129 \\
\hline 30 & 0.0120 & 0.0110 \\
\hline
\end{tabular}

Shipper responsibility to ensure.

Desigmer and fabricator to do and shipper responsibility to ensure.
Shipper responsibility to ensure.

Shipper responsibility to ensure. 


\section{ACTION REQUIRED/BY WHOM}

(3) Lumber used shall be wellseasoned, commercially dry, and free from decay, loose knots, knots that would interfere with nailing, and other defects that would materially lessen the strength.

(4) Welding and brazing shall be performed in a workmanlike manner using suitable and appropriate techniques, materials, and equipment.

(5) Packaging materials and contents shall be such that there will be no significant chemical or galvanic reaction among any of the materials in the package.

(6) Closure shall be adequate to prevent inadvertent leakage of the contents under normal conditions incident to transportation. Gasketed closures shall be fitted with gaskets of efficient materials which will not be deteriorated by the contents of the container.

(7) Nails, staples, and other metallic devices shall not protrude into the interior of the outer packaging in such a manner as to be likely to cause failures.

(8) The nature and thickness of the packaging shall be such that friction during transport does not generate any heating likely to decrease the chemical stability of the contents.
Designer and fabricator to do and shipper responsibility to ensure.

Fabricator to do and shipper responsibility to ensure.

Designer to do and shipper responsibility to ensure.

Designer to do and shipper responsibility to ensure.

Fabricator to do and shipper responsibility to ensure.

Fabricator to do and shipper responsibility to ensure.
Shipper responsibility to ensure.

Shipper responsibility to ensure.

Shipper responsibility to ensure.

Shipper responsibility to ensure.

Shipper responsibility to ensure.

Shipper responsibility to ensure. 
(d) Polyethylene packagings and receptacles:

(1) Polyethylene used in packagings and receptacles must be of a type compatible with the lading and may not be permeable to an extent that a hazardous condition occurs during transportation, handling, or refilling.

(2) Each polyethylene packaging or receptacle which is used for liquid hazardous materials must be capable of withstanding without failure the procedure specified in Appendix B of this part ("Procechure for Testing Chemical Compatibility and Rate of Permeation in Polyethylene Packagings and Receptacles") and the maximum rate of permeation of hazardous lading through or into the polyethylene packaging or receptacles may not exceed the following rates:

(i) 0.5 percent for materials meeting the definition of a poison according to this subchapter and 2.0 percent for other hazardous materials, when subjected to temperatures no lower than $18^{\circ} \mathrm{C}\left(64^{\circ} \mathrm{F}\right)$ for 180 days in accordance with Test Method 1 ;

(ii) 0.5 percent for materials meeting the definition of a poison according to this subchapter and 2.0 percent for other hazardous materials, when subjected to temperatures no lower than $50^{\circ} \mathrm{C}\left(122^{\circ} \mathrm{F}\right)$ for 28 days in accordance with Test Method 2;
Desigmer to do and shipper responsibility to ensure.

Desiomer, tester, and evaluator to do and shipper responsibility to ensure.
Shipper responsibility to ensure.

Shipper responsibility to ensure. 
(iii) 0.5 percent for materials meeting the definition of a poison according to this subchapter and 2.0 percent for other hazardous materials, when subjected to temperatures no lower than $60^{\circ} \mathrm{C}\left(140^{\circ} \mathrm{F}\right)$ for 14 days in accordance with Test Method 3;

(3) Alternative procedures or rates of permeation are permitted if they yield a level of safety equivalent to or greater than that provided by paragraph (d) (2) of this section and are approved by the Director, OHMT.

(4) Each polyethylene packaging used as an outside packaging for materials meeting the definition of a poison according to this subchapter shall be permanently marked, by embossment or other durable means, with the word "POISON" in letters of at least $1 / 4$ in. in height. Additional text or symbols may be included in the marking. The marking shall be located within six inches of the packaging's closure. The requirements of this subparagraph do not apply prior to September 1, 1985.

(e) For specification containers, compliance with the applicable specifications in Parts 178 and 179 of this subchapter shall be required in all details, except as otherwise provided in this subchapter.
Shipper responsibility to ensure.

Shipper responsibility to ensure.

Shipper responsibility to ensure.

Shipper responsibility to ensure.
Shipper responsibility to ensure.

Shipper responsibility to ensure. 
(a) Each package used for shipping hazardous material under this subchapter shall be so designed and constructed, and its contents so limited, that under conditions normally incident to transportation:

(1) There will be no significant release of the hazardous materials to the enviroment;

(2) The effectiveness of the packaging will not be substantially reduced; and

(3) There will be no mixture of gases or vapors in the package which could, through any credible spontaneous increase of heat or pressure or through an explosion, significantly reduce the effectiveness of the packaging.

(b) Materials for which detailed specifications for packaging are not set forth in this part must be securely packaged in strong, tight packages meeting the requirements of this section.

\section{ACIION REOUIRED/BY WHOM}

\section{PACKAGING CATEGORY STEEL BOXES}

To be considered during package design evaluation. Shipper responsibility to ensure.

To be considered during package design evaluation. Shipper responsibility to ensure. one aspect for strong consideration is effect of contents on packaging effectiveness.

Shipper responsibility to ensure.

Does not apply.
All packagings met the intent of this requirement as demonstrated by meeting the more severe Type A packaging requirements of $173.411, .412$, .465 , and / or .466 as demonstrated in MIM-3245 and this addendum.

All packagings met the intent of this requirement as demonstrated by meeting the more severe Type A packaging requirements of $173.411, .412$, .465 , and/or .466 as demonstrated in MLM-3245 and this addendum.

NOTE: Shipper responsibility to consider and evaluate, if necessary, the effect of the contents.

Shipper responsibility to ensure. 
(c) Packaging used for the shipment of hazardous matrials under this subchapter shall, unless otherwise specified or exempted therein, meet all of the following design and construction criteria:

(1) Each specification container must be marked as follows:

(i) In an unobstructed area with letters and mumerals identifying the container specification (e.g., DOT-1A, DOT-17E-304HT, DOT-23G40) . See 178.0-2 of this subchapter.

(ii) The name and address or symbol of person making the mark specified in paragraph (c) (1) (i) of this section. Symbol letters, if used, must be registered with the Director, OHMT. Duplicate symbols are not authorized.

(iii) The markings must be stamped, embossed, burned, printed, or otherwise marked on the packaging to provide adequate accessibility, permanency, and contrast so as to be readily apparent and understood.

(iv) Unless otherwise specified, letters and numerals must be at least $1 / 2$ in. high.
Package must be marked "DOT 7A Type A." Shipper responsibility to ensure.

Shipper responsibility to ensure.

Shipper responsibility to ensure.

Shipper responsibility to ensure.
Shipper responsibility to ensure.

Shipper responsibility to ensure.

Shipper responsibility to ensure.

Shipper responsibility to ensure. 
(v) Packaging which does not comply with the applicable specification listed in parts 178 and 179 of this subchapter must not be marked to indicate such compliance (see 178.0-2 and 179.1 of this subchapter).

(2) Steel used shall be low-carbon commercial quality steel. Stainless, open hearth, electric, basic oxygen, or other similar quality steels are acceptable. Steel sheets of specified gauges shall comply with the following:

\begin{tabular}{|c|c|c|}
\hline $\begin{array}{c}\text { Gauge } \\
\text { No. }\end{array}$ & $\begin{array}{l}\text { Normal } \\
\text { Thickness } \\
\text { (in.) }\end{array}$ & $\begin{array}{l}\text { Minimm } \\
\text { Thickness } \\
\text { (in.) }\end{array}$ \\
\hline 12 & 0.1046 & 0.0946 \\
\hline 13 & 0.0897 & 0.0817 \\
\hline 14 & 0.0747 & 0.0677 \\
\hline 15 & 0.0673 & 0.0603 \\
\hline 16 & 0.0598 & 0.0533 \\
\hline 27 & 0.0538 & 0.0478 \\
\hline 18 & 0.0478 & 0.0428 \\
\hline 19 & 0.0418 & 0.0378 \\
\hline 20 & 0.0359 & 0.0324 \\
\hline 22 & 0.0299 & 0.0269 \\
\hline 23 & 0.0269 & 0.0239 \\
\hline 24 & 0.0239 & 0.0209 \\
\hline 26 & 0.0179 & 0.0159 \\
\hline 28 & 0.0149 & 0.0129 \\
\hline 30 & 0.0120 & 0.0110 \\
\hline
\end{tabular}

\section{ACTION REOUIRED/BY WHOM}

Shipper responsibility to ensure.

Designer and fabricator to do and shipper responsibility to ensure.
PACKAGING CATEGORY

STEEL BOXES

Shipper responsibility to ensure.

Shipper responsibility to ensure. 
(3) Iumber used shall be wellseasoned, commercially dry, and free from decay, loose knots, knots that would interfere with nailing, and other defects that would materially lessen the strength.

(4) Welding and brazing shall be performed in a workmanlike manner using suitable and appropriate techniques, materials, and equipment.

(5) Packaging materials and contents shall be such that there will be no significant chemical or galvanic reaction among any of the materials in the package.

(6) Closure shall be adequate to prevent inadvertent leakage of the contents under normal conditions incident to transportation. Gasketed closures shall be fitted with gaskets of efficient materials which will not be deteriorated by the contents of the container.

(7) Nails, staples, and other metallic devices shall not protrude into the interior of the outer packaging in such a manner as to be likely to cause failures.

(8) The nature and thickness of the packaging shall be such that friction during transport does not generate any heating likely to decrease the chemical stability of the contents.
Designer and fabricator to do and shipper responsibility to ensure.

Fabricator to do and shipper responsibility to ensure.

Designer to do and shipper responsibility to ensure.

Designer to do and shipper responsibility to ensure.

Fabricator to do and shipper responsibility to ensure.

Fabricator to do and shipper responsibility to ensure.
Shipper responsibility to ensure.

Shipper responsibility to ensure.

Shipper responsibility to ensure.

Shipper responsibility to ensure.

Shipper responsibility to ensure.

Shipper responsibility to ensure. 
(d) Polyethylene packagings and receptacles:

(1) Polyethylene used in packagings and receptacles must be of a type compatible with the lading and may not be permeable to an extent that a hazardous condition oocurs during transportation, handling, or refilling.

(2) Each polyethylene packaging or receptacle which is used for liquid hazardous materials must be capable of withstanding without failure the procecture specified in Appendix B of this part ("Procedure for Testing Chemical Compatibility and Rate of Permeation in Polyethylene Packagings and Receptacles") and the maximum rate of permeation of hazardous lading through or into the polyethylene packaging or receptacles may not exceed the following rates:

(i) 0.5 percent for materials meeting the definition of a poison according to this subchapter and 2.0 percent for other hazardous materials, when subjected to temperatures no lower than $18^{\circ} \mathrm{C}\left(64^{\circ} \mathrm{F}\right)$ for 180 days in accordance with Test Method 1;

(ii) 0.5 percent for materials meeting the definition of a poison according to this subchapter and 2.0 percent for other hazardous materials, when subjected to temperatures no lower than $50^{\circ} \mathrm{C}\left(122^{\circ} \mathrm{F}\right)$ for 28 days in accordance with Test Method 2;
Desigmer to do and shipper responsibility to ensure.

Designer, tester, and evaluator to do and shipper responsibility to ensure.
Shipper responsibility to ensure.

Shipper responsibility to ensure. 
(iii) 0.5 percent for materials meeting the definition of a poison according to this subchapter and 2.0 percent for other hazardous materials, when subjected to temperatures no lower than $60^{\circ} \mathrm{C}\left(140^{\circ} \mathrm{F}\right)$ for 14 days in accordance with Test Method 3;

(3) Alternative procedures or rates of permeation are permitted if they yield a level of safety equivalent to or greater than that provided by paragraph (d) (2) of this section and are approved by the Director, OHMT.

(4) Each polyethylene packaging used as an outside packaging for materials meeting the definition of a poison according to this subchapter shall be permanently marked, by embossment or other durable means, with the word "POISON" in letters of at least $1 / 4$ in. in height. Additional text or symbols may be included in the marking. The marking shall be located within six inches of the packaging's closure. The requirements of this subparagraph do not apply prior to september 1, 1985.

(e) For specification containers, compliance with the applicable specifications in Parts 178 and 179 of this subchapter shall be required in all details, except as otherwise provided in this subchapter.
Shipper responsibility to ensure.

Shipper responsibility to ensure.

Shipper responsibility to ensure.
Shipper responsibility to ensure.

Shipper responsibility to ensure. 


\subsection{4 - STANDARD REQUIREMENTS FOR ALL PACKAGES}

(a) Each package used for shipping hazardous material under this subchapter shall be so designed and constructed, and its contents so limited, that under conditions normally incident to transportation:

(1) There will be no significant release of the hazardous materials to the enviromment;

(2) The effectiveness of the packaging will not be substantially reduced; and

(3) There will be no mixture of gases or vapors in the package which could, through any credible spontaneous increase of heat or pressure or through an explosion, significantly recuce the effectiveness of the packaging.

(b) Materials for which detailed specifications for packaging are not set forth in this part must be securely packaged in strong, tight packages meeting the requirements of this section.

\section{ACIION REOUIRED/BY WHOM}

\section{PACKAGING CATEGORY WOODEN BOXES}

To be considered during package design evaluation. Shipper responsibility to ensure.

To be considered during package design evaluation. Shipper responsibility to ensure. one aspect for strong consideration is effect of contents on packaging effectiveness.

Shipper responsibility to ensure.

Does not apply.
All packagings met the intent of this requirement as demonstrated by meeting the more severe Type A packaging requirements of $173.411, .412$, .465 , and/or .466 as demonstrated in MIM-3245 and this addendum.

All packagings met the intent of this requirement as demonstrated by meeting the more severe Type A packaging requirements of $173.411, .412$, .465 , and/or .466 as demonstrated in MIM-3245 and this addendum.

NOTE: Shipper responsibility to consider and evaluate, if necessary, the effect of the contents.

Shipper responsibility to ensure. 
(c) Packaging used for the shipment of hazardous matrials under this subchapter shall, unless otherwise specified or exempted therein, meet all of the following design and construction criteria:

(1) Each specification container must be marked as follows:

(i) In an unobstructed area with letters and numerals identifying the container specification (e.g. , DOT-1A, DOT-17E-304HT, DOT-23G40) . See 178.0-2 of this subchapter.

(ii) The name and address or symbol of person making the mark specified in paragraph (c) (1) (i) of this section. Symbol letters, if used, must be registered with the Director, OHMT. Duplicate symbols are not authorized.

(iii) The markings must be stamped, embossed, burned, printed, or otherwise marked on the packaging to provide adequate accessibility, permanency, and contrast so as to be readily apparent and understood.

(iv) Unless otherwise specified, letters and numerals must be at least $1 / 2$ in. high.
Package must be marked "DOT 7A Type A." Shipper responsibility to ensure.

Shipper responsibility to ensure.

Shipper responsibility to ensure.

Shipper responsibility to ensure.
Shipper responsibility to ensure.

Shipper responsibility to ensure.

Shipper responsibility to ensure.

Shipper responsibility to ensure. 


\section{ACIION REQUIRED/BY WHOM}

(v) Packaging which does not comply with the applicable specification listed in parts 178 and 179 of this subchapter-must not be marked to indicate such compliance (see 178.0-2 and 179.1 of this subchapter).

(2) Steel used shall be low-carbon conmercial quality steel. Stainless, open hearth, electric, basic oxygen, or other similar quality steels are acceptable. Steel sheets of specified gauges shall comply with the following:

\begin{tabular}{|c|c|c|}
\hline $\begin{array}{l}\text { Gauge } \\
\text { No. }\end{array}$ & $\begin{array}{l}\text { Normal } \\
\text { Thickness } \\
\text { (in.) }\end{array}$ & $\begin{array}{l}\text { Minimum } \\
\text { Thickness } \\
\text { (in.) }\end{array}$ \\
\hline 12 & 0.1046 & 0.0946 \\
\hline 13 & 0.0897 & 0.0817 \\
\hline 14 & 0.0747 & 0.0677 \\
\hline 15 & 0.0673 & 0.0603 \\
\hline 16 & 0.0598 & 0.0533 \\
\hline 17 & 0.0538 & 0.0478 \\
\hline 18 & 0.0478 & 0.0428 \\
\hline 19 & 0.0418 & 0.0378 \\
\hline 20 & 0.0359 & 0.0324 \\
\hline 22 & 0.0299 & 0.0269 \\
\hline 23 & 0.0269 & 0.0239 \\
\hline 24 & 0.0239 & 0.0209 \\
\hline 26 & 0.0179 & 0.0159 \\
\hline 28 & 0.0149 & 0.0129 \\
\hline 30 & 0.0120 & 0.0110 \\
\hline
\end{tabular}

Shipper responsibility to ensure.

Designer and fabricator to do and shipper responsibility to ensure.
PACKAGING CATEGORY

WOODEN BOXES

Shipper responsibility to ensure.

Shipper responsibility to ensure. 


\section{ACTION REOUIRED/BY WHOM}

(3) Iumber used shall be wellseasoned, commercially dry, and free from decay, loose knots, knots that would interfere with nailing, and other defects that would materially lessen the strength.

(4) Welding and brazing shall be performed in a workmanlike manner using suitable and appropriate techniques, materials, and equipment.

(5) Packaging materials and contents shall be such that there will be no significant chemical or galvanic reaction among any of the materials in the package.

(6) Closure shall be adequate to prevent inadvertent leakage of the contents under normal conditions incident to transportation. Gasketed closures shall be fitted with gaskets of efficient materials which will not be deteriorated by the contents of the container.

(7) Nails, staples, and other metallic devices shall not protrude into the interior of the outer packaging in such a manner as to be likely to cause failures.

(8) The nature and thickness of the packaging shall be such that friction curing transport does not generate any heating likely to decrease the chemical stability of the contents.
Designer and fabricator to do and shipper responsibility to ensure.

Fabricator to do and shipper responsibility to ensure.

Designer to do and shipper

Designer to do and shipper responsibility to ensure.

Fabricator to do and shipper responsibility to ensure.

Fabricator to do and shipper responsibility to ensure. responsibility to ensure.
PACKAGING CATEGORY

WOODEN BOXES

Shipper responsibility to ensure.

Shipper responsibility to ensure.

Shipper responsibility to ensure.

Shipper responsibility to ensure.

Shipper responsibility to ensure.

Shipper responsibility to ensure. 
(d) Polyethylene packagings and receptacles:

(1) Polyethylene used in packagings and receptacles must be of a type compatible with the lading and may not be permeable to an extent that a hazardous condition occurs churing transportation, handling, or refilling.

(2) Each polyethylene packaging or receptacle which is used for liquid hazardous materials must be capable of withstanding without failure the procedure specified in Appendix B of this part ("Procedure for Testing Chemical compatibility and Rate of Permeation in Polyethylene Packagings and Receptacles") and the maximum rate of permeation of hazardous lading through or into the polyethylene packaging or receptacles may not exceed the following rates:

(i) 0.5 percent for materials meeting the definition of a poison according to this subchapter and 2.0 percent for other hazardous materials, when subjected to temperatures no lower than $18^{\circ} \mathrm{C}\left(64^{\circ} \mathrm{F}\right)$ for 180 days in accordance with Test Method 1;

(ii) 0.5 percent for materials meeting the definition of a poison according to this subchapter and 2.0 percent for other hazardous materials, when subjected to temperatures no lower than $50^{\circ} \mathrm{C}\left(122^{\circ} \mathrm{F}\right)$ for 28 days in accordance with Test Method 2;
Designer to do and shipper responsibility to ensure.

Designer, tester, and evaluator to do and shipper responsibility to ensure.
Shipper responsibility to ensure.

Shipper responsibility to ensure. 
(iii) 0.5 percent for materials meeting the definition of a poison according to this subchapter and 2.0 percent for other hazardous materials, when subjected to temperatures no lower than $60^{\circ} \mathrm{C}\left(140^{\circ} \mathrm{F}\right)$ for 14 days in accordance with Test Method 3;

(3) Alternative procedures or rates of permeation are permitted if they yield a level of safety equivalent to or greater than that provided by paragraph (d) (2) of this section and are approved by the Director, OHMT.

(4) Each polyethylene packaging used as an outside packaging for materials meeting the definition of a poison according to this subchapter shall be permanently marked, by embossment or other durable means, with the word "POISON" in letters of at least $1 / 4$ in. in height. Additional text or symbols may be included in the marking. marking. The marking shall be located within six inches of the packaging's closure. The requirements of this subparagraph do not apply prior to September 1, 1985.

(e) For specification containers, compliance with the applicable specifications in Parts 178 and 179 of this subchapter shall be required in all details, except as otherwise provided in this subchapter.
Shipper responsibility to ensure.

Shipper responsibility to ensure.

Shipper responsibility to ensure.
Shipper responsibility to ensure.

Shipper responsibility to ensure.

Shipper responsibility to ensure. 
173.24 - STANDARD REQUIREMENTS FOR ALI PACKAGES

(a) Each package used for shipping hazardous material under this subchapter shall be so designed and constructed, and it: contents so limited, that under conditions normally incident to transportation:

(1) There will be no significant release of the hazardous materials to the enviroment;

(2) The effectiveness of the packaging will not be substantially reduced; and

(3) There will be no mixture of gases or vapors in the package which could, through any credible spontaneous increase of heat or pressure or through an explosion, significantly reduce the effectiveness of the packaging.

(b) Materials for which detailed specifications for packaging are not set forth in this part must be securely packaged in strong, tight packages meeting the requirements of this section.

\section{ACTION REQUIRED/BY WHOM}

\section{PACKAGING CATEGORY FIBERBOARD CONTATNERS}

To be considered during package design evaluation. Shipper responsibility to ensure.

To be considered during package design evaluation. Shipper responsibility to ensure. One aspect for strong consideration is effect of contents on packaging effectiveness.

Shipper responsibility to ensure.

Does not apply.
All packagings met the intent of this requirement as demonstrated by meeting the more severe Type A packaging requirements of $173.411, .412$, .465 , and/or .466 as demonstrated in MLM-3245 and this addendum.

All packagings met the intent of this requirement as demonstrated by meeting the more severe Type A packaging requirements of $173.411, .412$, .465 , and/or .466 as demonstrated in MIM-3245 and this addenchum.

NOTE: Shipper responsibility to consider and evaluate, if necessary, the effect of the contents.

Shipper responsibility to ensure. 
(c) Packaging used for the shipment of hazardous matrials under this subchapter shall, unless otherwise specified or exempted therein, meet all of the following design and construction criteria:

(1) Each specification container must be marked as follows:

(i) In an unobstructed area with letters and numerals identifying the container specification (e.g., DOT-1A, DOT-17E-304HT, DOT-23G40). See 178.0-2 of this subchapter.

(ii) The name and address or symbol of person making the mark specified in paragraph (c) (i) (i) of this section. Symbol letters, if used, must be registered with the Director, OHMT. Duplicate symbols are not authorized.

(iii) The markings must be stamped, embossed, burned, printed, or otherwise marked on the packaging to provide adequate accessibility, permanency, and contrast so as to be readily apparent and understood.

(iv) Unless otherwise specified, letters and numerals must be at least $1 / 2$ in. high.
Package must be marked "DOT 7A Type A." Shipper responsibility to ensure.

Shipper responsibility to ensure.

Shipper responsibility to ensure.

Shipper responsibility to ensure.
Shipper responsibility to ensure.

Shipper responsibility to ensure.

Shipper responsibility to ensure.

Shipper responsibility to ensure. 
(v) Packaging which does not comply with the applicable specification listed in parts 178 and 179 of this subchapter must not be marked to indicate such compliance (see 178.0-2 and 179.1 of this subchapter).

(2) Steel used shall be low-carbon commercial quality steel. Stainless, open hearth, electric, basic oxygen, or other similar quality steels are acceptable. Steel sheets of specified gauges shall comply with the following:

\begin{tabular}{|c|c|c|}
\hline $\begin{array}{c}\text { Gauge } \\
\text { No. }\end{array}$ & $\begin{array}{c}\text { Normal } \\
\text { Thickness } \\
\text { (in.) }\end{array}$ & $\begin{array}{l}\text { Minimm } \\
\text { Thickness } \\
\text { (in.) }\end{array}$ \\
\hline 12 & 0.1046 & 0.0946 \\
\hline 13 & 0.0897 & 0.0817 \\
\hline 14 & 0.0747 & 0.0677 \\
\hline 15 & 0.0673 & 0.0603 \\
\hline 16 & 0.0598 & 0.0533 \\
\hline 17 & 0.0538 & 0.0478 \\
\hline 18 & 0.0478 & 0.0428 \\
\hline 19 & 0.0418 & 0.0378 \\
\hline 20 & 0.0359 & 0.0324 \\
\hline 22 & 0.0299 & 0.0269 \\
\hline 23 & 0.0269 & 0.0239 \\
\hline 24 & 0.0239 & 0.0209 \\
\hline 26 & 0.0179 & 0.0159 \\
\hline 28 & 0.0149 & 0.0129 \\
\hline 30 & 0.0120 & 0.0110 \\
\hline
\end{tabular}

Shipper responsibility to ensure.

Designer and fabricator to do and shipper responsibility to ensure.
Shipper responsibility to ensure.

Shipper responsibility to ensure. 


\section{ACIION REQUIRED/BY WHOM}

(3) Iumber used shall be wellseasoned, commercially dry, and free from decay, loose knots, knots that would interfere with nailing, and other defects that would materially lessen the strength.

(4) Welding and brazing shall be performed in a workmanlike manner using suitable and appropriate techniques, materials, and equipment.

(5) Packaging materials and contents shall be such that there will be no significant chemical or galvanic reaction among any of the materials in the package.

(6) Closure shall be adequate to prevent inadvertent leakage of the contents under normal conditions incident to transportation. Gasketed closures shall be fitted with gaskets of efficient materials which will not be deteriorated by the contents of the container.

(7) Nails, staples, and other metallic devices shall not protrude into the interior of the outer packaging in such a manner as to be likely to cause failures.

(8) The nature and thickness of the packaging shall be such that friction during transport does not generate any heating likely to decrease the chemical stability of the contents.
Designer and fabricator to do and shipper responsibility to ensure.

Fabricator to do and shipper responsibility to ensure.

Designer to do and shipper responsibility to ensure.

Desioner to do and shipper responsibility to ensure.

Fabricator to do and shipper responsibility to ensure.

Fabricator to do and shipper responsibility to ensure.
Shipper responsibility to ensure.

Shipper responsibility to ensure.

Shipper responsibility to ensure.

Shipper responsibility to ensure.

Shipper responsibility to ensure.

Shipper responsibility to ensure. 
(d) Polyethylene packagings and receptacles:

(1) Polyethylene used in packagings and receptacles must be of a type compatible with the lading and may not be permeable to an extent that a hazardous condition occurs during transportation, handling, or refilling.

(2) Each polyethylene packaging or receptacle which is used for liquid hazardous materials must be capable of withstanding without failure the procedure specified in Appendix B of this part ("Procedure for Testing Chemical Compatibility and Rate of Permeation in Polyethylene Packagings and Receptacles") and the maximum rate of permeation of hazardous lading through or into the polyethylene packaging or receptacles may not exceed the following rates:

(i) 0.5 percent for materials meeting the definition of a poison according to this subchapter and 2.0 percent for other hazardous materials, when subjected to temperatures no lower than $18^{\circ} \mathrm{C}\left(64^{\circ} \mathrm{F}\right)$ for 180 days in accordance with Test Method 1;

(ii) 0.5 percent for materials meeting the definition of a poison according to this subchapter and 2.0 percent for other hazardous materials, when subjected to temperatures no lower than $50^{\circ} \mathrm{C}\left(122^{\circ} \mathrm{F}\right)$ for 28 days in accordance with Test Method 2;
Designer to do and shipper responsibility to ensure.

Designer, tester, and evaluator to do and shipper responsibility to ensure.
Shipper responsibility to ensure.

Shipper responsibility to ensure. 
(iii) 0.5 percent for materials meeting the definition of a poison according to this subchapter and 2.0 percent for other hazardous materials, when subjected to temperatures no lower than $60^{\circ} \mathrm{C}\left(140^{\circ} \mathrm{F}\right)$ for 14 days in accordance with Test Method 3;

(3) Alternative procedures or rates of permeation are permitted if they yield a level of safety equivalent to or greater than that provided by paragraph (d) (2) of this section and are approved by the Director, OHMI.

(4) Each polyethylene packaging used as an outside packaging for materials meeting the definition of a poison according to this subchapter shall be permanently marked, by embossment or other durable means, with the word "POISON" in letters of at least $1 / 4$ in. in height. Additional text or symbols may be included in the marking. The marking shall be located within six inches of the packaging's closure. The requirements of this subparagraph do not apply prior to September 1, 1985.

(e) For specification containers, compliance with the applicable specifications in Parts 178 and 179 of this subchapter shall be required in all details, except as otherwise provided in this subchapter.
Shipper responsibility to ensure.

Shipper responsibility to ensure.

Shipper responsibility to ensure.

Shipper responsibility to ensure. 
173.24 - STANDARD REQUIREMENTS FOR ALI PACKAGES

(a) Each package used for shipping hazardous material under this subchapter shall be so designed and constructed, and its contents so limited, that under conditions normally incident to transportation:

(1) There will be no significant release of the hazardous materials to the enviroment;

(2) The effectiveness of the packaging will not be substantially reduced; and

(3). There will be no mixture of gases or vapors in the package which could, through any credible spontaneous increase of heat or pressure or through an explosion, significantly reduce the effectiveness of the packaging.

(b) Materials for which detailed specifications for packaging are not set forth in this part must be securely packaged in strong, tight packages meeting the requirements of this section. effectiveness.

\section{ACTION REQUIRED/BY WHOM}

\section{PACKAGING CATEGORY UF-6 CYINNDERS}

To be considered during package design evaluation. Shipper responsibility to ensure.

To be considered during package design evaluation. Shipper responsibility to ensure. One aspect for strong consideration is effect of contents on packaging

Shipper responsibility to ensure.

Does not apply.

Does not apply.
All packagings met the intent of this requirement as demonstrated by meeting the more severe Type A packaging requirements of $173.411, .412$, .465 , and/or .466 as demonstrated in MIM-3245 and this addendum.

All packagings met the intent of this requirement as demonstrated by meeting the more severe Type A packaging requirements of $173.411, .412$, .465 , and/or .466 as demonstrated in MIM-3245 and this addendum.

NOTE: Shipper responsibility to consider and evaluate, if necessary, the effect of the contents.

Shipper responsibility to ensure. 
(c) Packaging used for the shipment of hazardous matrials under this subchapter shall, unless otherwise specified or exempted therein, meet all of the following design and construction criteria:

(1) Each specification container must be marked as follows:

(i) In an unobstructed area with letters and numerals identifying the container specification (e.g., DOT-1A, DOT-17E-304HT, DOT-23G40). See 178.0-2 of this subchapter.

(ii) The name and address or symbol of person making the mark specified in paragraph (c) (1) (i) of this section. Symbol letters, if used, must be registered with the Director, OHMT. Duplicate symbols are not authorized.

(iii) The markings must be stamped, embossed, burned, printed, or otherwise marked on the packaging to provide adequate accessibility, permanency, and contrast so as to be readily apparent and understood.

(iv) Unless otherwise specified, letters and mumerals must be at least $1 / 2$ in. high.
Package must be marked "DOT 7A Type A." Shipper responsibility to ensure.

Shipper responsibility to ensure.

Shipper responsibility to ensure.

Shipper responsibility to ensure.
Shipper responsibility to ensure.

Shipper responsibility to ensure.

Shipper responsibility to ensure.

Shipper responsibility to ensure. 


\section{ACIION REOUIRED/BY WHOM}

(v) Packaging which does not comply with the applicable specification listed in parts 178 and 179 of this subchapter must not be marked to indicate such compliance (see 178.0-2 and 179.1 of this subchapter).

(2) Steel used shall be low-carbon commercial quality steel. Stainless, open hearth, electric, basic oxygen, or other similar quality steels are acceptable. Steel sheets of specified gauges shall comply with the following:

\begin{tabular}{|c|c|c|}
\hline $\begin{array}{c}\text { Gauge } \\
\text { No. }\end{array}$ & $\begin{array}{l}\text { Normal } \\
\text { Thickness } \\
\text { (in.) }\end{array}$ & $\begin{array}{l}\text { Minimm } \\
\text { Thickness } \\
\text { (in.) }\end{array}$ \\
\hline 12 & 0.1046 & 0.0946 \\
\hline 13 & 0.0897 & 0.0817 \\
\hline 14 & 0.0747 & 0.0677 \\
\hline 15 & 0.0673 & 0.0603 \\
\hline 16 & 0.0598 & 0.0533 \\
\hline 17 & 0.0538 & 0.0478 \\
\hline 18 & 0.0478 & 0.0428 \\
\hline 19 & 0.0418 & 0.0378 \\
\hline 20 & 0.0359 & 0.0324 \\
\hline 22 & 0.0299 & 0.0269 \\
\hline 23 & 0.0269 & 0.0239 \\
\hline 24 & 0.0239 & 0.0209 \\
\hline 26 & 0.0179 & 0.0159 \\
\hline 28 & 0.0149 & 0.0129 \\
\hline 30 & 0.0120 & 0.0110 \\
\hline
\end{tabular}

Shipper responsibility to ensure.

Designer and fabricator to do and shipper responsibility to ensure.
PACKAGING CATEGORY

UF-6 CYIINDERS

Shipper responsibility to ensure.

Shipper responsibility to ensure. 
ACTION REQUIRED/BY WHOM

(3) Lumber used shall be wellseasoned, commercially dry, and free from decay, loose knots, knots that would interfere with nailing, and other defects that would materially lessen the strength.

(4) Welding and brazing shall be performed in a workmanlike manner using suitable and appropriate techniques, materials, and equipment.

(5) Packaging materials and contents shall be such that there will be no significant chemical or galvanic reaction among any of the materials in the package.

(6) Closure shall be adequate to prevent inadvertent leakage of the contents under normal conditions incident to transportation. Gasketed closures shall be fitted with gaskets of efficient materials which will not be deteriorated by the contents of the container.

(7) Nails, staples, and other metallic devices shall not protrude into the interior of the outer packaging in such a manner as to be likely to cause failures.

(8) The nature and thickness of the packaging shall be such that friction during transport does not generate any heating likely to decrease the chemical stability of the contents.
Designer and fabricator to do and shipper responsibility to ensure.

Fabricator to do and shipper responsibility to ensure.

Designer to do and shipper responsibility to ensure.

Designer to do and shipper responsibility to ensure.

Fabricator to do and shipper responsibility to ensure.

Fabricator to do and shipper responsibility to ensure.
PACKAGING CATEGORY

UF-6 CYLTNDERS

Shipper responsibility to ensure.

Shipper responsibility to ensure.

Shipper responsibility to ensure.

Shipper responsibility to ensure. 
(d) Polyethylene packagings and receptacles:

(1) Polyethylene used in packagings and receptacles must be of a type compatible with the lading and may not be permeable to an extent that a hazardous condition occurs during transportation, handling, or refilling.

(2) Each polyethylene packaging or receptacle which is used for liquid hazardous materials must be capable of withstanding without failure the procedure specified in Appendix B of this part ("Procedure for Testing Chemical Compatibility and Rate of Permeation in Polyethylene Packagings and Receptacles") and the maximum rate of permeation of hazardous lading through or into the polyethylene packaging or receptacles may not exceed the following rates:

(i) 0.5 percent for materials meeting the definition of a poison according to this subchapter and 2.0 percent for other hazardous materials, when subjected to temperatures no lower than $18^{\circ} \mathrm{C}\left(64^{\circ} \mathrm{F}\right)$ for 180 days in accordance with Test Method 1;

(ii) 0.5 percent for materials meeting the definition of a poison according to this subchapter and 2.0 percent for other hazardous materials, when subjected to temperatures no lower than $50^{\circ} \mathrm{C}\left(122^{\circ} \mathrm{F}\right)$ for 28 days in accordance with Test Method 2;
Designer to do and shipper responsibility to ensure.

Designer, tester, and evaluator to do and shipper responsibility to ensure.
Shipper responsibility to ensure.

Shipper responsibility to ensure. 
(iii) 0.5 percent for materials meeting the definition of a poison according to this subchapter and 2.0 percent for other hazardous materials, when subjected to temperatures no lower than $60^{\circ} \mathrm{C}\left(140^{\circ} \mathrm{F}\right)$ for 14 days in accordance with Test Method 3;

(3) Alternative procedures or rates of permeation are permitted if they yield a level of safety equivalent to or greater than that provided by paragraph (d) (2) of this section and are approved by the Director, OHMT.

(4) Each polyethylene packaging used as an outside packaging for materials meeting the definition of a poison according to this subchapter shall be permanently marked, by embossment or other durable means, with the word "POISON" in letters of at least $1 / 4$ in. in height. Additional text or symbols may be included in the marking. The marking shall be located within six inches of the packaging's closure. The requirements of this subparagraph do not apply prior to september 1, 1985.

(e) For specification containers, compliance with the applicable specifications in Parts 178 and 179 of this subchapter shall be required in all details, except as otherwise provided in this subchapter.
Shipper responsibility to ensure.

Shipper responsibility to ensure.

Shipper responsibility to ensure.

Shipper responsibility to ensure.

Shipper responsibility to ensure. 
173.24 - STANDARD REQUIREMENTS FOR ALU PACKAGES

(a) Each package used for shipping hazardous material under this subchapter shall be so designed and constructed, and it: contents so limited, that under conditions normally incident to transportation:

\section{ACTION REOUIRED/BY WHOM}

(1) There will be no significant release of the hazardous materials to the environment;

(2) The effectiveness of the packaging will not be substantially reduced; and

(3) There will be no mixture of gases or vapors in the package which could, through any credible spontaneous increase of heat or pressure or through an explosion, significantly reduce the effectiveness of the packaging.

(b) Materials for which detailed specifications for packaging are not set forth in this part must be securely packaged in strong, tight packages meeting the requirements of this section.
To be considered during package design evaluation. Shipper responsibility to ensure.

To be considered during package design evaluation. Shipper aspect for strong consideration is effect of contents on packaging effectiveness.

Shipper responsibility to ensure.

Does not apply. responsibility to ensure. One

\section{PACKAGING CATEGORY ITOUIDS AND GASES}

All packagings met the intent of this requirement as demonstrated by meeting the more severe Type A packaging requirements of $173.411, .412$, .465 , and/or .466 as demonstrated in MIM-3245 and this addendum.

All packagings met the intent of this requirement as demonstrated by meeting the more severe Type A packaging requirements of $173.411, .412$, .465 , and/or .466 as demonstrated in MIM-3245 and this addendum.

NOTE: Shipper responsibility to consider and evaluate, if necessary, the effect of the contents.

Shipper responsibility to ensure.

Does not apply. 
(c) Packaging used for the shipment of hazardous matrials under this subchapter shall, unless otherwise specified or exempted therein, meet all of the following design and construction criteria:

(1) Each specification container must be marked as follows:

(i) In an unobstructed area with letters and numerals identifying the container specification (e.g., DOT-1A, DOT-17E-304HT, DOT-23G40) . See $178.0-2$ of this subchapter.

(ii) The name and address or symbol of person making the mark specified in paragraph (c) (1) (i) of this section. Symbol letters, if used, must be registered with the Director, OHMT. Duplicate symbols are not authorized.

(iii) The markings must be stamped, embossed, burned, printed, or otherwise marked on the packaging to provide adequate accessibility, permanency, and contrast so as to be readily apparent and understood.

(iv) Unless otherwise specified, letters and numerals must be at least $1 / 2$ in. high.
Package must be marked "DOT 7A Type A." Shipper responsibility to ensure.

Shipper responsibility to ensure.

Shipper responsibility to ensure.

Shipper responsibility to ensure.
Shipper responsibility to ensure.

Shipper responsibility to ensure.

Shipper responsibility to ensure.

Shipper responsibility to ensure. 


\section{ACTION REOUIRED/BY WHOM}

(v) Packaging which does not comply with the applicable specification listed in parts 178 and 179 of this subchapter must not be marked to indicate such compliance (see 178.0-2 and 179.1 of this subchapter).

(2) Steel used shall be low-carbon commercial quality steel. Stainless, open hearth, electric, basic oxygen, or other similar quality steels are acceptable. Steel sheets of specified gauges shall comply with the following:

\begin{tabular}{|c|c|c|}
\hline $\begin{array}{c}\text { Gauge } \\
\text { No. }\end{array}$ & $\begin{array}{l}\text { Normal } \\
\text { Thickness } \\
\text { (in.) }\end{array}$ & $\begin{array}{l}\text { Minimum } \\
\text { Thickness } \\
\text { (in.) }\end{array}$ \\
\hline 12 & 0.1046 & 0.0946 \\
\hline 13 & 0.0897 & 0.0817 \\
\hline 14 & 0.0747 & 0.0677 \\
\hline 15 & 0.0673 & 0.0603 \\
\hline 16 & 0.0598 & 0.0533 \\
\hline 17 & 0.0538 & 0.0478 \\
\hline 18 & 0.0478 & 0.0428 \\
\hline 19 & 0.0418 & 0.0378 \\
\hline 20 & 0.0359 & 0.0324 \\
\hline 22 & 0.0299 & 0.0269 \\
\hline 23 & 0.0269 & 0.0239 \\
\hline 24 & 0.0239 & 0.0209 \\
\hline 26 & 0.0179 & 0.0159 \\
\hline 28 & 0.0149 & 0.0129 \\
\hline 30 & 0.0120 & 0.0110 \\
\hline
\end{tabular}

Shipper responsibility to ensure.

Desigmer and fabricator to do and shipper responsibility to ensure.
PACKAGING CATEGORY

IIOUIDS AND GASES

Shipper responsibility to ensure.

Shipper responsibility to ensure. 
(3) Lumber used shall be wellseasoned, conmercially dry, and free from decay, loose knots, knots that would interfere with nailing, and other defects that would materially lessen the strength.

(4) Welding and brazing shall be performed in a workmanlike manner using suitable and appropriate techniques, materials, and equipment.

(5) Packaging materials and contents shall be such that there will be no significant chemical or galvanic reaction among any of the materials in the package.

(6) Closure shall be adequate to prevent inadvertent leakage of the contents under normal conditions incident to transportation. Gasketed closures shall be fitted with gaskets of efficient materials which will not be deteriorated by the contents of the container.

(7) Nails, staples, and other metallic devices shall not protrude into the interior of the outer packaging in such a manner as to be iikely to cause failures.

(8) The nature and thickness of the packaging shall be such that friction during transport does not generate any heating likely to decrease the chemical stability of the contents.
Desigmer and fabricator to do and shipper responsibility to ensure.

Fabricator to do and shipper responsibility to ensure.

Designer to do and shipper responsibility to ensure.

Desigmer to do and shipper responsibility to ensure.

Fabricator to do and shipper responsibility to ensure.

Fabricator to do and shipper responsibility to ensure.
Shipper responsibility to ensure.

Shipper responsibility to ensure.

Shipper responsibility to ensure.

Shipper responsibility to ensure.

Shipper responsibility to ensure.

Shipper responsibility to ensure. 
(d) Polyethylene packagings and receptacles:

(1) Polyethylene used in packagings and receptacles must be of a type compatible with the lading and may not be permeable to an extent that a hazardous condition occurs during transportation, handling, or refilling.

(2) Each polyethylene packaging or receptacle which is used for liquid hazardous materials must be capable of withstanding without failure the procedure specified in Appendix B of this part ("Procedure for Testing Chemical compatibility and Rate of Permeation in Polyethylene Packagings and Receptacles") and the maximum rate of permeation of hazardous lading through or into the polyethylene packaging or receptacles may not exceed the following rates:

(i) 0.5 percent for materials meeting the definition of a poison according to this subchapter and 2.0 percent for other hazardous materials, when subjected to temperatures no lower than $18^{\circ} \mathrm{C}\left(64^{\circ} \mathrm{F}\right)$ for 180 days in accordance with Test Method 1;

(ii) 0.5 percent for materials meeting the definition of a poison according to this subchapter and 2.0 percent for other hazardous materials, when subjected to temperatures no lower than $50^{\circ} \mathrm{C}\left(122^{\circ} \mathrm{F}\right)$ for 28 days in accordance with Test Method 2;
Designer to do and shipper responsibility to ensure.

Shipper responsibility to ensure.

Designer, tester, and evaluator to do and shipper responsibility to ensure.
Shipper responsibility to ensure. 
(iii) 0.5 percent for materials meeting the definition of a poison according to this subchapter and 2.0 percent for other hazardous materials, when subjected to temperatures no lower than $60^{\circ} \mathrm{C}\left(140^{\circ} \mathrm{F}\right)$ for 14 days in accordance with Test Method 3;

(3) Alternative procedures or rates of permeation are permitted if they yield a level of safety equivalent to or greater than that provided by paragraph (d) (2) of this section and are approved by the Director, OHMT.

(4) Each polyethylene packaging used as an outside packaging for materials meeting the definition of a poison according to this subchapter shall be permanently marked, by embossment or other durable means, with the word "POISON" in letters of at least $1 / 4$ in. in height. Additional text or symbols may be included in the marking. The marking shall be located within six inches of the packaging's closure. The requirements of this subparagraph do not apply prior to september 1, 1985.

(e) For specification containers, compliance with the applicable specifications in Parts 178 and 179 of this subchapter shall be required in all details, except as otherwise provided in this subchapter.
Shipper responsibility to ensure.

Shipper responsibility to ensure.

Shipper responsibility to ensure.
Shipper responsibility to ensure.

Shipper responsibility to ensure.

Shipper responsibility to ensure. 
173.24 - STANDARD REQUIREMENIS FOR ALL PACKAGES

(a) Each package used for shipping hazardous material under this subchapter shall be so designed and constructed, and its contents so limited, that under conditions normally incident to transportation:

(1) There will be no significant release of the hazardous materials to the enviroment;

(2) The effectiveness of the packaging will not be substantially reduced; and

(3) There will be no mixture of gases or vapors in the package which could, through any credible spontaneous increase of heat or pressure or through an explosion, significantly reduce the effectiveness of the packaging.

(b) Materials for which detailed specifications for packaging are not set forth in this part must be securely packaged in strong, tight packages meeting the requirements of this section.

\section{ACIION REQUIRED/BY WHOM}

\section{PACKAGING CATEGORY MISCETIANEOUS}

To be considered during package design evaluation. Shipper responsibility to ensure.

To be considered during package design evaluation. Shipper responsibility to ensure. one aspect for strong consideration is effect of contents on packaging effectiveness.

Shipper responsibility to ensure.

Does not apply.
All packagings met the intent of this requirement as demonstrated by meeting the more severe Type A packaging requirements of $173.411, .412$, .465 , and/or .466 as demonstrated in MIM-3245 and this addendum.

All packagings met the intent of this requirement as demonstrated by meeting the more severe Type A packaging requirements of 173.411 , .412 , .465, and/or .466 as demonstrated in MIM- 3245 and this addendum.

NOTE: Shipper responsibility to consider and evaluate, if necessary, the effect of the contents.

Shipper responsibility to ensure.

Does not apply. 
(c) Packaging used for the shipment of hazardous matrials under this subchapter shall, unless otherwise specified or exempted therein, meet all of the following design and construction criteria:

(1) Each specification container must be marked as follows:

(i) In an unobstructed area with letters and numerals identifying the container specification (e.g., DOT-1A, DOT-17E-304HT, DOT-23G40) . See 178.0-2 of this subchapter.

(ii) The name and address or symbol of person making the mark specified in paragraph (c) (1) (i) of this section. Symbol letters, if used, must be registered with the Director, OHMI. Duplicate symbols are not authorized.

(iii) The markings must be stamped, embossed, burned, printed, or otherwise marked on the packaging to provide adequate accessibility, permanency, and contrast so as to be readily apparent and understood.

(iv) Unless otherwise specified, letters and numerals must be at least $1 / 2$ in. high.
Package must be marked "DOT 7A TYpe A." Shipper responsibility to ensure.

Shipper responsibility to ensure.

Shipper responsibility to ensure.

Shipper responsibility to ensure.
Shipper responsibility to ensure.

Shipper responsibility to ensure.

Shipper responsibility to ensure.

Shipper responsibility to ensure. 
(v) Packaging which does not comply with the applicable specification listed in parts 178 and 179 of this subchapter must not be marked to indicate such compliance (see 178.0-2 and 179.1 of this subchapter) .

(2) Steel used shall be low-carbon commercial quality steel. Stainless, open hearth, electric, basic oxygen, or other similar quality steels are acceptable. Steel sheets of specified gauges shall comply with the following:

\begin{tabular}{|c|c|c|}
\hline $\begin{array}{c}\text { Gauge } \\
\text { No. }\end{array}$ & $\begin{array}{l}\text { Normal } \\
\text { Thickness } \\
\text { (in.) } \\
\end{array}$ & $\begin{array}{l}\text { Minimum } \\
\text { Thickness } \\
\text { (in.) }\end{array}$ \\
\hline 12 & 0.1046 & 0.0946 \\
\hline 13 & 0.0897 & 0.0817 \\
\hline 14 & 0.0747 & 0.0677 \\
\hline 15 & 0.0673 & 0.0603 \\
\hline 16 & 0.0598 & 0.0533 \\
\hline 17 & 0.0538 & 0.0478 \\
\hline 18 & 0.0478 & 0.0428 \\
\hline 19 & 0.0418 & 0.0378 \\
\hline 20 & 0.0359 & 0.0324 \\
\hline 22 & 0.0299 & 0.0269 \\
\hline 23 & 0.0269 & 0.0239 \\
\hline 24 & 0.0239 & 0.0209 \\
\hline 26 & 0.0179 & 0.0159 \\
\hline 28 & 0.0149 & 0.0129 \\
\hline 30 & 0.0120 & 0.0110 \\
\hline
\end{tabular}

Shipper responsibility to ensure.

Designer and fabricator to do and shipper responsibility to ensure.
Shipper responsibility to ensure.

Shipper responsibility to ensure. 


\section{ACTTON REOUIRED/BY WHOM}

(3) Iumber used shall be wellseasoned, commercially dry, and free from decay, loose knots, knots that would interfere with nailing, and other defects that would materially lessen the strength.

(4) Welding and brazing shall be performed in a workmanlike manner using suitable and appropriate techniques, materials, and equipment.

(5) Packaging materials and contents shall be such that there will be no significant chemical or galvanic reaction among any of the materials in the package.

(6) Closure shall be adequate to prevent inadvertent leakage of the contents under normal conditions incident to transportation. Gasketed closures shall be fitted with gaskets of efficient materials which will not be deteriorated by the contents of the container.

(7) Nails, staples, and other metallic devices shall not protrude into the interior of the outer packaging in such a manner as to be likely to cause failures.

(8) The nature and thickness of the packaging shall be such that friction during transport does not generate any heating likely to decrease the chemical stability of the contents.
Desioner and fabricator to do and shipper responsibility to ensure.

Fabricator to do and shipper responsibility to ensure.

Designer to do and shipper responsibility to ensure.

Designer to do and shipper responsibility to ensure. responsibility to ensure.

Fabricator to do and shipper responsibility to ensure.
Fabricator to do and shipper
PACKAGING CATEGORY

MISCEILIANEOUS

Shipper responsibility to ensure.

Shipper responsibility to ensure.

Shipper responsibility to ensure.

Shipper responsibility to ensure.

Shipper responsibility to ensure.

Shipper responsibility to ensure. 
(d) Polyethylene packagings and receptacles:

(1) Polyethylene used in packagings and receptacles must be of a type compatible with the lading and may not be permeable to an extent that a hazardous condition occurs during transportation, handling, or refilling.

(2) Each polyethylene packaging or receptacle which is used for liquid hazardous materials must be capable of withstanding without failure the procedure specified in Appendix B of this part ("Procedure for Testing Chemical compatibility and Rate of Permeation in Polyethylene Packagings and Receptacles") and the maximum rate of permeation of hazardous lading through or into the polyethylene packaging or receptacles may not exceed the following rates:

(i) 0.5 percent for materials meeting the definition of a poison according to this subchapter and 2.0 percent for other hazardous materials, when subjected to temperatures no lower than $18^{\circ} \mathrm{C}\left(64^{\circ} \mathrm{F}\right)$ for 180 days in accordance with Test Method 1 ;

(ii) 0.5 percent for materials meeting the definition of a poison according to this subchapter and 2.0 percent for other hazardous materials, when subjected to temperatures no lower than $50^{\circ} \mathrm{C}\left(122^{\circ} \mathrm{F}\right)$ for 28 days in accordance with Test Method 2;
Designer to do and shipper responsibility to ensure.

Designer, tester, and evaluator to do and shipper responsibility to ensure.
Shipper responsibility to ensure.

Shipper responsibility to ensure. 
(iii) 0.5 percent for materials meeting the definition of a poison according to this subchapter and 2.0 percent for other hazardous materials, when subjected to temperatures no lower than $60^{\circ} \mathrm{C}\left(140^{\circ} \mathrm{F}\right)$ for 14 days in accordance with Test Method 3;

(3) Alternative procedures or rates of permeation are permitted if they yield a level of safety equivalent to or greater than that provided by paragraph (d) (2) of this section and are approved by the Director, OHNIT.

(4) Each polyethylene packaging used as an outside packaging for materials meeting the definition of a poison according to this subchapter shall be permanently marked, by embossment or other durable means, with the word "POISON" in letters of at least $1 / 4$ in. in height. Additional text or symbols may be included in the marking. The marking shall be located within six inches of the packaging's closure. The requirements of this subparagraph do not apply prior to september 1, 1985.

(e) For specification containers, compliance with the applicable specifications in Parts 178 and 179 of this subchapter shall be required in all details, except as otherwise provided in this subchapter.
Shipper responsibility to ensure.

Shipper responsibility to ensure.

Shipper responsibility to ensure.

Shipper responsibility to ensure.

Shipper responsibility to ensure.
Shipper responsibility to ensure. 


\subsection{1 - GENERAL DESIGN REQUIREMENTS}

Except for a package that contains a limited quantity or excepted instrument or article under 173.421 through 173.424 , each package used for shipment of radioactive materials shall be designed so that:

\section{GUIDANCE FOR APPLICATION}

(a) The package can be easily handled and properly secured in or on a conveyance during transport;

(b) A package with gross weight exceeding 10 kilograms (22 $1 \mathrm{~b})$ and up to 50 kilograms (110 lb) has a means for manual handling;
This does not necessarily mean handles are required. The intent is to maintain a package size and geometry which allow conformance to paragraph (a). For example, a package $4 \mathrm{ft} \times 6$ ft $\times 4$ ft cannot be easily handled by hand. For such a package, other handling methods would be designed. A package with sharp edges or camponents may not be easily handled manually. Also, package stability is required during transport. A round-shaped package, a top-heavy package, or any similar package which would not maintain its initial orientation and load position under conditions incidental to routine transportation would not meet these requirements. Tie-downs are required for the packagings mentioned in this paragraph, and exclusive use shipments or documented special provisions with the carrier are required. Designer to do and shipper responsibility to ensure.

This does not necessarily mean that handles are required. As in the comment on paragraph (a) above, physical size, geometry, and exterior surface design should be conducive to manual handling. Excluded are:

- Large, awkard packages or odd-shaped packages with no reasonable way to lift, hold, or move by hand;

- Surfaces with sharp edges or points which make handling difficult.

Designer to do and shipper responsibility to ensure.

\section{PACKAGING CATEGORY} STEEL DRIMS

All the drums evaluated meet the intent of this requirement. In all cases, the shipper should avoid loading a top-heavy package and should be aware of the need for tie-downs for any such packages.

All the drums evaluated meet the intent of this requirement when in the $10-\mathrm{kg}(22-\mathrm{lb})$ to $50-\mathrm{kg}$ (110-1b) range. 


\section{GUIDANCE FOR APPIICATION}

(c) A package with a gross weight of 50 kilograms (110 lb) or more can safely be handled by mechanical means;

(d) Each lifting attachment on the package, when used in the intended manner, with a minimum safety factor of 3 , does not impose an unsafe stress on the structure of the package. In addition, the lifting attachment shall be so designed that failure under excessive load would not impair the ability of the package to meet all other requirements of this subpart. Each attachment or other feature on the outer surface of the packaging that could be used to lift the package must be removable or otherwise capable of being made inoperable for transport, or shall be designed with strength equivalent to that required for lifting attachments;
Thought should be given to how the the packages will be handled, and they should be designed accordingly. If skids are used, the balance stability of the package on the forklift must be considered. One must also ensure that, when lifted by a forklift, the bottom structure can support the weight without significant distortion or loss of containment integrity. If hooks/lifting devices are used, they must meet 173.411 (d). In most cases, this is for the shipper to evaluate, particularly the requirement that failure "would not impair the ability of the package to meet all other requirements."

Designer to do and shipper responsibility to ensure.

A sign saying "Do Not Use As A Lifting Device," "Not A lifting Device," etc. is not adequate to prevent the use of the unauthorized lifting devices. The procedures for use of the packaging should also state the intended use of any attaching points for other purposes (i.e., "For lifting the lid only not entire packaging"). Desioner, and perhaps tester and evaluator, to do and shipper responsibility to ensure.
PACKAGE CATEGORY STEET DRUMS

All the drums evaluated meet the intent of this requirement. There are many drum/barrel handling devices which have proven effective and safe for drums weighing more than $50 \mathrm{~kg}$ (110 lb).

All the drums evaluated meet the intent of this requirement. The only drum with a handle is the 17C (178.115) 5-gal drum. This packaging was tested (1) at greater than $3001 \mathrm{~b}$ with no failure of handle, and (2) at 400 Ib where the handle did fail, but only pulled free from the side coupling. Thus, the failure was in an acceptable mode. There were no other lifting devices or attachments. 


\section{GUIDANCE FOR APPLICATION}

(e) The external surfaces, as far as practical, may be easily decontaminated;

(f) The outer layer of packaging will avoid, as far as pratical, pockets or crevices where water might collect; and

(g) Each feature that is added to the package at the time of transport and that is not part of the package will not reduce the safety of the package.
Plywood, although not normally thought of as easily decontaminated, is acceptable. The intent is to promote surfaces that are relatively smooth and that minimize cracks and crevices in which surface contamination could reside. Consideration should be given to actions such as sanding or painting surfaces. Desiomer to do and shipper responsibility to ensure.

This is not intended to eliminate 55-gal drums as Spec $7 \mathrm{~A}$ packaging. The intent is for packaging design personnel to consider this aspect. Do not design a puddle on top of a box or provide cavities to collect water which could spill during transport or handling or could promote rusting and general deterioration of the packaging, possibly in locations difficult to detect. Desioner to do and shipper responsibility to ensure.

For example, a canvas cover placed over a package for protection against the rain must not adversely affect heat transfer requirements. Shipper responsibility to ensure.
PACKAGING CATEGORY STEET DRUMS

All the drums evaluated meet the intent of this requirement.

All the drums evaluated meet the intent of the regulation. A newly designed package should consider this requirement.

This is a shipper responsibility since the regulation addresses items added to the packaging that was already evaluated. 
173.411 - GENERAL DESIGN REQUIREMENTS

Except for a package that contains a limited quantity or excepted instrument or article under 173.421 through 173.424 , each package used for shipment of radicactive materials shall be designed so that:

\section{GUIDANCE FOR APPLICATION}

(a) The package can be easily handled and properly secured in or on a conveyance during transport;

(b) A package with gross weight exceeding 10 kilograms (22 $1 \mathrm{~b})$ and up to 50 kilograms (110 1b) has a means for manual handling;
This does not necessarily mean handles are required. The intent is to maintain a package size and geometry which allow conformance to paragraph (a). For example, a package 4 ft $\times 6$ ft $\times 4$ ft cannot be easily handled by hand. For such a package, other handling methods would be designed. A package with sharp edges or components may not be easily handled manually. Also, package stability is required during transport. A round-shaped package, a top-heavy package, or any similar package which would not maintain its initial orientation and load position under conditions incidental to routine transportation would not meet these requirements. Tie-downs are required for the packagings mentioned in this paragraph, and exclusive use shipments or documented special provisions with the carrier are required. Designer to do and shipper responsibility to ensure.

This does not necessarily mean that handles are required. As in the conment on paragraph (a) above, physical size, geometry, and exterior surface design should be conducive to mamual handling. Excluded are:

- Large, awkard packages or odd-shaped packages with no reasonable way to lift, hold, or move by hand;

- Surfaces with sharp edges or points which make handling difficult.

Designer to do and shipper responsibility to ensure.
PACKAGING CATEGORY STEELL BOXES

All the steel boxes evaluated meet the intent of this requirement. None are intended for manual handling and all have a large, stable base.

This does not apply since all the steel boxes will weigh more than $50 \mathrm{~kg}$ (110 1b) . 


\section{GUIDANCE FOR APPLICATION}

(c) A package with a gross weight of 50 kilograms (110 1b) or more can safely be handled by mechanical means;

(d) Each lifting attachment on the package, when used in the intended manner, with a minimm safety factor of 3 , does not impose an unsafe stress on the structure of the package. In addition, the lifting attachment shall be so designed that failure under excessive load would not impair the ability of the package to meet all other requirements of this subpart. Each attachment or other feature on the outer surface of the packaging that could be used to lift the package must be removable or otherwise capable of being made inoperable for transport, or shall be designed with strength equivalent to that required for lifting attachments;
Thought should be given to how the the packages will be handled, and they should be designed accordingly. If skids are used, the balance stability of the package on the forklift must be considered. One must also ensure that, when lifted by a forklift, the bottom structure can support the weight without significant distortion or loss of contaimment integrity. If hooks/lifting devices are used, they must meet 173.411 (d). In most cases, this is for the shipper to evaluate, particularly the requirement that failure "would not impair the ability of the package to meet all other requirements." Designer to do and shipper responsibility to ensure.

A sign saying "Do Not Use As A Lifting Device," "Not A Lifting Device," etc. is not adequate to prevent the use of the unauthorized lifting devices. The procedures for use of the packaging should also state the intended use of any attaching points for other purposes (i.e., "For lifting the lid only not entire packaging"). Designer, and perhaps tester and evaluator, to do and shipper responsibility to ensure.

\section{PACKAGE CATEGORY} STEEL BOXES

These boxes are typically designed for handling with a truck or forklift. In all the steel box packagings, experience, testing, and/or design analysis have demonstrated compliance.

The $M-4$ bin and the SAND box have lifting devices which far exceed the required safety fator of 3; however, because of the strength of the lifting device, in each case the box will fail before the lifting device. This will not negatively affect the evaluation of these boxes since both are used within overpacks and the lifting devices are not used during transportation. RoGar boxes have lifting devices on the lid. These are intended only for lifting the lid and must be removed or rendered inoperable before transport. This is the shipper's responsibility. 


\section{GUIDANCE FOR APPIICATION}

(e) The external surfaces, as far as practical, may be easily decontaminated;

(f) The outer layer of packaging will avoid, as far as pratical, pockets or crevices where water might collect; and

(g) Each feature that is added to the package at the time of transport and that is not part of the package will not reduce the safety of the package.
Plywood, although not normally thought of as easily decontaminated, is acceptable. The intent is to promote surfaces that are relatively smooth and that minimize cracks and crevices in which surface contamination could reside. Consideration should be given to actions such as sanding or painting surfaces. Designer to do and shipper responsibility to ensure.

This is not intended to eliminate 55-gal drums as spec 7A packaging. The intent is for packaging design personnel to consider this aspect. Do not design a puddle on top of a box or provide cavities to collect water which could spill during transport or handling or could promote rusting and general deterioration of the packaging, possibly in locations difficult to detect. Designer to do and shipper responsibility to ensure.

For example, a carvas cover placed over a package for protection against the rain must not adversely affect heat transfer requirements. Shipper responsibility to ensure.
PACKAGING CATEGORY STEEI BOXFS

All the boxes evaluated meet the intent of this requirement.

All the boxes evaluated meet the intent of the requirement

This is a shipper responsibility since the regulation addresses items added to the packaging that was already evaluated. 
173.411 - GENERAL DESIGN REQUIREMENIS

Except for a package that contains a limited quantity or excepted instrument or article under 173.421 through 173.424 , each package used for shipment of radioactive materials shall be designed so that:

\section{GUIDANCE FOR APPLICATION}

(a) The package can be easily handled and properly secured in or on a conveyance during transport;

(b) A package with gross weight exceeding 10 kilograms (22 1b) and up to 50 kilograms (110 lb) has a means for mamual handling;
This does not necessarily mean handles are required. The intent is to maintain a package size and geometry which allow conformance to paragraph (a). For example, a package $4 \mathrm{ft} \times 6 \mathrm{ft} \times 4$ ft cannot be easily handled by hand. For such a package, other handling methods would be designed. A package with sharp edges or components may not be easily handled mamually. Also, package stability is required during transport. A round-shaped package, a top-heavy package, or any similar package which would not maintain its initial orientation and load position under conditions incidental to routine transportation would not meet these requirements. Tie-downs are required for the packagings mentioned in this paragraph, and exclusive use shipments or documented special provisions with the carrier are required. Designer to do and shipper responsibility to ensure.

This does not necessarily mean that handles are required. As in the comment on paragraph (a) above, physical size, geometry, and exterior surface design should be conducive to manual handling. Excluded are:

- Large, awkard packages or odd-shaped packages with no reasonable way to lift, hold, or move by hand;

- Surfaces with sharp edges or points which make handling difficult.

Designer to do and shipper responsibility to ensure.

\section{PACKAGING CATEQORY} WOODEN BOXES

All the wooden boxes evaluated meet the intent of this requirement. In all cases the shipper should avoid loading a top-heavy package and should be aware of the need for tie-downs for any such packages.'

All the wooden boxes evaluated meet the intent of this requirement when used in the 10-kg (22-1b) to 50-kg (110-lb) range. 


\section{GUIDANCE FOR APPLICATION}

(c) A package with a gross weight of 50 kilograms (110 1b) or more can safely be handled by mechanical means;

(d) Each lifting attachment on the package, when used in the intended manner, with a minimum safety factor of 3 , does not impose an unsafe stress on the structure of the package. In addition, the lifting attachment shall be so designed that failure under excessive load would not inpair the ability of the package to meet all other requirements of this subpart. Each attachment or other feature on the outer surface of the packaging that could be used to lift the package must be removable or otherwise capable of being made inoperable for transport, or shall be designed with strength equivalent to that required for lifting attachments;
Thought should be given to how the the packages will be handled, and they should be designed accordingly. If skids are used, the balance stability of the package on the forklift must be considered. One must also ensure that, when lifted by a forklift, the bottom structure can support the weight without significant distortion or loss of contaiment integrity. If hooks/lifting devices are used, they must meet 173.411 (d). In most cases, this is for the shipper to evaluate, particularly the requirement that failure "would not impair the ability of the package to meet all other requirements." Designer to do and shipper responsibility to ensure.

A sign saying "Do Not Use As A lifting Device," "Not A lifting Device," etc. is not adequate to prevent the use of the unauthorized lifting devices. The procedures for use of the packaging should also state the intended use of any attaching points for other purposes (i.e., "For lifting the lid only not entire packaging"). Designer, and perhaps tester and evaluator, to do and shipper responsibility to ensure.
PACKAGE CATEGORY WOODEN BOXES

These boxes are typically designed for handling with a truck or forklift. For all of these packagings, experience, testing, and or design analysis have demonstrated compliance.

None of the wooden boxes have lifting attachments; this requirement does not apply. 


\section{GUIDANCE FOR APPLICATION}

(e) The external surfaces, as far as practical, may be easily decontaminated;

(f) The outer layer of packaging will avoid, as far as pratical, pockets or crevices where water might collect; and

(g) Each feature that is added to the package at the time of transport and that is not part of the package will not reduce the safety of the package.
Plywood, although not normally thought of as easily decontaminated, is acceptable. The intent is to promote surfaces that are relatively smooth and that minimize cracks and crevices in which surface contamination could reside. Consideration should be given to actions such as sanding or painting surfaces. Designer to do and shipper responsibility to ensure.

This is not intended to eliminate 55-gal drums as Spec 7A packaging. The intent is for packaging design personnel to consider this aspect. Do not design a puddle on top of a box or provide cavities to collect water which could spill during transport or handling or could promote rusting and general deterioration of the packaging, possibly in locations difficult to detect. Designer to do and shipper responsibility to ensure.

For example, a canvas cover placed over a package for protection against the rain must not adversely affect heat transfer requirements. Shipper responsibility to ensure.

\section{PACKAGING CATEGORY} WOODEN BOXES

All the boxes evaluated meet the intent of this requirement. If contamination is a significant potential problem, then sanding, painting, or similar surface preparation should be completed.

All the boxes evaluated meet the intent of the requirement.

This is a shipper responsibility since the regulation addresses items added to the packaging that was already evaluated. 


\subsection{1 - GENERAL DESIGN REQUIREMENTS}

Except for a package that contains a limited quantity or excepted instrument or article under 173.421 through 173.424 , each package used for shipment of radioactive materials shall be designed so that:

\section{GUIDANCE FOR APPLICATION}

(a) The package can be easily handled and properly secured in or on a conveyance during transport;

(b) A package with gross weight exceeding 10 kilograms (22 $\mathrm{lb})$ and up to 50 kilograms (110 lb) has a means for mamual handling;
This does not necessarily mean handles are required. The intent is to maintain a package size and geometry which allow conformance to paragraph (a). For example, a package 4 ft $\times 6$ ft $\times 4$ ft cannot be easily handled by hand. For such a package, other handling methods would be designed. A package with sharp edges or components may not be easily handled manually. Also, package stability is required during transport. A round-shaped package, a top-heavy package, or any similar package which would not maintain its initial orientation and load position under conditions incidental to routine transportation would not meet these requirements. Tie-downs are required for the packagings mentioned in this paragraph, and exclusive use shipments or documented special provisions with the carrier are required. Designer to do and shipper responsibility to ensure.

This does not necessarily mean that handles are required. As in the comment on paragraph (a) above, physical size, gecmetry, and exterior surface design should be conducive to manual handling. Excluded are:

- Iarge, awkard packages or odd-shaped packages with no reasonable way to lift, hold, or move by hand;

- Surfaces with sharp edges or points which make handling difficult.

Designer to do and shipper responsibility to ensure.
PACKAGING CATEGORY FIBERBOARD PACKAGINGS

All the fiberboard boxes and drums meet the intent of this requirement. In all cases the shipper should avoid loading a top-heavy package and should be aware of the need for tie-downs for any such packages.

All fiberboard boxes and drums meet the intent of this requirement when used in the 10-kg (22-1b) to 50-kg (110-1b) range. Obviously, the Tri-wall packaging (Page D-1l) is intended for weights exceeding $50 \mathrm{~kg}$ and will require mechanical handling equipment. 


\section{GUIDANCE FOR APPLICATION}

(c) A package with a gross weight of 50 kilograms (110 lb) or more can safely be handled by mechanical means;
Thought should be given to how the the packages will be handled, and they should be designed accordingly. If skids are used, the balance stability of the package on the forklift mast be considered. One must also ensure that, when lifted by a forklift, the bottom structure can support the weight without significant distortion or loss of containment integrity. If hooks/lifting devices are used, they must meet 173.411 (d). In most cases, this is for the shipper to evaluate, particularly the requirement that failure "would not impair the ability of the package to meet all other requirements." Desigmer to do and shipper responsibility to ensure.
PACKAGE CATEGORY FIBERBOARD PACKAGINGS

The boxes and drums evaluated are typically designed for handling with hand-trucks and/or forklifts when weighing in excess of $50 \mathrm{~kg}$. For all of these packagings, experience, testing, andy or design analysis have demonstrated cormpliance. As in all packages, but particularly important in Tri-wall packaging, the shipper shall ensure that the content load is in the center of the box or evenly distributed along the bottom. 


\section{GUIDANCE FOR APPLICATION}

(d) Each lifting attachment on the package, when used in the intended manner, with a minimum safety factor of 3 , does not impose an unsafe stress on the structure of the package. In addition, the lifting attachment shall be so designed that failure under excessive load would not impair the ability of the package to meet all other requirements of this subpart. Each attachment or other feature on the outer surface of the packaging that could be used to lift the package must be removable or otherwise capable of being made inoperable for transport, or shall be designed with strength equivalent to that required for lifting attachments;

(e) The extermal surfaces, as far as practical, may be easily decontaminated;
A sign saying "Do Not Use As A Iifting Device," "Not A Lifting Device," etc. is not adequate to prevent the use of the unauthorized lifting devices. The procedures for use of the packaging should also state the intended use of any attaching points for other purposes (i.e., "For lifting the Iid only not entire packaging"). Designer, and perhaps tester and evaluator, to do and shipper responsibility to ensure.

Plywood, although not normally thought of as easily decontaminated, is acceptable. The intent is to promote surfaces that are relatively smooth and that minimize cracks and crevices in which surface contamination could reside. Consideration should be given to actions such as sanding or painting surfaces. Designer to do and shipper responsibility to ensure.
PACKAGING CATEGORY FIBERBOARD PACKAGINGS

None of the fiberboard packagings have lifting attachments; this requirement does not apply.

All the packagings evaluated meet the intent of this requirement. If contamination is a significant potential problem, covering, painting, or similar surface preparation should be completed. 


\section{GUIDANCE FOR APPLICATTON}

(f) The outer layer of packaging will avoid, as far as pratical, pockets or crevices where water might collect; and

(g) Each feature that is added to the package at the time of transport and that is not part of the package will not reduce the safety of the package.
This is not intended to eliminate 55-gal drums as Spec 7A packaging. The intent is for packaging design personnel to consider this aspect. Do not design a puddle on top of a box or provide cavities to collect water which could spill during transport or handling or could promote rusting and general deterioration of the packaging, possibly in locations difficult to detect. Designer to do and shipper responsibility to ensure.

For example, a canvas cover placed over a package for protection against the rain must not adversely affect heat transfer requirements. Shipper responsibility to ensure.
PACKAGING CATEGORY FIBERBOARD PACKAGINGS

All the packagings evaluated meet the intent of the requirement.

This is a shipper responsibility since the regulation addresses items added to the packaging that was already evaluated. 


\subsection{1 - GENERAL DESIGN REQUIREMENIS}

Except for a package that contains a limited quantity or excepted instrument or article under 173.421 through 173.424 , each package used for shipment of radioactive materials shall be designed so that:

\section{GUIDANCE FOR APPLICATION}

(a) The package can be easily handled and properly secured in or on a conveyance during transport;

(b) A package with gross weight exceeding 10 kilograms (22 lb) and up to 50 kilograms (110 lb) has a means for manual handling;
This does not necessarily mean handles are required. The intent is to maintain a package size and geometry which allow conformance to paragraph (a). For example, a package 4 ft $\times 6$ ft $\times 4$ ft cannot be easily handled by hand. For such a package, other handling methods would be designed. A package with sharp edges or components may not be easily handled manually. Also, package stability is required during transport. A round-shaped package, a top-heavy package, or any similar package which would not maintain its initial orientation and load position under conditions incidental to routine transportation would not meet these requirements. Tie-downs are required for the packagings mentioned in this paragraph, and exclusive use shipments or documented special provisions with the carrier are required. Designer to do and shipper responsibility to ensure.

This does not necessarily mean that handles are required. As in the comment on paragraph (a) above, physical size, geometry, and exterior surface design should be conducive to mamual handling. Excluded are:

- Iarge, awkard packages or odd-shaped packages with no reasonable way to lift, hold, or move by hand;

- Surfaces with sharp edges or points which make handling difficult.

Designer to do and shipper responsibility to ensure.
PACKAGING CATEGORY UF-6 CYLTNDERS

All cylinders evaluated meet the intent of this requirement. The experience data base demonstrates the stability of these packages in transport and their ease of handling.

This applies only to the 1S, 2S, and $5 \mathrm{~A}$ cylinders. As stated above, a vast experience base demonstrates compliance. 


\section{GUIDANCE FOR APPIICATION}

(c) A package with a gross weight of 50 kilograms (110 1b) or more can safely be handled by mechanical means;

(d) Each lifting attachment on the package, when used in the intended manner, with a minimum safety factor of 3 , does not impose an unsafe stress on the structure of the package. In addition, the lifting attachment shall be so designed that failure under excessive load would not impair the ability of the package to meet all other requirements of this subpart. Each attachment or other feature on the outer surface of the packaging that could be used to lift the package must be removable or otherwise capable of being made inoperable for transport, or shall be designed with strength equivalent to that required for lifting attachments;
Thought should be given to how the the packages will be handled, and they should be designed accordingly. If skids are used, the balance stability of the package on the forklift must be considered. One must also ensure that, when lifted by a forklift, the bottom structure can support the weight without significant distortion or loss of contaimment integrity. If hooks/lifting devices are used, they must meet 173.411 (d). In most cases, this is for the shipper to evaluate, particularly the requirement that failure "would not impair the ability of the package to meet all other requirements." Designer to do and shipper responsibility to ensure.

A sign saying "Do Not Use As A Lifting Device," "Not A lifting Device," etc. is not adequate to prevent the use of the unauthorized lifting devices. The procedures for use of the packaging should also state the intended use of any attaching points for other purposes (i.e., "For lifting the lid only not entire packaging"). Designer, and perhaps tester and evaluator, to do and shipper responsibility to ensure.
PACKAGE CATEGORY

UF-6 CXITNDERS

For the cylinders other than 1S, 2S, and 5A, a variety of mechanical systems are provided and have been used effectively and reliably for years. See Table C-4, page c-39.

All cylinders meet this requirement, as demonstrated in Table C-4, Page C-39. 


\section{GUIDANCE FOR APPLICATION}

(e) The external surfaces, as far as practical, may be easily decontaminated;

(f) The outer layer of packaging will avoid, as far as pratical, pockets or crevices where water might collect; and

(g) Each feature that is added to the package at the time of transport and that is not part of the package will not reduce the safety of the package.
Plywood, although not normally thought of as easily decontaminated, is acceptable. The intent is to promote surfaces that are relatively smooth and that minimize cracks and crevices in which surface contamination could reside. Consideration should be given to actions such as sanding or painting surfaces. Designer to do and shipper responsibility to ensure.

This is not intended to eliminate 55-gal drums as Spec 7A packaging. The intent is for packaging design personnel to consider this aspect. Do not design a puddle on top of a box or provide cavities to collect water which could spill during transport or handling or could promote rusting and general deterioration of the packaging, possibly in locations difficult to detect. Designer to do and shipper responsibility to ensure.

For example, a canvas cover placed over a package for protection against the rain must not adversely affect heat transfer requirements. Shipper responsibility to ensure.

\section{PACKAGING CATEGORY}

UF-6 CYITNDERS

The metal and painted metal surfaces have demonstrated, through experience, compliance with this requirement.

These packages meet the intent of the requirement as shown in the sketches in $M I M-3245$.

No features are added other than those described in operating procedures and these are evaluated by the shipper. 


\subsection{1 - GENERAI DESIGN REQUIREMENTS}

Except for a package that contains a limited quantity or excepted instrument or article under 173.421 through 173.424 , each package used for shipment of radicactive materials shall be designed so that:

\section{GUIDANCE FOR APPLICATION}

(a) The package can be easily handled and properly secured in or on a conveyance during transport;

(b) A package with gross weight exceeding 10

kilograms (22 $\mathrm{lb})$ and up to 50 kilograms (110 $1 \mathrm{~b})$ has a means for manual handling; ensure.
PACKAGTNG CATECORY IIOUIDS AND GASES

This does not necessarily mean handles are required. The intent is to maintain a package size and geometry which allow conformance to paragraph (a). For example, a package $4 \mathrm{ft} \times 6 \mathrm{ft} \times 4 \mathrm{ft}$ cannot be easily handled by hand. For such a package, other handling methods would be designed. A package with sharp edges or components may not be easily handled mamually. Also, package stability is required during transport. A round-shaped package, a top-heavy package, or any similar package which would not maintain its initial orientation and load position under conditions incidental to routine transportation would not meet these requirements.

Tie-downs are required for the packagings mentioned in this paragraph, and exclusive use shipments or documented special provisions with the carrier are required. Desiomer to do and shipper responsibility to

This does not necessarily mean that handles are required. As in the comment on paragraph (a) above, physical size, geometry, and exterior surface design should be conducive to manual handling. Excluded are:

- Iarge, awkard packages or odd-shaped packages with no reasonable way to lift, hold, or move by hand;

- Surfaces with sharp edges or points which make handling difficult.

Desioner to do and shipper responsibility to ensure.
All packagings meet the intent of this requirement per analysis of the sketches and as demonstrated by actual experience. In all cases, the shipper should avoid loading a top-heavy package and should be aware of the need for tie-downs for any such packages.

All the packagings evaluated meet the intent of this requirement when used in the 10-kg $(22-\mathrm{kg})$ to $50-\mathrm{kg}$ (110-1b) range. 


\section{GUIDANCE FOR APPLICATION}

(c) A package with a gross weight of 50 kilograms (110 lb) or more can safely be handled by mechanical means;

(d) Each lifting attachment on the package, when used in the intended manner, with a minimum safety factor of 3 , does not impose an unsafe stress on the structure of the package. In addition, the lifting attachment shail be so designed that failure under excessive load would not impair the ability of the package to meet all other requirements of this subpart. Each attachment or other feature on the outer surface of the packaging that could be used to lift the package must be removable or otherwise capable of being made inoperable for transport, or shall be designed with strength equivalent to that required for

lifting attachments;
Thought should be given to how the the packages will be handled, and they should be designed accordingly. If skids are used, the balance stability of the package on the forklift must be considered. One must also ensure that, when lifted by a forklift, the bottom structure can support the weight without significant distortion or loss of contaimment integrity. If hooks/lifting devices are used, they must meet 173.411 (d). In most cases, this is for the shipper to evaluate, particularly the requirement that failure "would not impair the ability of the package to meet all other requirements." Designer to do and shipper responsibility to ensure.

A sign saying "Do Not Use As A Iifting Device," "Not A lifting Device," etc. is not adequate to prevent the use of the unauthorized lifting devices. The procedures for use of the packaging should also state the intended use of any attaching points for other purposes (i.e., "For lifting the lid only not entire packaging"). Designer, and perhaps tester and evaluator, to do and shipper responsibility to ensure.

\section{PACKAGE CATEGORY} IIOUIDS AND GASES

The only two packagings that fit these criteria are the ORNL Returnable Shielded Shipping Container and the J. L. Sheppard Gas Cylinder No. 4 (see Pages F-26 and F-36 of MIM-3245). Both of these packages have outer boxes designed for routine handling with hand/mechanical devices. Experience has demonstrated packaging compliance with this requirement

The only package with a lifting attachment is ORNL's returnable plastic box (Page F-30, MIM3245). Tests at ORNL demonstrated compliance with this requirement, and failure of the handle would not impair the ability of the packaging to meet the contaiment integrity requirements. 


\section{GUIDANCE FOR APPLICATION}

(e) The external surfaces, as far as practical, may be easily decontaminated;

(f) The outer layer of packaging will avoid, as far as pratical, pockets or crevices where water might collect; and

(g) Each feature that is added to the package at the time of transport and that is not part of the package will not recuce the safety of the package.
Plywood, although not normally thought of as easily decontaminated, is acceptable. The intent is to promote surfaces that are relatively smooth and that minimize cracks and crevices in which surface contamination could reside. Consideration should be given to actions such as sanding or painting surfaces. Desiomer to do and shipper responsibility to ensure.

This is not intended to eliminate 55-gal drums as Spec 7A packaging. The intent is for packaging design personnel to consider this aspect. Do not design a puddle on top of a box or provide cavities to collect water which could spill during transport or handling or could promote rusting and general deterioration of the packaging, possibly in locations difficult to detect. Designer to do and shipper responsibility to ensure.

For example, a canvas cover placed over a package for protection against the rain must not adversely affect heat transfer requirements. Shipper responsibility to ensure.
PACKAGING CATEGORY IIOUIDS AND GASES

The variety of surfaces meet the intent of this requirement

These packages meet the intent of this requirement by analysis of the sketches/engineering drawings in MIM-3245.

This is a shipper responsibility since the regulation addresses items added to the packaging that was already evaluated. 


\subsection{1 - GENERAL DESIGN REQUIREMEINIS}

Except for a package that contains a limited quantity or excepted instrument or article under 173.421 through 173.424 , each package used for shipment of radioactive materials shall be designed so that:

\section{GUIDANCE FOR APPIICATION}

(a) The package can be easily handled and properly secured in or on a conveyance during transport;

(b) A package with gross weight exceeding 10 kilograms (22 $1 \mathrm{~b})$ and up to 50 kilograms (110 1b) has a means for mamul handling;
This does not necessarily mean handles are required. The intent is to maintain a package size and geometry which allow conformance to paragraph (a). For example, a package $4 \mathrm{ft} \times 6 \mathrm{ft} \times 4 \mathrm{ft}$ cannot be easily handled by hand. For such a package, other handling methods would be designed. A package with sharp edges or cormponents may not be easily handled manually. Also, package stability is required during transport. A round-shaped package, a top-heavy package, or any similar package which would not maintain its initial orientation and load position under conditions incidental to routine transportation would not meet these requirements. Tie-downs are required for the packagings mentioned in this paragraph, and exclusive use shipments or documented special provisions with the carrier are required. Designer to do and shipper responsibility to ensure.

This does not necessarily mean that handles are required. As in the comment on paragraph (a) above, physical size, geometry, and exterior surface design should be conducive to manual handling. Excluded are:

- Large, awkard packages or odd-shaped packages with no reasonable way to lift, hold, or move by hand;

- Surfaces with sharp edges or points which make handling difficult.

Designer to do and shipper responsibility to ensure.

\section{PACKAGING CATEGORY} MISCETIAANEOUS

All the packagings meet the intent of this requirement per analysis of the sketches and as demonstrated by actual experience. In all cases, the shipper should avoid loading a top-heavy package and shoild be aware of the need for tie-downs for any such packages.

Only the LUNL shielded container (see Page G-1, MIM-3245) fits this criterion and, as can be seen, it has a handle. 


\section{GUIDANCE FOR APPLICATION}

(c) A package with a gross weight of 50 kilograms (110 1b) or more can safely be handled by mechanical means;
Thought should be given to how the the packages will be handled, and they should be designed acoordingly. If skids are used, the balance stability of the package on the forklift must be considered. One must also ensure that, when lifted by a forklift, the bottom structure can support the weight without significant distortion or loss of contairment integrity. If hooks/lifting devices are used, they must meet 173.411 (d). In most cases, this is for the shipper to evaluate, particularly the requirement that failure "would not impair the ability of the package to meet all other requirements."

Designer to do and shipper responsibility to ensure.

\section{PACKAGE CATEGORY} MISCELLANEOUS

The three packages exceeding $110 \mathrm{lb}$ all have means for mechanical handling, and experience has demonstrated compliance. 


\section{GUIDANCE FOR APPLICATION}

(d) Each lifting attachment on the package, when used in the intended manner, with a minimum safety factor of 3 , does not impose an unsafe stress on the structure of the package. In addition, the lifting attachment shall be so designed that failure under excessive load would not impair the ability of the package to meet all other requirements of this subpart. Each attachment or other feature on the outer surface of the packaging that could be used to lift the package must be removable or otherwise capable of being made inoperable for transport, or shall be designed with strength equivalent to that required for lifting attachments;
A sign saying "Do Not Use As A Lifting Device," "Not A Iifting Device," etc. is not adequate to prevent the use of the unauthorized lifting devices. The procedures for use of the packaging should also state the intended use of any attaching points for other purposes (i.e., "For lifting the lid only not entire packaging"). Designer, and perhaps tester and evaluator, to do and shipper responsibility to ensure.
PACKAGING CATEGORY MISCEIITANEOUS

The ORNL TRU Package (see Page G-5, MIIM-3245) and the FEMA Source overpack (see Page G-9, MLM-3245) are the only two packagings with lifting devices. A structural analysis by Mound has demonstrated compliance with three times the gross weight requirement for both packages. With the ORNL TRU package, the outer metal skin will fail prior to the handle, but this would not compromise the overall ability to comply with this requirement. A similar analysis demonstrated that the handles of the FEMA package also comply. with the three times the gross weight requirement, and failure of the lid handles or side handles would not reduce the ability of the packaging to comply with this requirement. 


\section{GIDANCE FOR APPLICATION}

(e) The external surfaces, as far as practical, may be easily decontaminated;

(f) The outer layer of packaging will avoid, as far as pratical, pockets or crevices where water might collect; and

(g) Each feature that is added to the package at the time of transport and that is not part of the package will not reduce the safety of the package.
Plywood, although not normally thought of as easily decontaminated, is acceptable. The intent is to promote surfaces that are relatively smooth and that minimize cracks and crevices in which surface contamination could reside. Consideration should be given to actions such as sanding or painting surfaces. Designer to do and shipper responsibility to ensure.

This is not intended to eliminate 55-gal drums as Spec 7A packaging. The intent is for packaging design personnel to consider this aspect. Do not design a puddle on top of a box or provide cavities to collect water which could spill during transport or handling or could promote rusting and general deterioration of the packaging, possibly in locations difficult to detect. Designer to do and shipper responsibility to ensure.

For example, a canvas cover placed over a package for protection against the rain must not adversely affect heat transfer requirements. Shipper responsibility to ensure.
PACKAGING CATEGORY MISCETLANEOUS

The external surfaces are all metal and comply with this requirement.

Compliance is obvious by analysis of the sketches. The only exception is the SNL drum (see Page G-13, MLM-3245), which complies with the intent per the column on the left.

This is a shipper responsibility since the regulation addresses items added to the packaging that was already evaluated. 
173.412 - ADDITIONAL DESIGN REOUIREMENIS FOR TYPE A PACKAGES

In addition to meeting the general design requirements prescribed in 173.411, each Type A packaging shall be designed so that:

\section{GIDANCE FOR APPLICATION}

(a) The smallest overall external dimension of the package is not less than 10 centimeters (4 in.):

(b) The outside of the packaging incorporates a feature, such as a seal, that is not readily breakable, and that, while intact, is evidence that the package has not been opened. In the case of packages shipped in exclusive use closed transport vehicles, the cargo compartment may be sealed instead of the individual packages;

(c) As far as practicable, the external surfaces are free from protrusions and are designed so that they can be easily decontaminated;
Desigmer to do and shipper responsibility to ensure.

For this requirement, the package designer may need to be skilled and creative. This is especially true for packages such as fiberboard cartons and wooden boxes. A padlock is not effective as a security seal. It is not possible with most types of padlocks to ascertain if they have been illicitly opened. One acceptable approach toward meeting this requirement is serially mubered lead-wire seals, or, in the case of fiberboand packages, a tape of sufficient adhesive strength to damage the fiberboard upon removal. Designer to do and shipoer responsibility to ensure.

The intent is to minimize the number and nature of protrusions by consideration during design and/or as a result of any modifications to the packaging. Designer to do and shipper responsibility to ensure.

\section{PACKAGTNG CATEGORY} STEET DRUMS

As shown on the sketches and as given in the packaging description in MIM-3245, all packagings meet this requirement.

There are acceptable approaches to compliance for all evaluated packagings. It is the shipper's responsibility to ensure compliance with this requirement.

All evaluated packagings meet this requirement. 


\section{GUIDANCE FOR APPIICATION}

(d) Contairment and shielding would be maintained curing transportation and storage in a temperature range of $-40^{\circ} \mathrm{C}\left(-40^{\circ} \mathrm{F}\right)$ to $+70^{\circ} \mathrm{C}\left(+158^{\circ} \mathrm{F}\right)$ with account taken of the possibilities of brittle fracture;

(e) It is able to withstand the effects of any acceleration, vibration, or vibration resonance that may arise during normal transportation, without any deterioration of the effectiveness of closing devices or of the integrity of the package as a whole and without loosening or unintentional release of nuts, bolts, or other securing devices even after repeated use;
This does not mean any of the tests must necessarily be performed at the temperature extremes. [Note: 173.461(b) .] The regulations allow the assumption that the packaging is in equilibrium at $38^{\circ} \mathrm{C}$ prior to testing. one must evaluate the packaging components with respect to behavior at the temperature extremes under conditions incidental to transportation (i.e., the jiggles, bounces, and bumps normally encountered in transportation). Gaskets and packaging components need to be evaluated to determine if they will become excessively brittle at $-40 \%$. This may be accomplished by actual testing, referring to property of material tables, obtaining data from manufacturers, etc. The shipper must consider such things as freezing of liquid contents and evaluate the effect to ensure contimued contairment integrity. The shipper must also consider the buildup of pressure at elevated temperatures and ensure continued contaimment. Desigmer, tester, and evaluator to do and shipper responsibility to ensure.

Typically, one uses actual experience as a guide. If experience is not available, one normally uses a comparison to a similar packaging with an experience profile. If this isn't possible, vibration testing can be performed. The purpose of this section is to prevent the loosening of nuts, bolts, and contaiment devices under conditions incident to routine transportation. Designer, tester, and evaluator to do and shipper responsibility to ensure.

\section{PACKAGING CATEGORY} STEEL DRUMS

Metals used in these drums will not become excessively brittle at $-40^{\circ} \mathrm{C}$ and all gaskets used also meet this requirement. None of these packagings are authorized for liquids, so freezing of contents is not a concern. Temperatures of $+70^{\circ} \mathrm{C}$ will not result in any significant decrease in contairment integrity, as show in property of materials tables.

Experience has consistently demonstrated that these packagings or similar designs comply with this requirement. The shipper must ensure the application of quality assurance necessary to achieve this requirement. 


\section{GUIDANCE FOR APPLTCATION}

(f) It includes a contaiment system securely closed by a positive fastening device that cannot be opened unintentionally or by pressure that may arise within the package during normal transport. special form, as demonstrated in accordance with 173.469 , may be considered as a component of the contairment system;

(g) The materials of the packaging and any components or structures are physically and chemically compatible with each other and with the contents, taking into account the behavior of each under irradiation;

(h) For each component of the contaiment system, account is taken where applicable of radiolytic decomposition of materials and the generation of gas by chemical reaction and radiolysis;

(i) The contaimment system will retain its radioactive contents under the reduction of ambient pressure to 0.25 kilograms per square centimeter $(3.5 \mathrm{lb} /$ in $^{2}$ ); to ensure.
"Screw-type" closures can qualify. "Friction fit" normally does not qualify. security clips on cans could be acceptable. However, one cannot depend on friction alone. Desigmer, tester, and evaluator to do and shipper responsibiity to ensure.

Designer to do and shipper responsibility

Desigmer to do and shipper responsibility to ensure.

The containment system is defined as the components intended to retain the radioactive contents during transportation. Thus, one starts by identifying the contairment system. The radioative contents must be completely retained in the contaiment system if the package is subjected to reduced
PACKAGING CATEGORY STEELL DRUMS

All packagings evaluated meet this requirement, as shown on the sketches or in the packaging descriptions.

Shipper responsibility to ensure.

Shipper responsibility to ensure.

This analysis requires a more detailed description to provide adequate information. See Table C-1. 
TABLE C-I

SUMMARY OF "REDUCED PRESSURE" TESTS

ON THE EVALUATED STEEL DRUMS

\section{INIRODUCTION:}

Paragraph 173.412 (i) in effect requires a pressure differential of 0.75 atm (11.2 psi) across the surfaces of the containment system acting from the inside to the outside. In all of the steel drum packagings the contairment system is defined as the drum itself. To achieve the pressure differential, the inside of the packaging was pressurized to 11.2 psig using compressed air and held for approximately $5 \mathrm{~min}$. The pass/fail criteria were:

(1) No release of contents as determined by the absence of any detectable air flow or fluorscein after the test.

(2) The retention of pressure, $11.2 \pm 0.3 \mathrm{psig}$. This was held for approximately $5 \mathrm{~min}$.

(3) No structural distortion which would cause an increase exceeding $20 \%$ in the dose rate at the surface of the package as compared to the dose rate prior to beginning the test.

17C 55-gal drums with vent clips and with high-efficiency filters installed in the lids were tested. In this case the criteria became just contairment (no release of contents) since the packaging will not hold pressure. This last statement is technically correct; however, in the instance above (vent clips and filters in lid), the pressure was raised to $11.2 \mathrm{psig}$ and held for $5 \mathrm{~min}$ by adjusting the inward flow to equal the loss through the vent clip and/or filter. This was over-testing since there are no realistic conditions of normal transport in which a pressure differential of this magnitude could arise in a matter of seconds. In the unlikely event of such a pressure change over longer periods of time, the vent clip or filter would allow the pressures to equilibrate before differentials approaching $11.2 \mathrm{psi}$ could be reached. The table below provides detailed information concerning the testing of the steel drums and the results. 
TABLE C-1

Steel Drums in
Order of
Presentation in
MIM-3245

Test Results on standard Production Packagings without RIV

No. Tested Result

Spec 6C 5-gal (178.88)

Spec 6C 10-gal (178.99)

Spec 17C 5-gal (178.115)

Spec 17C 30-gal (178.115)
0

0

2

2 pass

1 Fail

2

2
Test Results with RIV Adhesive Sealent (Requires 24-hr Cure Before Testing)

No.

Tested

Result

2 pass

Vermiculite with flour and fluorescein on top

Vermiculite with flowr and fluorescein on top

Vermiculite with flour and fluorescein on top

\section{comments}

Containers without RTV were not tested because they were not expected to pass based on previous test results.

Containers without RIV were not tested because they were not expected to pass based on previous test results.

After one failed without RIV, the next two were tested with RIV.
None tested due to limited DOE contractor use. Evaluation based on testing/analysis of Spec $17 \mathrm{H}$ 30-gal packaging, a drum of less expected structural strength (i.e., 18-gauge sheet steel vs. 16-gauge sheet steel, etc.) 


\begin{tabular}{|c|c|c|c|c|c|}
\hline \multirow{2}{*}{$\begin{array}{l}\text { Steel Drums in } \\
\text { Order of } \\
\text { Presentation in } \\
\text { MIM-3245 }\end{array}$} & \multicolumn{2}{|c|}{$\begin{array}{l}\text { Test Results } \\
\text { on Standard } \\
\text { Production } \\
\text { Packagings } \\
\text { Without RTV } \\
\end{array}$} & \multicolumn{2}{|c|}{$\begin{array}{l}\text { Test Results with RIV } \\
\text { Adhesive Sealent (Requires } \\
\text { 24-hr cure Before Testing) }\end{array}$} & \multirow[t]{2}{*}{ Contents } \\
\hline & $\begin{array}{l}\text { No. } \\
\text { Tested }\end{array}$ & Result & $\begin{array}{l}\text { No. } \\
\text { Tested }\end{array}$ & Result & \\
\hline \multirow{4}{*}{$\begin{array}{l}\text { Spec 17C 55-gal } \\
(178.115)\end{array}$} & 5 & 5 pass & 0 & & Empty \\
\hline & 1 & \multicolumn{2}{|c|}{$\begin{array}{l}1 \text { fail } \\
\text { (see comments) }\end{array}$} & & Floir and fluorescein \\
\hline & 5 & 5 pass & 0 & & $\begin{array}{l}\text { Vermiculite with flour } \\
\text { and fluorescein }\end{array}$ \\
\hline & $\begin{array}{l}3 \text { IINL } \\
\text { Galvanized } \\
\text { Drums }\end{array}$ & 3 pass & 0 & & $\begin{array}{l}\text { Vermiculite with flour } \\
\text { and fluoriescein }\end{array}$ \\
\hline $\begin{array}{l}\text { Spec 17C 55-gal } \\
\text { (178.115) } \\
\text { with pressure } \\
\text { relief devices }\end{array}$ & \multicolumn{2}{|c|}{$\begin{array}{l}5 \text { Rockwell } 5 \text { pass } \\
\text { Hanford }\end{array}$} & 0 & & Flour and fluorescein \\
\hline - Vent clip & $\begin{array}{l}5 \text { Rockwell } \\
\text { Hanford }\end{array}$ & 5 pass & 0 & & $\begin{array}{l}\text { Vermiculite with flour } \\
\text { and fluorescein }\end{array}$ \\
\hline
\end{tabular}

Upon inspection, a manufacturing defect in the gasket was noted. Drums from same supplier tested again and all passed.

This test with no vent clips was to demonstrate the integrity of a standard production drum without RIV.

At $11.2 \mathrm{psig}$, air readily escaped, but no fluorescein was detected during or after these tests. 
TABIE C-1 (continued)

\begin{tabular}{|c|c|c|c|c|c|}
\hline \multirow[t]{2}{*}{$\begin{array}{l}\text { Steel Drums in } \\
\text { Order of } \\
\text { Presentation in } \\
\text { MIM-3245 } \\
\end{array}$} & \multicolumn{2}{|c|}{$\begin{array}{l}\text { Test Results } \\
\text { on Standard } \\
\text { Production } \\
\text { Packagings } \\
\text { Without RIV }\end{array}$} & \multicolumn{2}{|c|}{$\begin{array}{l}\text { Test Results with RIV } \\
\text { Adhesive Sealent (Requires } \\
\text { 24-hr cure Before Testing) }\end{array}$} & \multirow[t]{2}{*}{ Contents } \\
\hline & $\begin{array}{l}\text { No. } \\
\text { Tested }\end{array}$ & Result & $\begin{array}{l}\text { No. } \\
\text { Tested }\end{array}$ & $\underline{\text { Result }}$ & \\
\hline - Filter & $\begin{array}{l}3 \text { Rocky } \\
\text { Flats }\end{array}$ & 3 pass & 0 & & $\begin{array}{l}\text { Vermiculite with flour } \\
\text { and fluorescein }\end{array}$ \\
\hline $\begin{array}{l}\text { - Filter } \\
\text { (same drums } \\
\text { as above) }\end{array}$ & $\begin{array}{l}3 \text { Rocky } \\
\text { Flats }\end{array}$ & 3 pass & 0 & & $\begin{array}{l}\text { Vermiculite with flour } \\
\text { and fluorescein }\end{array}$ \\
\hline $\begin{array}{l}\text { Spec 17C 55-gal } \\
\text { (178.115) } \\
\text { with 90-mil } \\
\text { HDPE liner }\end{array}$ & \multicolumn{5}{|c|}{$\begin{array}{l}\text { No tests were required since the } 17 \mathrm{C} 55-\mathrm{gal} \text { drums had already been } \\
\text { tested and had met this requirement. }\end{array}$} \\
\hline \multirow{4}{*}{$\begin{array}{l}\text { Spec } 17 \mathrm{H} 30 \text {-gal } \\
(178.118)\end{array}$} & 5 IASL & 5 fail & & & Empty \\
\hline & 3 LASL & 3 fail & & & Flour and fluorescein \\
\hline & & & 3 LASL & 3 pass & Flour and fluorescein \\
\hline & $\begin{array}{l}3 \text { Rocky } \\
\text { Flats }\end{array}$ & 3 fail & & & Empty \\
\hline
\end{tabular}

The opening on the filter was covered on the inside and 11.2 psi pressure was applied to test the drums and the filter housing. As previously stated, all passed.

At 11.2 psig; air readily escaped, but no fluorescein was detected during or after these tests. 


\begin{tabular}{|c|c|c|}
\hline \multirow[t]{4}{*}{$\begin{array}{l}\text { Steel Drums in } \\
\text { Order of } \\
\text { Presentation in } \\
\text { MIM-3245 }\end{array}$} & \multicolumn{2}{|c|}{$\begin{array}{l}\text { Test Results } \\
\text { on Standard } \\
\text { Production } \\
\text { Packagings } \\
\text { Without RIV }\end{array}$} \\
\hline & $\begin{array}{c}\text { No. } \\
\text { Tested }\end{array}$ & Result \\
\hline & $\begin{array}{l}1 \text { Rocky } \\
\text { Flats }\end{array}$ & 1 pass \\
\hline & $\begin{array}{l}3 \text { Rocky } \\
\text { Flats }\end{array}$ & 3 fail \\
\hline $\begin{array}{l}\text { Spec } 17 \mathrm{H} 55 \text {-gal } \\
(178.118)\end{array}$ & $\begin{array}{l}7 \text { Mound } \\
2 \text { Mound } \\
5 \text { Mound }\end{array}$ & $\begin{array}{l}7 \text { fail } \\
2 \text { pass } \\
5 \text { fail }\end{array}$ \\
\hline
\end{tabular}

Test Results with RIV Adhesive Sealent (Requires 24-hr Cure Before Testingl

No.

Tested Result

Empty

Vermiculite with flour and fluorescein

Enpty

Empty

Vermiculite with flour and fluorescein

\section{Mound $\quad 10$ pass}

2 Rocky 2 fail

Flats

2 Rocky
Flats

2 IINL 2 fail

3 IUNL 3 fail

\section{Empty}

Vermiculite with flour and fluorescein

2 LNL 2 pass Empty

Both empty and full tests were performed to demonstrate that not only were the drums leaking, but they were leaking particulates detectable with UV light. 
TABLE C-1 (continued)

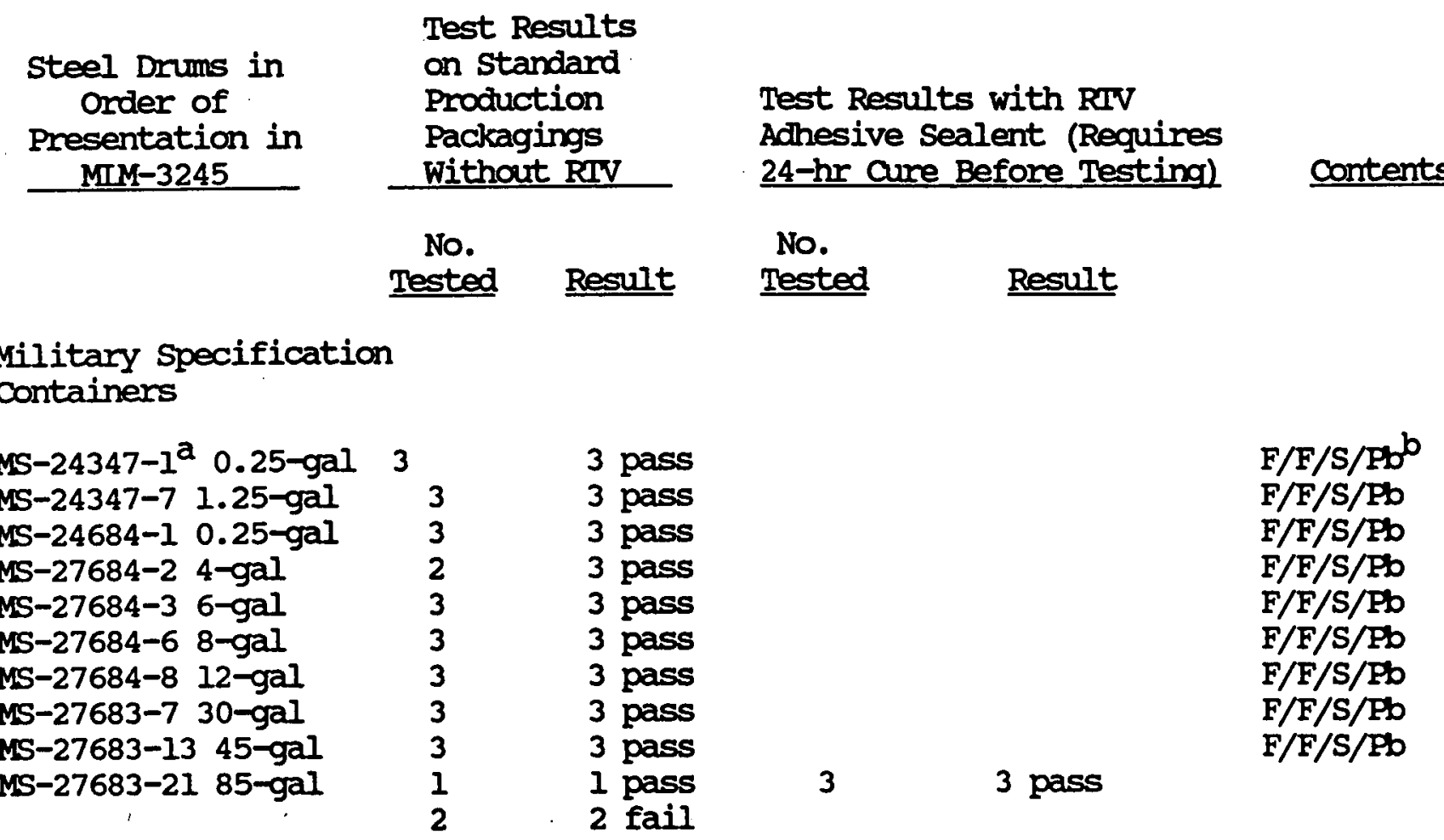

The 85-gal packaging is the only one requiring RIV.

a Drum assembly number.

blour, fluorescein, sand, and lead.

NOIE: Twenty-one Spec 17C 55-gal drums from three different DOE contractors were tested and demonstrated compliance with this requirement.

NOTE: Thirty-five $17 \mathrm{H} 55$-gal steel drums were tested. Of the 21 tested (from three different DOE contractors) without RIV: 19 failed, 2 passed. of the 14 tested with RTV: 14 passed. 


\section{GUIDANCE FOR APPLTCATION}

pressure. A filtered packaging is possible as long as it can be demonstrated that the filtered package will retain the contents and that the filter is not susceptible to damage from any other tests. Caution should be exercised to ensure that the contents and internal packaging components (i.e., plastic boxes, etc.) will not effectively seal the filter during normal use. In cases where a pressure differential will not build up because of the free-flow through a filter, the requirement of demonstrating the retention of contents must still be met. For a package that breathes (does not hold 11.2 psi), such as a wooden box, one must demonstrate that, even with breathing, the contents will be retained. Otherwise, a separate inner contaiment capable of meeting the reduced pressure requirement is required. Designer, tester, and evaluator to do and shipper responsibility to ensure.

(j) Each valve through which: the radioactive contents could otherwise escape is protected against damage and unauthorized operation and, except for a pressure relief device, has an enclosure to retain any leakage;

\section{PACKAGING CATEGORY}

STEEL DRUMS

None of these packagings ......sis have valves. 
GUIDANCE FOR APPLICATION

(k) Any radiation shield that encloses a component of the packaging specified as part of the contaiment system will prevent the unintentional escape of that component from the shield;

(1) Failure of any tie-down attachment on the pack-

aging under excessive load will not impair the ability of the package to meet other requirements of this subpart.
The shield shall be securely closed or, by way of packaging design, ensure against escape of a contairment component. One example is a package with cellotex on top of a lead shield with a press-fit lid in which closure of the cellotex holds the lid in place. The shipper must make sure that under the tests prescribed in 173.465 there will be no rearrangement of the original contairment/shield orientation. Desioner, tester, evaluator to do and shipper responsibility to ensure.

Designer, tester, evaluator to do and shipper responsibility to ensure.

\section{PACKAGTNG CATEGORY} STEELL DRUMS

None of these packagings have shielding as decribed.

None of these packagings have tie-down attachments as described. 


\subsection{2 - ADDITIONAL DESIGN REQUIREMENTS FOR TYPE A PACKAGES}

In addition to meeting the general design requirements prescribed in 173.411 , each Type A packaging shall be designed so that:

\section{GUIDANCE FOR APPLICATION}

(a) The smallest overall external dimension of the package is not less than 10 centimeters (4 in.):

(b) The outside of the packaging incorporates a feature, such as a seal, that is not readily breakable, and that, while intact, is evidence that the package has not been opened. In the case of packages shipped in exclusive use closed transport vehicles, the cargo compartment may be sealed instead of the individual packages;

(c) As far as practicable, the external surfaces are free from protrusions and are designed so that they can be easily decontaminated;
Desigmer to do and shipper responsibility to ensure.

For this requirement, the package designer may need to be skilled and creative. This is especially true for packages such as fiberboard cartons and wooden boxes. A padlock is not effective as a security seal. It is not possible with most types of padlocks to ascertain if they have been illicitly opened. One acceptable approach toward meeting this requirement is serially numbered lead-wire seals, or, in the case of fiberboard packages, a tape of sufficient adhesive strength to damage the fiberboard upon removal. Designer to do and shipper responsibility to ensure.

The intent is to minimize the number and nature of protrusions by consideration during design and/or as a result of any modifications to the packaging. Desigmer to do and shipper responsibility to ensure.
PACKAGING CATEGORY STEET BOXFS

As shown on the sketches and as given in the packaging description in MLM-3245, all packagings meet this requirement.

There are acceptable approaches to compliance for all evaluated packagings. It is the shipper's responsibility to ensure compliance with this requirement.

All evaluated packagings meet this requirement. 


\section{GUIDANCE FOR APPLICATION}

(d) Contaiment and shielding would be maintained during transportation and storage in a temperature range of $-40^{\circ} \mathrm{C}\left(-40^{\circ} \mathrm{F}\right)$ to $+70^{\circ} \mathrm{C}\left(+158^{\circ} \mathrm{F}\right)$ with account taken of the possibilities of brittle fracture;

(e) It is able to withstand the effects of any acoeleration, vibration, or vibration resonance that may arise during normal transportation, without any deterioration of the effectiveness of closing devices or of the integrity of the package as a whole and without loosening or unintentional release of nuts, bolts, or other securing devices even after repeated use;
This does not mean any of the tests must necessarily be performed at the temperature extremes. [Note: $173.461(\mathrm{~b})$.$] The regula-$ tions allow the assumption that the packaging is in equilibrium at $38^{\circ} \mathrm{C}$ prior to testing. One must evaluate the packaging components with respect to behavior at the temperature extremes under conditions incidental to transportation (i.e., the jiggles, bounces, and bumps normally encountered in transportation). Gaskets and packaging components need to be evaluated to determine if they will become excessively brittle at $-40^{\circ} \mathrm{F}$. This may be accomplished by actual testing, referring to property of material tables, obtaining data from manufacturers, etc. The shipper must consider such things as freezing of liquid contents and evaluate the effect to ensure contimued contairment integrity. The shipper must also consider the buildup of pressure at elevated temperatures and ensure contimued contairment. Designer, tester, and evaluator to do and shipper responsibility to ensure.

Typically, one uses actual experience as a guide. If experience is not available, one normally uses a comparison to a similar packaging with an experience profile. If this isn't possible, vibration testing can be performed. The purpose of this section is to prevent the loosening of muts, bolts, and contaimment devices under conditions incident to routine transportation. Designer, tester, and evaluator to do and shipper responsibility to ensure.

\section{PACKAGING CATEGORY} STEET BOXES

Metals used in these boxes will not become excessively brittle at $-40^{\circ} \mathrm{C}$ and all gaskets used also meet this requirement. None of these packagings are authorized for liquids, so freezing of contents is not a concern. Temperatures of $+70^{\circ} \mathrm{C}$ will not result in any significant decrease in contaiment integrity, as show in property of materials tables.

Experience has consistently demonstrated that these packagings or similar designs comply with this requirement. The shipper must ensure the application of quality assurance necessary to achieve this requirement. 


\section{GUIDANCE FOR APPLICATION}

(f) It includes a containment system securely closed by a positive fastening device that cannot be opened unintentionally or by pressure that may arise within the package during normal transport. special form, as demonstrated in accordance with 173.469, may be considered as a component of the containment system;

(g) The materials of the packaging and any components or structures are physically and chemically compatible with each other and with the contents, taking into account the behavior of each under irradiation;

(h) For each component of the contaimment system, acoount is taken where applicable of radiolytic decomposition of materials and the generation of gas by chemical reaction and radiolysis;

(i) The contaiment system will retain its radioactive contents under the reduction of ambient pressure to 0.25 kilograms per square centimeter (3.5 lb/ $\left.i^{2}\right)$;
"Screw-type" closures can qualify.

"Friction fit" normally does not qualify. Security clips on cans could be acceptable. However, one cannot depend on friction alone. Designer, tester, and evaluator to do and shipper responsibiity to ensure.

Designer to do and shipper responsibility to ensure.

Designer to do and shipper responsibility to ensure.

The contaimment system is defined as the components intended to retain the radioactive contents during transportation. Thus, one starts by identifying the containment system. The radioative contents must be completely retained in the contaiment system if the package is to be subjected to reduced
PACKAGING CATEGORY

STEET BOXES

All packagings evaluated meet this requirement, as shown on the sketches or in the packaging descriptions.

Shipper responsibility to ensure.

Shipper responsibility to ensure.

This analysis requires a more detailed description to provide adequate information. see Table C-2. 
TABIE C-2

\section{STEET BOXFS}

The contaiment system is defined as the box itself. To achieve the pressure differential, the inside of the packaging (steel box) was pressurized to 11.2 psig using compressed air, compressed nitrogen, or water, as described below. In all cases, the pressure was held for approximately $5 \mathrm{~min}$. The pass/fail criteria were essentially the same as given in Table $C-1$, with the exception of the Capital Industry test, which used water. In this case, obviously no flour or fluorescein was used; however, the absence of a visible water leak (and retention of water pressure) was really a more sensitive test than detection of fluorescein. Note that this test applies only to the nonfiltered packagings since this differential could not reasonably be expected to be encounted in transportation with a filtered packaging. 
Steel Boxes in Order of Presentation in MIM-3245

Capital Industries

\begin{tabular}{|c|c|c|}
\hline $\begin{array}{c}\text { Size/Model } \\
\text { No. } \\
\end{array}$ & $\begin{array}{c}\text { Test } \\
\text { Methodology }\end{array}$ & $\begin{array}{c}\text { Test } \\
\text { Results }\end{array}$ \\
\hline S-0510-0823 & $\begin{array}{l}\text { Pressurized } \\
\text { with water to } \\
11.2 \text { psi }\end{array}$ & Pass \\
\hline$V-0510-0823$ & $\begin{array}{l}\text { Vented/filtered } \\
\text { so this test is } \\
\text { not applicable }\end{array}$ & Pass \\
\hline S-0450-0846 & $\begin{array}{l}\text { Engineering } \\
\text { analysis by com- } \\
\text { parison to } \\
\text { S-0510-0823 above }\end{array}$ & Pass \\
\hline S-0730-0846 & $\begin{array}{l}\text { Engineering } \\
\text { analysis by com- } \\
\text { parison to } \\
\text { S-0730-1006 below }\end{array}$ & Pass \\
\hline S-0240-0906 & $\begin{array}{l}\text { Engineering } \\
\text { analysis by com- } \\
\text { parison to } \\
\text { S-0510-0823 above }\end{array}$ & Pass \\
\hline S-0480-0906 & $\begin{array}{l}\text { Engineering } \\
\text { analysis by com- } \\
\text { parison to } \\
\text { S-510-0823 above }\end{array}$ & Pass \\
\hline S-0730-1006 & $\begin{array}{l}\text { Pressurized with } \\
\text { water to } 11.2 \mathrm{psi}\end{array}$ & \\
\hline
\end{tabular}

\section{comments}

No leakage of water and pressure held for $5 \mathrm{~min}$.
No leakage of water and pressure held for $5 \mathrm{~min}$. 
TABLE C-2 (contimued)

Steel Boxes in Order of Presentation in MIM-3245

Container

Products corp.

$\frac{\begin{array}{c}\text { Size/Model } \\ \text { No. }\end{array}}{\text { S-0480-1376 }}$
Test Methodology

\section{Engineering} analysis by comparison to S-0730-1006 above

S-0840-1440

Pressurized with water to $11.2 \mathrm{psi}$

Pass

Pass air to 11.2 psi

Pass

\section{B-96-5 S/L RA}

B-96-5-RA-B

\section{B-96-5 S/L FD Vented/filtered \\ so test not applicable}

Pressurized with air to $11.2 \mathrm{psi}$

\section{Pressurized with}

Test

Results

Pass

All the remaining Container Products corp. models are vented/filtered; therefore, this test is not applicable.

\begin{abstract}
RoGar Chemical
\& Nuclear

Services, Inc.
\end{abstract}

$\mathrm{R}-1$

$\mathrm{R}-\mathbf{2}$
Engineering analysis by comparison to $\mathrm{R}-3$ below.

Engineering analysis by comparison to $\mathrm{R}-3$ below.
No leakage of water and pressure held for $5 \mathrm{~min}$.

No leakage of air and pressure held for 2 min.

No leakage of air and pressure held for $2 \mathrm{~min}$. 
TABIE C-2 (contimued) Steel Boxes in
Order of $\begin{array}{r}\text { Presentation } \\ \text { in MIM-3245 } \\ \hline\end{array}$

\section{Size/Model No.}

$\mathrm{R}-3$

R-4

R-4
$\begin{aligned} & \text { Rocky Flats, } \\ & \text { Golden, } \infty\end{aligned}$

Style 1
Style 2

$\begin{aligned} & \text { Argonne } \\ & \text { National } \\ & \text { Iaboratory - } \\ & \text { Argonne, Il }\end{aligned}$
Style 4
Sty-4 Bin

ANL-West

\begin{abstract}
ANL-West
\end{abstract} steel box

$\begin{array}{cc}\text { Test } & \text { Test } \\ \text { Methodology } & \text { Results }\end{array}$

Pressurized with nitrogen to 11.2 psi

Pass

Engineering analysis by comparison to $R-3$ above.

$\begin{array}{ll}\text { Each style (1-4) } & \text { Pass } \\ \text { pressurized with } & \\ \text { nitrogen to } & \text { Pass } \\ \text { slightly above } & \\ 12 \text { psi } & \text { Pass } \\ & \text { Pass } \\ \text { Pressurized with } & \\ \text { water to } 11.5 & \\ \text { psig }\end{array}$

certified only for Form 3 material; thus, test not meaningful
Not Required

Box is not designed with a gasket seal intended to retain Form 1 or Form 2 contents.
No leakage of nitrogen and pressure held for $5 \mathrm{~min}$.

No leakage of water and pressure held for more than $5 \mathrm{~min}$.

No leakage of nitrogen and pressure held for 5 mimutes. 
(j) Each valve through which the radioactive contents could otherwise escape is protected against damage and unauthorized operation and, except for a pressure relief device, has an enclosure to retain any leakage; pressure. A filtered packaging is possible as long as it can be demonstrated that the filtered package will retain the contents and that the filter is not susceptible to damage from any other tests. Caution should be exercised to ensure that the contents and internal packaging components (i.e., plastic boxes, etc.) will not effectively seal the filter during normal use. In cases where a pressure differential will not build up because of the free-flow through a filter, the requirement of demonstrating the retention of contents must still be met. For a package that breathes (does not hold 11.2 psi), such as a wooden box, one must demonstrate that, even with breathing, the contents will be retained. Otherwise, a separate inner contairment capable of meeting the reduced pressure requirement is required. Designer, tester, and evaluator to do and shipper responsibility to ensure.

Designer to do and shipper responsibility to ensure.
None of these packagings have valves. 


\section{GUIDANCE FOR APPLICATION}

(k) Any radiation shield that encloses a component of the packaging specified as part of the contairment system will prevent the unintentional escape of that component from the shield;

(1) Failure of any tie-down attachment on the packaging under excessive load will not impair the ability of the package to meet other requirements of this subpart.
The shield shall be securely closed or, by way of packaging design, ensure against escape of a contaimment component. One example is a package with cellotex on top of a lead shield with a press-fit lid in which closure of the cellotex holds the lid in place. The shipper must make sure that under the tests prescribed in 173.465 there will be no rearrangement of the original contaimment/shield orientation. Designer, tester, evaluator to do and shipper responsibility to ensure.

Desigmer, tester, evaluator to do and shipper responsibility to ensure.

\section{PACKAGTNG CATEGORY} STEET BOXES

None of these packagings have shielding as decribed.

None of these packagings have tie-down attachments as described. 
173.412 - ADDITIONAL DESIGN REQUIREMENIS FOR TYPE A PACKAGES

In addition to meeting the general design requirements prescribed in 173.411 , each Type A packaging shall be designed so that:

\section{GUIDANCE FOR APPTICATION}

(a) The smallest overall external dimension of the package is not less than 10 centimeters (4 in.);

(b) The outside of the packaging incorporates a feature, such as a seal, that is not readily breakable, and that, while intact, is evidence that the package has not been opened. In the case of packages shipped in exclusive use closed transport vehicles, the cargo compartment may be sealed instead of the individual packages;

(c) As far as practicable, the external surfaces are free from protrusions and are designed so that they can be easily decontaminated;
Designer to do and shipper responsibility to ensure.

For this requirement, the package designer may need to be skilled and creative. This is especially true for packages such as fiberboard cartons and wooden boxes. A padlock is not effective as a security seal. It is not possible with most types of padlocks to ascertain if they have been illicitly opened. One acceptable approach toward meeting this requirement is serially numbered lead-wire seals, or, in the case of fiberboand packages, a tape of sufficient adhesive strength to damage the fiberboard upon removal. Designer to do and shipper responsibility to ensure.

The intent is to minimize the mumber and nature of protrusions by consideration during design and/or as a result of any modifications to the packaging. Designer to do and shipper responsibility to ensure.

\section{PACKAGING CATEGORY} WOODEN BOXES

As shown on the sketches and as given in the packaging description in $\mathrm{MIM}-3245$, all packagings meet this requirement.

There are acceptable approaches to compliance for all evaluated packagings. It is the shipper's responsibility to ensure compliance with this requirement.

All evaluated packagings meet this requirement. 


\section{GUIDANCE FOR APPLICATION}

(d) Contaiment and shielding would be maintained during transportation and storage in a temperature range of $-40^{\circ} \mathrm{C}\left(-40^{\circ} \mathrm{F}\right)$ to $+70^{\circ} \mathrm{C}\left(+158^{\circ} \mathrm{F}\right)$ with account taken of the possibilities of brittle fracture;

(e) It is able to withstand the effects of any acceleration, vibration, or vibration resonance that may arise during normal transportation, without any deterioration of the effectiveness of closing devices or of the integrity of the package as a whole and without loosening or unintentional release of nuts, bolts, or other securing devices even after repeated use;
This does not mean any of the tests must necessarily be performed at the temperature extremes. [Note: 173.461(b) . ] The regulations allow the assumption that the packaging is in equilibrium at $38^{\circ} \mathrm{C}$ prior to testing. One must evaluate the packaging components with respect to behavior at the temperature extremes under conditions incidental to transportation (i.e., the jiggles, bounces, and bumps normally encountered in transportation). Gaskets and packaging components need to be evaluated to determine if they will become excessively brittle at $-40^{\circ} \mathrm{F}$. This may be accomplished by actual testing, referring to property of material tables, obtaining data from manufacturers, etc. The shipper must consider such things as freezing of liquid contents and evaluate the effect to ensure continued contairment integrity. The shipper must also consider the buildup of pressure at elevated temperatures and ensure continued contaimment. Designer, tester, and evaluator to do and shipper responsibility to ensure.

Typically, one uses actual experience as a guide. If experience is not available, one normally uses a comparison to a similar packaging with an experience profile. If this isn't possible, vibration testing can be performed. The purpose of this section is to prevent the loosening of muts, bolts, and contaimment devices under conditions incident to routine transportation. Designer, tester, and evaluator to do and shipper responsibility to ensure.

\section{PACKAGING CATEGORY} WOODEN BOXES

The materials (wood, caulking, metal strips, nails, gaskets, etc.) would not become excessively brittle at $-40^{\circ} \mathrm{C}$ and all gaskets used met this requirement. None of these packagings are authorized for liquids, so freezing of contents is not a concern. Temperatures of $+70^{\circ} \mathrm{C}$ would not result in any significant decrease in integrity either, as shown in property of materials tables.

Experience has consistently demonstrated that these packagings or similar designs comply with this requirement. The shipper must ensure the application of quality assurance necessary to achieve this requirement. 


\section{GUIDANCE FOR APPLICATION}

(f) It includes a containment system securely closed by a positive fastening device that cannot be opened unintentionally or by pressure that may arise within the package during normal transport. Special form, as demonstrated in accordance with 173.469 , may be considered as a component of the contaiment system;

(g) The materials of the packaging and any components or structures are physically and chemically compatible with each other and with the contents, taking into account the behavior of each under irradiation;

(h) For each component of the contairment system, account is taken where applicable of radiolytic decomposition of materials and the generation of gas by chemical reaction and radiolysis;

(i) The contaimment system will retain its radioactive contents under the reduction of ambient pressure to 0.25 kilograms per square centimeter $(3.5 \mathrm{lb} /$ in. ${ }^{2}$. to ensure.
"Screw-type" closures can qualify. "Friction fit" normally does not qualify. security clips on cans could be acceptable. However, one cannot depend on friction alone. Designer, tester, and evaluator to do and shipper responsibiity to ensure.

Designer to do and shipper responsibility

Designer to do and shipper responsibility to ensure.

The containment system is defined as the components intended to retain the radioactive contents during transportation. Thus, one starts by identifying the contaimment system. The radioative contents must be completely retained in the contaimment system if the package is subjected to reduced pressure. A filtered packaging is possible as long as it can be demonstrated that the filtered package will retain the contents and that the filter is not susceptible to damage from any other tests. Caution should be exercised to ensure that the contents and internal
PACKAGING CATEGORY

WOODEN BOXES

All packagings evaluated meet this requirement, as shown on the sketches or in the packaging descriptions.

Shipper responsibility to ensure.

Shipper responsibility to ensure.

Based on the testing discussed below (see Table $C-3$ ), these packagings all meet this requirement for Form 2 and 3 materials. The contaiment system in each case is the wooden box itself. Obviously, the box is not expected to be air-leak tight with a significant pressure differential applied. Thirteen separate boxes were subjected to this test. The contents in all 


\section{GUIDANCE FOR APPLICATION}

package will retain the contents and that the filter is not susceptible to damage from any other tests. Caution should be exercised to ensure that the contents and intermal packaging components (i.e., plastic boxes, etc.) will not effectively seal the filter curing normal use. In cases where a pressure differential will not build up because of the free-flow through a filter, the requirement of demonstrating the retention of contents must still be met. For a package that breathes (does not hold 11.2 psi), such as a wooden box, one must demonstrate that, even with breathing, the contents will be retained. Otherwise, a separate inner contairment capable of meeting the reduced pressure requirement is required. Desiomer, tester, and evaluator to do and shipper responsibility to ensure.

\section{PACKAGING CATEGORY}

\section{WOODEN BOXES}

cases were flour, fluorescein, and sand. In each case, the box did not hold pressure, as expected. Typically, boxes started leaking air at less than 1 psi. As the pressure increased, leak-paths increased until they began leaking all over (at the seams, around nails, etc.) at 9 psi. In each case, no sand was released, so these packagings passed for Form 2 and 3 materials (which is what they were evaluated for). In all cases, fluorescein was detected, but again, this simply means the packaging cannot be authorized for Form I materials. This does not present a problem since the boxes were never intended for use with Form 1 materials, and each evaluation states that Form I materials are "Not authorized without separate contaiment tested to Type A requirements with appropriate documentation." 
TABTE C-3

WOODEN BOXES

This test method, raising the internal pressure to 9-11 psi and maintaining it for several minutes, is very conservative. This is because, in transport, any pressure differential encountered would be equilibrated very slowly, and the strong driving force encountered in this test would not exist.

Type of Wooden Box/ Principal User

ANL-West

Model/Size

$7 A-217$

$7 A-375$

$7 A-670$

$7 A-880$

$7 A-995$

$7 A-1315$

ITNL

Flush Panel

$4 \mathrm{ft} \times 4 \mathrm{ft} \times 7 \mathrm{ft}$

MOUND

MA-1

Configuration A $\quad$ MA-2

MA-3

\section{Test/Analysis}

These packagings are authorized only for Form 3 materials. Test results discussed in this section demonstrate that Form 3 materials would not be released.

Test data on similar packagings as discussed below demonstrate that Form 2 and 3 materials would not be released as a result of this test.

Tests data on similar packagings as discussed in this table demonstrate that Form 2 and 3 materials would not be released as a result of this test.

\section{Results Comments}

Pass Authorized only for Form 3 materials.

Pass

Authorized only for Form 2 and 3 materials.

Pass

Authorized only for Form 2 and 3 materials. 


\section{Type of Wooden Box/} Principal User

\section{Model/Size}

MOUND

Configuration B

MOOND

Configuration C

$M C-1$

MC-2

$M C-3$

$\mathrm{MC}-4$

MC-5

$\begin{array}{ll}\text { MOUND } & \mathrm{MD}-1 \\ \text { Configuration D } & \mathrm{MD}-2 \\ & \mathrm{MD}-3 \\ \mathrm{MD}-4 \\ \mathrm{MD}-5 \\ \mathrm{MD}-6\end{array}$

\section{Test/Analysis}

Tests were conducted on $M B-1,2,3$, 4 , and 5 with flour, fluorescein, and sand as contents. The package was pressurized to between 9 and 11.2 psi, and an equilibrium (escape vs. imput) was achieved and held for 1-2 min. Air leaked out almost immediately. Fluorescein was detected in all cases, but in no instance was sand detected.

Tests data on similar packagings as discussed in this table demonstrate that Form 2 and 3 materials would not be released as a result of this test.

Tests were conducted on MD-1, 2, 3, 4,5 , and 6 with flour, fluorescein, and sand as contents. The package was pressurized to between 9 and 11.2 psi, and an equilibrium (escape vs. imput) was achieved and held for 1-2 min. Air leaked out almost immediately. Fluorescein was detected in all cases, but in no instance was sand detected.

\section{Results Comments}

Pass

There was no release of Form 2 (or 3 by extrapolation) contents. Thus, these packagings are authorized for Form 2 and 3 materials.

Pass

Authorized only for Form 2 and 3 materials.

Pass

There was no release of Form 2 (or 3 by extrapolation) contents. Thus, these packagings are authorized for Form 2 and 3 materials. 
TABLE C-3 (continued)

\section{Type of Wooden Box/} Principal User

\section{MOUND}

Configuration $\mathrm{E}$

ME-1

$\mathrm{ME}-2$

ME-3

\section{Model/Size}

\section{Test/Analysis}

Tests were conducted on all three models with flour, fluorescein, and sand as contents. The package was pressurized to between 9 and 11.2 psi, and an equilibrium (escape vs. imput) was achieved and held for 1-2 min. Air leaked out almost immediately. Fluorescein was detected in all cases, but in no instance was sand detected.
Results

Pass

There was no release of Form 2 (or 3 by extrapolation) contents. Thus, these packagings are authorized for Form 2 and 3 materials.

In summary, 13 of the Mound series boxes were tested and passed this test for Form 2 and 3 materials. These tests demonstrate that all of the boxes in this section would meet this requirement for Form 2 and 3 materials.

$\begin{array}{ll}\text { NLO Family } & G-4214 \\ \text { of Boxes } & G-4245 \\ & G-4255 \\ & G-4273 \\ G-4292\end{array}$

$\mathrm{Y}-12$

Series B

$B-1$
$B-2$
$B-3$
$B-4$
$B-5$
$B-6$
$B-7$
$B-8$

These packagings are authorized only for Form 3 materials. The test results discussed in this section demonstrate that Form 3 materials would not be released.

These packagings are authorized only for Form 3 materials. Test results discussed in this section demonstrate that Form 3 materials would not be released.
Pass

Authorized only for Form 3 materials.

Pass
Authorized only for Form 3 materials. 
TABLE C-3 (continued)

\section{Type of Wooden Box/} Principal User

$\mathrm{Y}-12$

Picture Frames

Rocky Flats

RA Series

\section{Model/Size}

PF-1

PF-2

$\mathrm{PF}-3$

$\mathrm{PF}-4$

PF-5

PF-6

$\mathrm{PF}-7$

$\mathrm{PF}-8$

Configuration 1

Configuration 1

\section{Test/Analysis}

These packagings are authorized only for Form 3 materials. Test results discussed in this section demonstrate that Form 3 materials would not be released.

These packagings are authorized only for Form 3 materials. Test results discussed in this section demonstrate that form 3 materials would not be released.

\section{Results comments}

Pass Authorized only for Form 3 materials.

Pass

Authorized only for Form 3 materials. 


\section{GIDANCE FOR APPLICATION}

(j) Each valve through which the radioactive contents could otherwise escape is protected against damage and unauthorized operation and, except for a pressure relief device, has an enclosure to retain any leakage;

(k) Any radiation shield that encloses a component of the packaging specified as part of the contairment system will prevent the unintentional escape of that component from the shield;

(1) Failure of any tie-down attachment on the packaging under excessive load will not impair the ability of the package to meet other requirements of this subpart;
Designer to do and shipper responsibility to ensure.

The shield shall be securely closed or, by way of packaging design, ensure against escape of a containment component. One example is a package with cellotex on top of a lead shield with a press-fit lid in wich closure of the cellotex holds the lid in place. The shipper must make sure that under the tests prescribed in 173.465 there will be no rearrangement of the original containment/shield orientation. Desioner, tester, evaluator to do and shipper responsibility to ensure.

Designer, tester, evaluator to do and shipper responsibility to ensure.

\section{PACKAGING CATEGORY}

WOODEN BOXES

None of these packagings have valves.

None of these packagings have shielding as decribed.
None of these packagings have tie-down attachments as described. 
173.412 - ADDITIONAL DESIGN REQUIREMENIS FOR TYPE A PACKAGES

In addition to meeting the general design requirements prescribed in 173.411 , each Type A packaging shall be designed so that:

\section{GUIDANCE FOR APPLICATION}

(a) The smallest overall external dimension of the package is not less than 10 centimeters (4 in.);

(b) The outside of the packaging incorporates a feature, such as a seal, that is not readily breakable, and that, while intact, is evidence that the package has not been opened. In the case of packages shipped in exclusive use closed transport vehicles, the cargo compartment may be sealed instead of the individual packages;

(c) As far as practicable, the external surfaces are free from protrusions and are designed so that they can be easily decontaminated;
Designer to do and shipper responsibility to ensure.

For this requirement, the package designer may need to be skilled and creative. This is especially true for packages such as fiberboard cartons and wooden boxes. A padiock is not effective as a security seal. It is not possible with most types of padiocks to ascertain if they have been illicitly opened. One acceptable approach toward meeting this requirement is serially numbered lead-wire seals, or, in the case of fiberboand packages, a tape of sufficient adhesive strength to damage the fiberboard upon removal. Designer to do and shipper responsibility to ensure.

The intent is to minimize the number and nature of protrusions by consideration curing design and/or as a result of any modifications to the packaging. Designer to do and shipper responsibility to ensure.
PACKAGING CATEGORY FIBERBOARD CONTATNERS

As shown on the sketches and as given in the packaging description in MIM-3245, all packagings meet this requirement.

There are acceptable approaches to compliance for all evaluated packagings. It is the shipper's responsibility to ensure compliance with this requirement.

All evaluated packagings meet this requirement. 


\section{GUIDANCE FOR APPLICATION}

(d) contairment and shielding would be maintained curing transportation and storage in a temperature range of $-40^{\circ} \mathrm{C}\left(-40^{\circ} \mathrm{F}\right)$ to $+70^{\circ} \mathrm{C}\left(+1580^{\circ}\right)$ with account taken of the possibilities of brittle fracture;

(e) It is able to withstand the effects of any acceleration, vibration resonance that may arise during normal transportation, without any deterioration of the effectiveness of closing devices or of the intetgrity of the package as a whole and without loosening or unintentional release of nuts, bolts, or other securing devices even after repeated use;
This does not mean any of the tests must necessarily be performed at the temperature extremes. [Note: 173.461(b) .] The regulations allow the assumption that the packaging is in equilibrium at $38^{\circ} \mathrm{C}$ prior to testing. one must evaluate the packaging components with respect to behavior at the temperature extremes under conditions incidental to transportation (i.e., the jiggles, bounces, and bumps normally encountered in transportation). Gaskets and packaging components need to be evaluated to determine if they will become excessively brittle at $-40 \%$. This may be accomplished by actual testing, referring to property of material tables, obtaining data from manufacturers, etc. The shipper must consider such things as freezing of liquid contents and evaluate the effect to ensure contimued contairment integrity. The shipper must also consider the buildup of pressure at elevated temperatures and ensure contimued contairment. Desioner, tester, and evaluator to do and shipper responsibility to ensure.

Typically, one uses actual experience as a guide. If experience is not available, one normally uses a comparison to a similar packaging with an experience profile. If this isn't possible, vibration testing can be performed. The purpose of this section is to prevent the loosening of nuts, bolts, and contaimment devices under conditions incident to routine transportation. Designer, tester, and evaluator to do and shipper responsibility to ensure.
PACKAGTNG CATEGORY FIBERBOARD CONTAINERS

The materials (fiberboard, metal strips, nails, gaskets, etc.) would not become excessively brittle at $-40^{\circ} \mathrm{C}$ and all gaskets used met this requirement. None of these packagings are authorized for liquids, so this requirement is not applicable. Temperatures of $+70^{\circ} \mathrm{C}$ would not result in any significant decrease in integrity, as shown in property of materials tables.

Experience has consistently demonstrated that these packagings or similar designs comply with this requirement. The shipper must ensure the application of quality assurance necessary to achieve this requirement. 


\section{GUIDANCE FOR APPLICATION}

(f) It includes a contairment system securely closed by a positive fastening device that cannot be opened unintentionally or by pressure that may arise within the package during normal transport. Special form, as demonstrated in accordance with 173.469 , may be considered as a component of the contairment system;

(g) The materials of the packaging and any components or structures are physically and chemically compatible with each other and with the contents, taking into account the behavior of each under irradiation;

(h) For each component of the contaiment system, account is taken where applicable of radiolytic decomposition of materials and the generation of gas by chemical reaction and radiolysis;

(i) The contaiment system will retain its radioactive contents under the reduction of ambient pressure to 0.25 kilograms per square centimeter (3.5 lb/ in. ${ }^{2}$ ):
"Screw-type" closures can qualify. "Friction fit" normally does not qualify. security clips on cans could be acceptable. However, one cannot depend on friction alone. Designer, tester, and evaluator to do and shipper responsibiity to ensure.

Designer to do and shipper responsibility to ensure.

Desigmer to do and shipper responsibility to ensure.

The contaiment system is defined as the components intended to retain the radioactive contents during transportation. Thus, one starts by identifying the contaimment system. The radioative contents must be completely retained in the contaiment system if the package is subjected to reduced pressure. A filtered packaging is possible as long as it can be demonstrated that the filtered package will retain the contents and that the filter is not susceptible to damage from any
All packagings evaluated meet this requirement, as shown on the sketches or in the packaging descriptions.

Shipper responsibility to ensure.

Shipper responsibility to ensure.

Except for LWNL's package, this test was not conducted on any of the fiberboand packagings since they obviously are not leak tight. With the exception of the IINL package previously mentioned, these packagings are authorized only for Form 3 materials. Since Form 3 materials by definition have no dispersible contamina- 

the requirement of demonstrating the

(j) Each valve through which the radioactive contents could otherwise escape is protected against damage and unauthorized operation and, except for a pressure relief device, has an enclosure to retain any leakage;

\section{GUIDANCE FOR APPLICATION}

other tests. Caution should be exercised to ensure that the contents and internal packaging components (i.e., plastic boxes, etc.) will not effectively seal the filter curing normal use. In cases where a pressure differential will not build up because of the free-flow through a filter, retention of contents must still be met. For a package that breathes (does not hold 11.2 psi), such as a wooden box, one must demonstrate that, even with breathing, the contents will be retained. Otherwise, a separate inner containment capable of meeting the recuced pressure requirement is required. Designer, tester, and evaluator to do and shipper responsibility to ensure.

PACKAGING CATEGORY FIBERBOARD CONTATNERS

tion, a movement of air from inside the package to the outside would have no adverse consequences. Thus, all these packagings authorized for only Form 3 material would meet this requirement.

For the one exception, the IINL packaging, two separate inner metal containers (No. 10 cans), were tested in a bell jar assembly and passed. The metal inner container (containment system) was inmersed in a beaker of water inside a bell jar for approximately $5 \mathrm{~min}$, and the pressure inside the bell jar was reduced to 3.6 psi. The water was checked for bubbles and, in both cases, none were detected. Thus, the metal inner container (No. 10 can) passed this test by itself.

Designer to do and shipper responsibility to ensure.
None of these packagings have valves. 


\section{GUIDANCE FOR APPLICATION}

(k) Any radiation shield that encloses a component of the packaging specified as part of the containment system will prevent the unintentional escape of that component from the shield;

(1) Failure of any tie-down attachment on the packaging under excessive load will not impair the ability of the package to meet other requirements of this subpart.
The shield shall be securely closed or, by way of packaging design, ensure against escape of a contaimment component. One example is a package with cellotex on top of a lead shield with a press-fit lid in which closure of the cellotex holds the lid in place. The shipper must make sure that under the tests prescribed in 173.465 there will be no rearrangement of the original contaiment/shield orientation. Desiomer, tester, evaluator to do and shipper responsibility to ensure.

Designer, tester, evaluator to do and shipper responsibility to ensure.
PACKAGING CATEGORY FIBERBOARD CONTATINERS

None of these packagings have shielding as decribed.

None of these packagings have tie-down attachments as described. 
173.412 - ADDITIONAL DESIGN REQUIREMENIS FOR TYPE A PACKAGES

In addition to meeting the general design requirements prescribed in 173.411, each Type A packaging shall be designed so that:

\section{GUIDANCE FOR APPLICATION}

(a) The smallest overall external dimension of the package is not less than 10 centimeters (4 in.);

(b) The outside of the packaging incorporates a feature, such as a seal, that is not readily breakable, and that, while intact, is evidence that the package has not been opened. In the case of packages shipped in exclusive use closed transport vehicles, the cargo compartment may be sealed instead of the individual packages;

(c) As far as practicable, the external surfaces are free from protrusions and are designed so that they can be easily decontaminated;
Desigmer to do and shipper responsibility to ensure.

For this requirement, the package designer may need to be skilled and creative. This is especially true for packages such as fiberboard cartons and wooden boxes. A padlock is not effective as a security seal. It is not possible with most types of padlocks to ascertain if they have been illicitly opened. One acceptable approach toward meeting this requirement is serially mubered lead-wire seals, or, in the case of fiberboard packages, a tape of sufficient adhesive strength to damage the fiberboard upon removal. Designer to do and shipper responsibility to ensure.

The intent is to minimize the number and nature of protrusions by consideration during design and/or as a result of any modifications to the packaging. Designer to do and shipper responsibility to ensure.

\section{PACKAGTNG CATEGORY}

UF-6 CYLTNDERS

As shown on the sketches and as given in the packaging description in MLM-3245, all packagings meet this requirement.

There are acceptable approaches to compliance for all evaluated packagings. It is the shipper's responsibility to ensure compliance with this requirement.

All evaluated packagings meet this requirement. 


\section{GUIDANCE FOR APPLICATION}

(d) Contairment and shielding would be maintained during transportation and storage in a temperature range of $-40^{\circ} \mathrm{C}\left(-40^{\circ} \mathrm{F}\right)$ to $+70^{\circ} \mathrm{C}\left(+158^{\circ} \mathrm{F}\right)$ with account taken of the possibilities of brittle fractures;

(e) It is able to withstand the effects of any acceleration, vibration, or vibration resonance that may arise during normal transportation, without any deterioration of the effectiveness of closing devices or of the integrity of the package as a whole and without loosening or unintentional release of nuts, bolts, or other securing devices even after repeated use;
This does not mean any of the tests must necessarily be performed at the temperature extremes. [Note: $173.461(\mathrm{~b})$.$] The regula-$ tions allow the assumption that the packaging is in equilibrium at $38^{\circ} \mathrm{C}$ prior to testing. one must evaluate the packaging components with respect to behavior at the temperature extremes under conditions incidental to transportation (i.e., the jiggles, bounces, and bumps normally encountered in transportation). Gaskets and packaging components need to be evaluated to determine if they will become excessively brittle at $-40^{\circ} \mathrm{F}$. This may be accomplished by actual testing, referring to property of material tables, obtaining data from mamufacturers, etc. The shipper must consider such things as freezing of liquid contents and evaluate the effect to ensure continued contaimment integrity. The shipper must also consider the buildup of pressure at elevated temperatures and ensure continued contaimment. Desigmer, tester, and evaluator to do and shipper responsibility to ensure.

Typically, one uses actual experience as a guide. If experience is not available, one normally uses a comparison to a similar packaging with an experience profile. If this isn't possible, vibration testing can be performed. The purpose of this section is to prevent the loosening of muts, bolts, and containment devices under conditions incident to routine transportation. Desigmer, tester, and evaluator to do and shipper responsibility to ensure.

\section{PACKAGING CATEKORY} UF-6 CYLTNDERS

Metals used in these cylinders will not become excessively brittle at $-40^{\circ} \mathrm{C}$ and all gaskets used also meet this requirement. None of these packagings are authorized for liquids, so freezing of contents is not a concern. Temperatures of $+70^{\circ} \mathrm{C}$ will not result in any significant decrease in contaimment integrity, as show in property of materials tables.

Experience has consistently demonstrated that these packagings or similar designs comply with this requirement. The shipper must ensure the application of quality assurance necessary to achieve this requirement. 


\section{GUIDANCE FOR APPLICATION}

(f) It includes a contairment system securely closed by a positive fastening device that cannot be opened unintentionally or by pressure that may arise within the package during normal transport. special form, as demonstrated in accordance with 173.469 , may be considered as a component of the contairment system;

(g) The materials of the packaging and any components or structures are physically and chemically compatible with each other and with the contents, taking into account the behavior of each under irradiation;

(h) For each component of the contaimment system, account is taken where applicable of radiolytic decomposition of materials and the generation of gas by chemical reaction and radiolysis;

(i) The containment system will retain its radioactive contents under the reduction of ambient pressure to 0.25 kilograms per square centimeter (3.5 lb/ in. ${ }^{2}$ ); to ensure.
"Screw-type" closures can qualify. "Friction fit" normally does not qualify. Security clips on cans could be acceptable. However, one cannot depend on friction alone. Desigmer, tester, and evaluator to do and shipper responsibility to ensure.

Designer to do and shipper responsibility

Desigmer to do and shipper responsibility to ensure.

The containment system is defined as the components intended to retain the radioactive contents during transportation. Thus, one starts by identifying the contairment system. The radioative contents must be completely retained in the contaiment system if the package is subjected to reduced pressure. A filtered packaging is possible as long as it can be demonstrated that the filtered package will retain the contents and that the filter is not susceptible to damage
PACKAGING CATEGORY

\section{UF-6 CYITNDERS}

All packagings evaluated meet this requirement, as shown on the sketches or in the packaging descriptions.

Shipper responsibility to ensure.

Shipper responsibility to ensure.

All cylinders are designed to withstand pressures far in excess of 11.2 psi. The minimum service pressure for any of these cylinders is $100 \mathrm{psig}$ and extends up to $200 \mathrm{psig}$ for nine of the cylinders. 
(j) Each valve through which the radioactive contents could otherwise escape is protected against damage and unauthorized operation and, except for a pressure relief device, has an enclosure to retain any leakage;

(k) Any radiation shield that encloses a component of the packaging specified as part of the contaimment system will prevent the unintentional escape of that component from the shield;

\section{GIDANCE FOR APPLICATION}

from any other tests. Caution should be exercised to ensure that the contents and internal packaging components (i.e., plastic boxes, etc.) will not effectively seal the filter during normal use. In cases where a pressure differential will not build up because of the free-flow through a filter, the requirement of demonstrating the retention of contents must still be met. For a package that breathes (does not hold 11.2 psi), such as a wooden box, one must demonstrate that, even with breathing, the contents will be retained.

otherwise, a separate inner containment capable of meeting the reduced pressure requirement is required. Desioner, tester, and evaluator to do and shipper responsibility to ensure.

Designer to do and shipper responsibility to ensure.

The shield shall be securely closed or, by way of packaging design, ensure against escape of a containment component. One example is a package with cellotex on top of a lead shield with a press-fit lid in which closure of the cellotex holds the lid in
PACKAGTNG CATEGORY UF-6 CYLTNDERS

Each valve is protected against damage, sealed against unauthorized operation, and capped to retain any leakage.

None of these packagings have shielding as decribed. 
(1) Failure of any tie-down attachment on the packaging under excessive load will not impair the ability of the package to meet other requirements of this subpart.

\section{GUIDANCE FOR APPIICATION}

place. The shipper must make sure that under the tests prescribed in 173.465 there will be no rearrangement of the original contaimment/shield orientation. Designer, tester, evaluator to do and shipper responsibility to ensure.

Desigmer, tester, evaluator to do and shipper responsibility to ensure.

TABLE C-4

\begin{tabular}{lccc} 
Cylinder & $\begin{array}{c}\text { Weight } \\
(1 \mathrm{~b})\end{array}$ & $\begin{array}{c}\text { Calculated } \\
\text { Safety Factor }\end{array}$ & Result \\
\cline { 2 - 4 } & & 12 & Pass \\
48X & 25,530 & 10 & Pass \\
48Y & 32,760 & 10 & Pass \\
$48 G$ & 30,600 & 10 & Pass \\
48H & 31,190 & 10 & Pass \\
48HX & 31,190 & &
\end{tabular}

PACKAGING CATECORY

UF-6 CYITNDERS

Only one configuration

(48-in. cylinder) uses/ incorporates tie-down attachments. Table C-4 shows the calculated safety factors and the failure mode analyses. In all cases, it was demonstrated that the Iug would fail, not the cylinder. Thus, the integrity of the cylinder would not be impaired. 


\subsection{2 - ADDITIONAL DESIGN REQUIREMENTS FOR TYPE A PACKAGES}

In addition to meeting the general design requirements prescribed in 173.411 , each Type A packaging shall be designed so that:

(a) The smallest overall extermal dimension of the package is not less than 10 centimeters (4 in.);

(b) The outside of the packaging incorporates a feature, such as a seal, that is not readily breakable, and that, while intact, is evidence that the package has not been opened. In the case of packages shipped in exclusive use closed transport vehicles, the cargo compartment may be sealed instead of the individual packages;

(c) As far as practicable, the external surfaces are free from protrusions and are designed so that they can be easily decontaminated;

\section{GUIDANCE FOR APPLICATION}

Designer to do and shipper responsibility to ensure.

For this requirement, the package designer may need to be skilled and creative. This is especially true for packages such as fiberboard cartons and wooden boxes. A padlock is not effective as a security seal. It is not possible with most types of padlocks to ascertain if they have been illicitly opened. One acceptable approach toward meeting this requirement is serially numbered lead-wire seals, or, in the case of fiberboard packages, a tape of sufficient adhesive strength to damage the fiberboard upon removal. Designer to do and shipper responsibility to ensure.

The intent is to minimize the number and nature of protrusions by consideration during design and/or as a result of any modifications to the packaging. Designer to do and shipper responsibility to ensure.

\section{PACKAGING CATEGORY} ITQUIDS AND GASES

As shown on the sketches and as given in the packaging description in MIM-3245, all packagings meet this requirement.

There are acceptable approaches to compliance for all evaluated packagings. It is the shipper's responsibility to ensure compliance with this requirement.

All evaluated packagings meet this requirement. 


\section{GUIDANCE FOR APPLICATION}

(d) Contaimment and shielding would be maintained curing transportation and storage in a temperature range of $-40^{\circ} \mathrm{C}\left(-40^{\circ} \mathrm{F}\right)$ to $+70^{\circ} \mathrm{C}\left(+158 \mathrm{O}^{\circ}\right)$ with account taken of the possibilities of brittle fracture;

(e) It is able to withstand the effects of any acceleration, vibration resonance that may arise during normal transportation, without any deterioration of the effectiveness of closing devices or of the intetgrity of the package as a whole and without loosening or unintentional release of muts, bolts, or other securing devices even after repeated use;
This does not mean any of the tests must necessarily be performed at the temperature extremes. [Note: $173.461(\mathrm{~b})$.] The regulations allow the assumption that the packaging is in equilibrium at $38^{\circ} \mathrm{C}$ prior to testing. One must evaluate the packaging components with respect to behavior at the temperature extremes under conditions incidental to transportation (i.e., the jiggles, bounces, and bumps normally enoountered in transportation). Gaskets and packaging components need to be evaluated to determine if they will become excessively brittle at -40 F. This may be accomplished by actual testing, referring to property of material tables, obtaining data from manufacturers, etc. The shipper must consider such things as freezing of liquid contents and evaluate the effect to ensure contimued contairment integrity. The shipper must also consider the buildup of pressure at elevated temperatures and ensure contimued contaimment. Desigmer, tester, and evaluator to do and shipper responsibility to ensure.

Typically, one uses actual experience as a guide. If experience is not available, one normally uses a comparison to a similar packaging with an experience profile. If this isn't possible, vibration testing can be performed. The purpose of this section is to prevent the loosening of muts, bolts, and contairment devices under conditions incident to routine transportation. Designer, tester, and evaluator to do and shipper responsibility to ensure.
PACKAGING CATEGORY IIQUIDS AND GASES

The materials (wood, caulking, metal strips, nails, gaskets, etc.) would not become excessively brittle at $-40^{\circ} \mathrm{C}$. Temperatures of $+70^{\circ} \mathrm{C}$ would not result in any significant decrease in integrity either, as shown in property of materials tables. The shipper must ensure that, if the contents freeze, no rupture of the container will oocur. In addition, the shipper must evaluate the potential for pressure buildup at elevated temperatures.

Experience has consistently demonstrated that these packagings or similar designs comply with this requirement. The shipper must ensure the application of quality assurance necessary to achieve this requirement. 


\section{GUIDANCE FOR APPLICATION}

(f) It includes a contairment system securely closed by a positive fastening device that cannot be opened unintentionally or by pressure that may arise within the package during normal transport. Special form, as demonstrated in accordance with 173.469 , may be considered as a component of the contairment system;

(g) The materials of the packaging and any components or structures are physically and chemically compatible with each other and with the contents, taking into account the behavior of each under irradiation;

(h) For each component of the contaimment system, account is taken where applicable of radiolytic decomposition of materials and the generation of gas by chemical reaction and radiolysis;

(i) The contaimment system will retain its radioactive contents under the reduction of ambient pressure to 0.25 kilograms per square centimeter $(3.5 \mathrm{lb} /$ in. ${ }^{2}$ ); to ensure.
"Screw-type" closures can qualify.

"Friction fit" normally does not qualify. Security clips on cans could be acceptable. However, one cannot depend on friction alone. Designer, tester, and evaluator to do and shipper responsibility to ensure.

Designer to do and shipper responsibility to ensure.

Designer to do and shipper responsibility

The contaiment system is defined as the components intended to retain the radioactive contents curing transportation. Thus, one starts by identifying the contairment system. The radioative contents must be completely retained in the containment system if the package is subjected to reduced pressure. A filtered packaging is possible as long as it can be demonstrated that the filtered package will retain the contents and that the filter is not susceptible to damage from any other tests. Caution should be exercised to

\section{PACKAGING CATEGORY}

IIQUIDS AND GASES

All packagings evaluated meet this requirement, as shown on the sketches or in the packaging descriptions.

Shipper responsibility to ensure.

Shipper responsibility to ensure.

This analysis requires a more detailed discussion to provide adequate informatiohn. see Table C-5. 
TABIE C-5

Packaging/ Principal User

IOVETACE Model/Size

MS-24347-7

Fiberboard box with inmer lead container

$3 A-1800$

$3 E-1800$
Contairment System

Glass bottle with screw cap

Inmer lead container with screw-top cap and o-ring seal

Steel drumGas cylinders
Test/Analysis

Results

Two of these glass bottles with caps screwed on by hand were inverted in a beaker of water, and a vacuum was drawn (3.6 psi). After $5 \mathrm{~min}$ there was no evidence of leakage (bubbles in the water).

Also, the metal drum itself passed the reduced pressure test, so the tests on the bottles would not have been required.

The inner lead container was inverted in a beaker of water, and a vacunm was drawn (3.6 psi). After $5 \mathrm{~min}$, there was no evidence of leakage (bubbles in the water).

Each of the cylinders was pressurized before being sent to Mound. The pressure was measured in each one upon receipt and averaged approximately 92 psig per cylinder. These data and the fact that the service pressure is 1800 psig demonstrated compliance with the 11.2 psi requirements.
Pass

Pass

Pass 
TABLE C-5 (continued)

Packaging/

Principal User

ORNL

Model/Size

Fiberboard box for liquids and solids

Fiberboard box for gases

Fiberboard box for liquids and solids with shielding

ORNL

Aluminum clad wood box (returnable)
Containment System

Glass bottles with plastic screw-top caps:

$$
\begin{array}{r}
15 \mathrm{~mL}-6 \text { tested } \\
25 \mathrm{~mL}-6 \text { tested } \\
50 \mathrm{~mL}-5 \text { tested } \\
100 \mathrm{~mL}-4 \text { tested }
\end{array}
$$

\section{Glass ampules:}

$$
\begin{array}{r}
2 \propto-4 \text { tested } \\
5 \propto-4 \text { tested } \\
10 \propto-4 \text { tested } \\
20 \propto-4 \text { tested }
\end{array}
$$

Glass bottles with plastic screw-top caps:

see above

Glass bottles with plastic screw-top caps:

see above
Test/Analysis

Results

Four to six bottles of each size were inverted in a glass beaker of water in a bell jar. The pressure was reduced (vacuum drawn) to $3.6 \mathrm{psig}$ and held for $5 \mathrm{~min}$. There was no leakage (bubbles in the water) in any case.

Four ampules of each size were immersed in water in a glass beaker in a bell jar. The pressure was reduced (vacuum drawn) to 3.6 psig and held for $5 \mathrm{~min}$. There was no leakage (bubbles in the water) in any case.

Four to six bottles of each size were inverted in a glass beaker of water in a bell jar. The pressure was reduced (vacuum drawn) to $3.6 \mathrm{psig}$ and held for $5 \mathrm{~min}$. There was no leakage (bubbles in the water) in any case.

Four to six bottles of each size were inverted in a glass beaker of water in a bell jar. The pressure was reduced (vacurm drawn) to $3.6 \mathrm{psig}$ and held for $5 \mathrm{~min}$. There was no leakage (bubbles in the water) in any case.
Pass

Pass

Pass

Pass 
TABLE C-5 (contimued)

Packaging/ Principal User

ORNL
Model/Size

Gas cylinders in returnable plastic boxes
Containment system

Gas cylinders as listed on pages $F-31,32$, and 36
Test/Analysis

Each of these cylinders is designed for and tested at pressures well above 11.2 psi.
Results

Pass 
(j) Each valve through which the radioactive contents could otherwise escape is protected against damage and unauthorized operation and, except for a pressure relief device, has an enclosure to retain any leakage;

\section{GUIDANCE FOR APPTICATTON}

ensure that the contents and internal

packaging components (i.e., plastic boxes, etc.) will not effectively seal the filter during normal use. In cases where a pressure differential will not build up because of the free-flow through a filter, the requirement of demonstrating the retention of contents must still be met. For a package that breathes (does not hold 11.2 psi), such as a wooden box, one must demonstrate that, even with breathing, the contents will be retained. Otherwise, a separate inner contaiment capable of meeting the reduced pressure requirement is required. Desigmer, tester, and evaluator to do and shipper responsibility to ensure.

PACKAGING CATESORY

Designer to do and shipper responsibility to ensure.
Two packagings in this category have valves as described below:

(1) IINL Gas Cylinders These cylinders are packaged in a $17 \mathrm{H}$ 30-gal steel drum, which provides the physical protection and protects against unauthorized operation. The $17 \mathrm{H}$ 30-gal drum also provides an enclosure to retain any leakage. More positively, each valve outlet is capped to retain any leakage.

(2) ORNL Gas Cylinders Each cylinder has a threaded protective cap and is sealed against unauthorized operation. The threaded caps also retain any leakage. 


\section{GUIDANCE FOR APPLICATION}

(k) Any radiation shield that encloses a component of the packaging specified as part of the containment system will prevent the unintentional escape of that component from the shield;
The shield shall be securely closed or, by way of packaging design, ensure against escape of a contaimment component. One example is a package with cellotex on top of a lead shield with a press-fit lid in which closure of the cellotex holds the lid in place. The shipper must make sure that under the tests prescribed in 173.465 there will be no rearrangement of the original containment/shield orientation. Designer, tester, evaluator to do and shipper responsibility to ensure.
The packagings meeting this critrion are discussed below.

only a few packages have a design fitting this criterion. These are:

\section{Packaging}

IASI fiberboard box with inner lead shielded containers

ORNL fiberboard boxes with shielded inner containers

ORNL alumimm clad wood box

\section{Contaiment System}

Inner lead container (2-in. o.d.) with screw-cap and o-ring seal.

Glass ampule or bottle with screw cap and a sealed metal can.

Glass bottle and the $2 \mathrm{R}$ containers.

\section{Analysis}

As shown in the sketch on p. F-6, the inner container is held in place by a lid with three bolts. Thus, the outer shield is securrely closed. There was no rearrangement cluring the tests specified in 173.465.

As shown on pp. F-20 and 21, the packaging components are firmly held in place by the sealed metal can.

As shown on p. F-26, the 2R container is held in place by the bolt closure lid of the stainless steel-clad lead carrier.
Results

Pass

Pass

Pass 
Packaging

ORNL gas cylinder

(1) Failure of any tie-down attachment on the packaging under excessive load will not impair the ability of the package to meet other requirements of this subpart.
The cylinder itself.

\section{Analysis}

Results

As shown on pp. F-31, 32, and 36, the lead shielding, when used, fills the void between the inner and outer wall and prevents escape.

Pass
Designer, tester, evaluator to do and shipper responsibility to ensure.
None of these packagings have tie-down attachments as described. 


\subsection{2 - ADDITIONAL DESIGN REOUIREMENIS FOR TYPE A PACKAGES}

In addition to meeting the general design requirements prescribed in 173.411 , each Type A packaging shall be designed so that:

\section{GUIDANCE FOR APPLICATION}

(a) The smallest overall external dimension of the package is not less than 10 centimeters (4 in.):

(b) The outside of the packaging incorporates a feature, such as a seal, that is not readily breakable, and that, while intact, is evidence that the package has not been opened. In the case of packages shipped in exclusive use closed transport vehicles, the cargo compartment may be sealed instead of the individual packages;

(c) As far as practicable, the external surfaces are free from protrusions and are designed so that they can be easily decontaminated;
Designer to do and shipper responsibility to ensure.

For this requirement, the package designer may need to be skilled and creative. This is especially true for packages such as fiberboard cartons and wooden boxes. A padlock is not effective as a security seal. It is not possible with most types of padlocks to ascertain if they have been illicitly opened. One acceptable approach towand meeting this requirement is serially mubered lead-wire seals, or, in the case of fiberboard packages, a tape of sufficient adhesive strength to damage the fiberboard upon removal. Desigmer to do and shipper responsibility to ensure.

The intent is to minimize the number and nature of protrusions by consideration curing design and/or as a result of any modifications to the packaging. Designer to do and shipper responsibility to ensure.

\section{PACKAGTNG CATTEGORY MISCETIANEOUS}

As shown on the sketches and as given in the packaging description in MIM-3245, all packagings meet this requirement.

There are acceptable approaches to compliance for all evaluated packagings. It is the shipper's responsibility to ensure compliance with this requirement.

All evaluated packagings meet this requirement. 


\section{GUIDANCE FOR APPLICATION}

(d) Contairment and shielding would be maintained during transportation and storage in a temperature range of $-40^{\circ} \mathrm{C}\left(-40^{\circ} \mathrm{F}\right)$ to $+70^{\circ} \mathrm{C}\left(+158^{\circ} \mathrm{F}\right)$ with account taken of the possibilities of brittle fracture;

(e) It is able to withstand the effects of any acceleration, vibration, or vibration resonance that may arise during normal transportation, without any deterioration of the effectiveness of closing devices or of the integrity of the package as a whole and without loosening or unintentional release of nuts, bolts, or other securing devices even after repeated use;
This does not mean any of the tests must necessarily be performed at the temperature extremes. [Note: $173.461(\mathrm{~b})$.$] The regula-$ tions allow the assumption that the packaging is in equilibrium at $38^{\circ} \mathrm{C}$ prior to testing. one must evaluate the packaging components with respect to behavior at the temperature extremes under conditions incidental to transportation (i.e., the jiggles, bounces, and bumps normally encountered in transportation). Gaskets and packaging cormponents need to be evaluated to determine if they will become excessively brittle at $-40^{\circ} \mathrm{F}$. This may be accomplished by actual testing, referring to property of material tables, obtaining data from manufacturers, etc. The shipper must consider such things as freezing of liquid contents and evaluate the effect to ensure contimued contairment integrity. The shipper must also consider the buildup of pressure at elevated temperatures and ensure continued contaimment. Designer, tester, and evaluator to do and shipper responsibility to ensure.

Typically, one uses actual experience as a guide. If experience is not available, one normally uses a comparison to a similar packaging with an experience profile. If this isn't possible, vibration testing can be performed. The purpose of this section is to prevent the loosening of nuts, bolts, and contaimment devices under conditions incident to routine transportation. Designer, tester, and evaluator to do and shipper responsibility to ensure.

\section{PACKAGTNG CATEGORY} MISCELIANEOUS

The materials (wood, caulking, metal straps, nails, gaskets, etc.) would not become excessively brittle at $-40^{\circ} \mathrm{C}$. Temperatures at $+70^{\circ} \mathrm{C}$ would not result in any significant decrease in containment integrity, as shown in property of material tables.

Experience has consistently demonstrated that these packagings or similar designs comply with this requirement. The shipper must ensure the application of quality assurance necessary to achieve this requirement. 


\section{GUIDANCE FOR APPLICATION}

(f) It includes a contaimment system securrely closed by a positive fastening device that cannot be opened unintentionally or by pressure that may arise within the package during normal transport. Special form, as demonstrated in accordance with 173.469, may be considered as a component of the contairment system;

(g) The materials of the packaging and any components or structures are physically and chemically cormpatible with each other and with the contents, taking into account the behavior of each under irradiation;

(h) For each component of the contairment system, account is taken where applicable of radiolytic decomposition of materials and the generation of gas by chemical reaction and radiolysis;

(i) The contairment system will retain its radioactive contents under the reduction of ambient pressure to 0.25 kilograms per square centimeter $(3.5 \mathrm{lb} /$ in. ${ }^{2}$ ) :
"Screw-type" closures can qualify. "Friction fit" normally does not qualify. security clips on cans could be acceptable. However, one cannot depend on friction alone. Designer, tester, and evaluator to do and shipper responsibility to ensure.

Designer to do and shipper responsibility to ensure.

Designer to do and shipper responsibility to ensure.

The contairment system is defined as the components intended to retain the radioactive contents during transportation. Thus, one starts by identifying the containment system. The radioative contents must be completely retained in the contaimment system if the package is subjected to reduced pressure. A filtered packaging is possible as long as it can be demonstrated that the

\section{PACKAGING CATEGORY}

MISCELIANEOUS

All packagings evaluated meet this requirement, as shown on the sketches or in the packaging descriptions.

Shipper responsibility to ensure.

Shipper responsibility to ensure.

See Table C-6. 
TABLE C-6

REIDUCED PRESSURE TESTS

Packaging/

Principal User

IINL

Model/Size

Spec 55

ORNL

ORNL-TRU

FEMA

FEMA

Source Overpack

IINL

\section{Contaiment System}

There is only one packaging component, so this abviously is the containment system.

Since the contents are restricted to special Form [49CFR 173.403(z)], this provides the containment system.

Since the contents are restricted to special Form [49CFR 173.403(z)], this provides the contairment system.

Modified DOT 5C-304

SNL Tritium Waste Package 15-gal stainless steel drum.
Test/Analysis

The cavity of this packaging was filled with a water-fluorescein solution. The package was inverted in a bell jar and subjected to a reduced pressure of $3.6 \mathrm{psi}$ for $5 \mathrm{~min}$. Upon cormpletion of the test there was visible no loss of contents, and no loss was found with a black light.

This test has little meaning since there is no loose contamination available for dispersion or transfer. This test was not conducted, but obviously would meet the criterion, if tested, of "No Loss of contents."

This test has little meaning since there is no loose contamination available for dispersion or transfer. This test was not conducted, but obviously would meet the criterion, if tested, of "No Ioss of contents."

The inner container was subjected to a hydrostatic pressure of 80 psi for $5 \mathrm{~min}$ with no leakage.
Results

Pass

Pass

Pass

Pass 
(j) Each valve through which the radicactive contents could otherwise escape is protected against damage and unauthorized operation and, except for a pressure relief device, has an enclosure to retain any leakage; filtered package will retain the contents and that the filter is not susceptible to damage from any other tests. Caution should be exercised to ensure that the contents and internal packaging components (i.e., plastic boxes, etc.) will not effectively seal the filter during normal use. In cases where a pressure differential will not build up because of the free-flow through a filter, the requirement of demonstrating the retention of contents must still be met. For a package that breathes (does not hold 11.2 psi), such as a wooden box, one must demonstrate that, even with breathing, the contents will be retained.

Otherwise, a separate inner contairment capable of meeting the reduced pressure requirement is required. Desigmer, tester, and evaluator to do and shipper responsibility to ensure.

Designer to do and shipper responsibility to ensure.
The only packaging meeting this criterion is the SNL Tritium Waste Package. The 17H 30-gal drum provides the physical protection against unauthorized operation. The asphalt which surrounds the entire inner packaging and the $17 \mathrm{H}$ steel drum will retain any contents. 


\section{GUIDANCE FOR APPLICATION}

(k) Any radiation shield that encloses a component of the packaging specified as part of the contaimment system will prevent the unintentional escape of that component from the shield;

(1) Failure of any tie-down attachment on the packaging under excessive load will not impair the ability of the package to meet other requirements of this subpart.
The shield shall be securely closed or, by way of packaging design, ensure against escape of a contaiment component. One example is a package with cellotex on top of a lead shield with a press-fit lid in which closure of the cellotex holds the lid in

place. The shipper must make sure that under the tests prescribed in 173.465 there will be no rearrangement of the original containment/shield orientation. Designer, tester, evaluator to do and shipper responsibility to ensure.

Desiomer, tester, evaluator to do and shipper responsibility to ensure.

\section{PACKAGING CATEGORY \\ MISCETIANEOUS}

The only packaging meeting this criterion is the LINL (Spec. 55) container. The packaging/shield is one piece, so it is obviously the containment system also. since the containment system and the radiation shield are all the same, they cannot escape/ separate.

None of these packagings have tie-down attachments as described. 
SUMMARY OF TYPE A PACKAGING TESTS

(49 CFR 173.465)

The purpose of this section is to provide more details concerning the Type A packaging tests that were conducted or against which the packages were analyzed for compliance. The tests involved are:
1. Water Spray
2. Free Drop
3. Compression
4. Penetration

These tests, test methods, and determination of pass/fail criteria are discussed at length in the MLM-3245 Introduction.

173.465 (a) The proposed packaging with proposed contents must be capable of withstanding the tests prescribed in this section. One prototype may be used for all tests if the requirements of Paragraph (b) of this section are complied with. 
WATER SPRAY TEST

(b) Water Spray Test.

The water spray test must precede each test or test sequence prescribed in this section. The water spray test shall simulate exposure to rainfall of approximately 5 centimeters ( 2 in.) per hour for at least one hour. The time interval between the end of the water spray test and the beginning of the next test shall be such that the water has soaked in to the maximm extent without appreciable drying of the exterior of the specimen. In the absence of evidence to the contrary, this interval may be assumed to be two hours if the water spray is applied from four different directions simultaneously. However, no time interval may elapse if the water spray is applied from each of the four directions consecutively.
Major Points.

(I) Must precede each test

(2) 2 in. $/ \mathrm{hr}$

(3) 1-hr duration

Comments:

This is usually a conditioning of a package, rather than a test as such. One would not expect a loss of contents or significant increase in dose rate resulting from just the water spray test. However, consideration must be given to the possibility of water leakage into the package with subsequent transport of radioactive contents out as leakage.

Designer, tester, evaluator to do and shipper responsibility to ensure. 
WATER SPRAY TEST

\section{PACKAGING CATEGORY: STEEU DRUMS}

In evaluating steel drums against this requirement, one would consider such things as:

(1) The effect the water spray would have on the ability of the steel drums to meet the other Spec 7A performance requirements;

(2) The potential for inleakage of water with the subsequent potential for transport of the radioactive contents out of the packagings;

(3) Because these same packagings are air-leak tight, one would also expect them to prevent the inleakage of water under such passive conditions as a water spray (rain).

As shown in Table D-1, nine different types of steel drums (a total of 26 different packagings) were subjected to this test. In all cases, as one would expect based on materials and methods of construction, closure mechanisms, gaskets, and the painted surfaces, the water spray had no effect that could possibly be interpreted as decreasing the ability of the steel drums to meet all Spec 7A performance criteria. This is not surprising since there are years of experience demonstrating that lengthy exposures to rain have not had a negative effect on contaiment integrity. In addition, in each of the 26 individual tests, a careful inspection demonstrated there was no inleakage of water as a result of these tests. Because these same packagings are air-leak tight, one would also expect them to prevent the inleakage of water under such passive conditions as a water spray (rain).

As a final point of mainly academic discussion, since the steel drums are air-leak tight to begin with, in the unlikely event of an inleakage of water, it would be equally unlikely that this expected minute quantity of water would leak out. Thus, based on the test data below and after comparison of the similarity in materials and methods of construction of the untested steel drums, one can readily conclude that these steel drums meet this requirement. 
TABLE D-1

Specific

Packaging

Spec 6C 5-gal

Spec 6C 10-gal

Spec 17C 5-gal

Spec $17 \mathrm{C}$ 30-gal

Spec 17C 55-gal

Spec 17C 55-gal

with pressure relief device Spec 17C 55-gal w/HDPE liner

Spec 17H 30-gal Spec $17 \mathrm{H}$ 55-gal

MS-24347-1

MS-24347-7

MS-27684-1

MS-27684-2

MS-27684-3

MS-27684-6

MS-27684-8

MS-27683-7

MS-27683-13

MS-24683-21

\section{Test/Analysis Results}

By comparison, this drum would meet this requirement. By comparison, this drum would meet this requirement. By comparison, this drum would meet this requirement. By comparison, this drum would meet this requirement. Three drums were subjected to this test and passed. Three lids with the "Nuc-Fil" filters were subjected to the water spray test and no water passed through the filter.

The same data shown for the 17C 55-gal drum would apply here.

Three drums were subjected to this test and passed. Three drums were subjected to this test and passed.

By comparison, this drum would meet this requirement. Two drums were subjected: to this test and passed.

By comparison, this drum would meet this requirement. By comparison, this drum would meet this requirement. Three drums were subjected to this test and passed. By comparison, this drum would meet this requirement. Three drums were subjected to this test and passed. Three drums were subjected to this test and passed.

By comparison, this drum would meet this requirement. Three drums were subjected to this test and passed. 


\section{PACKAGING CATEGORY: STEEL BOXES}

In evaluating steel boxes against this requirement, one would consider such things as:

(1) The effect the water spray would have on the ability of the steel boxes to meet the other Spec 7A performance requirements;

(2) The potential for inleakage of water with the subsequent potential for transport of the radioactive contents out of the packagings;

(3) Because these same packagings are air-leak tight, one would also expect them to prevent the inleakage of water under such passive conditions as a water spray (rain).

In all cases but one (the ANL-West 7A 960 steel box), as one would expect based on materials and methods of construction, closure mechanisms, gaskets, and painted surfaces, the water spray would have no effect that could be interpreted as decreasing the ability of the steel boxes to meet all Spec 7A performance criteria. This is not surprising since there are years of experience demonstrating that lengthy exposures to rain have not had a negative effect on contaiment integrity. Because these same packagings are air-leak tight, one would also expect them to prevent the inleakage of water under such passive conditions as a water spray (rain).

As a final point of mainly academic discussion, since the steel boxes are air-leak tight to begin with, in the unlikely event of an inleakage of water, it would be equally unlikely that this expected minute quantity of water would leak out. Thus, based on the information below and after comparison of the similarity in materials and methods of construction of the steel boxes, one can readily conclude that all the steel boxes meet this requirement (with the exception of the ANL-West 7A-960 discussed in Table D-2). 
WATER SPRAY TEST RESUITSS FOR STEET BOXES

\section{TABLE D-2}

Specific

packaging

All

- Capital Industries

- Container Products corp.

- RoGar Chemical and Nuclear Services

- Rocky Flat SAND Boxes

- Argonne M-4 Steel Bin

ANL-West

$7 \mathrm{~A}-960$

\section{Test/Analysis Results}

All these boxes pass by analysis of materials, methods of construction, years of experience (exposure to a variety of weather conditions, including heavy rains), and airleak or water-leak tests which have demonstrated the boxes to be leak tight. The tests referenced are the reduced pressure tests, Page c-14, of this document. The filters (for filtered boxes) have been tested and demonstrated to be water-leak resistant also.

Since this package does not have a gasket, one has to assume there could be an inleakage of water, however slight. To protect against this possible exposure to water, the contents must be enclosed in plastic or equally water resistant materials, or the shipper must ensure that, if the contents were exposed to such water, there would be no transfer of radioactive materials to the liquid. See Restriction/ Specification section on Page B-28. A preferred method (since the introduction of any water into a radioactive material shipping container is highly undesirable) is to use a gasket.

Thus, all of the steel boxes except the ANL-West 7A-960 meet this requirement without any restrictions or specifications, and the ANL-West 7A-960 meets this requirement when used as prescribed on Page B-28. 
WATER SPRAY TEST

\section{PACKAGING CATEGORY: WOODEN BOXES}

In evaluating wooden boxes against this requirement, one would consider such things as:

(1) The effect the water spray would have on the ability of the wooden boxes to meet the other Spec 7A performance requirements;

(2) The potential for inleakage of water with the subsequent potential for transport of radioactive contents out of the packagings.

As shown in Table D-3, 14 different types of wooden boxes (a total of 24 different packagings) were subjected to this test. In all cases, as one would expect based on materials and methods of construction, closure mechanisms, and caulking/glue, the water spray had no effect that could be interpreted as decreasing the ability of the wooden boxes to meet the remaining Spec 7A performance criteria. This is not surprising since there are years of experience demonstrating that exposure to rain has not had a significant effect on contairment integrity.

With respect to Item 2 above, the potential for inleakage of water, some boxes constructed of normal exterior grade plywood did allow small amounts of water to penetrate. For test purposes, the insides of the test boxes were lined with paper, and the box was subjected to the water spray test for $1 \mathrm{hr}$ and allowed to sit for $2 \mathrm{hr}$. At the end of this period, the paper was inspected for spots which would indicate the presence of water. 


\section{WATER SPRAY TEST RESUITS FOR ANL AND LINL WOODEN BOXES}

TABLE D-3

Specific Packaging

ANI-West Family of Boxes

LINL Flush

Panel Box
Test/Analysis Results

By comparison these boxes would meet this requirement.

By comparison these boxes would meet this requirement. 
WATER SPRAY TEST RESUIISS FOR MOUND WOODEN BOXES

TABLE D-4

\begin{tabular}{|c|c|c|c|}
\hline $\begin{array}{l}\text { Configuration } \\
\text { (Dimensions in Inches) }\end{array}$ & $\begin{array}{l}\text { 1st Test } \\
\text { As Built }\end{array}$ & $\begin{array}{c}\text { 2nd Test } \\
\text { RIV Used to } \\
\text { Seal Seams on Inside }\end{array}$ & $\begin{array}{c}\text { 3rd Test } \\
\text { Water Sealant } \\
\text { Applied to Boxes }\end{array}$ \\
\hline $\begin{array}{l}\text { Mound Configuration A } \\
\qquad 8 \times 8 \times 36\end{array}$ & $\begin{array}{l}\text { Pass - No indication } \\
\text { of water }\end{array}$ & Fail $^{b}$ & Pass \\
\hline $\begin{array}{l}\text { Mound configuration B } \\
12 \times 12 \times 36\end{array}$ & $\begin{array}{l}\text { Pass - No indication } \\
\text { of water }\end{array}$ & Pass & Pass \\
\hline $\begin{array}{l}\text { Mound Configuration C } \\
12 \times 12 \times 36\end{array}$ & $\begin{array}{l}\text { Fail - Water absorbed } \\
\text { on paper }\end{array}$ & Fail & Pass \\
\hline $\begin{array}{l}\text { Mound Configuration D } \\
12 \times 151 / 2 \times 48\end{array}$ & $\begin{array}{l}\text { Fail - Water absorbed } \\
\text { on paper }\end{array}$ & Fail & Pass \\
\hline $\begin{array}{l}\text { Mound Configuration E } \\
21 \times 21 \times 221 / 2\end{array}$ & $\begin{array}{l}\text { Fail - Water absorbed } \\
\text { on paper }\end{array}$ & Fail & Pass \\
\hline
\end{tabular}


WATER SPRAY TEST RESULTS FOR WOODEN BOXES

TABLE D-5

Specific

Packaging

NLO Family of

Boxes

$\underline{y-12}$ B Series

B-1 through

B-8

\section{$\mathrm{Y}-12$ Picture}

Frame Boxes

$\mathrm{PF}-1$ through

$\mathrm{PF}-8$

Rocky Flats - RA

Series of Boxes

\section{Test/Analysis Results}

By comparison these boxes would meet this requirement.

Each of these packagings was subjected to the water spray for $1 \mathrm{hr}$, allowed to sit for $2 \mathrm{hr}$, and then subjected to the drop test. There was no evidence of a decrease in contaimment integrity as a result of this test. considering the materials and methods of construction, all of the other wooden boxes would also meet this requirement.

By comparison these boxes would meet this requirement.

By comparison these boxes would meet this requirement. 
As shown in Table D-4, small amounts of water did appear at times on the paper, indicating an inleakage of water. The majority of the inleakage cocurred at the cormers and at some points in the seams; however, a few spots occurred that indicated inleakage through the walls themselves. Three possible approaches are described that are acceptable with respect to addressing this inleakage and ensuring that there is no transport of radioactive materials out of the packaging.

(1) Securely enclose the radicactive contents within the box so that any inleaking water cannot come in contact with the radioactive material.

(2) Seal the box using GFOCEI or its equivalent. If the box is reused, it must be recoated with at least one coat to cover the seal areas before each shipment.

(3) Assure that there is no loose or removable contamination which could be entrained in any liquid and that the radioactive material is not soluble in the liquid. Thus, even if the liquids come in contact with the radioactive material, there could be no transport from the package.

NOTE: These three approaches are presented in the Restrictions/Specifications section for each of the evaluated packagings in MIM-3245. There are obviously other possible approaches; however, if an alternative approach is chosen, the basis for the choice must be supported and documented. The use of one of these alternatives or an equivalent allows these wooden boxes to meet this requirement. 


\section{WATER SPRAY TEST RESUITS FOR FIBERBOARD CONTATNERS}

\section{TABLE D-6}

Specific

Packaging

Fiberboand Boxes 12B-65

(p. $D-2)^{a}$

Fiberboand Box

LINL (p. D-6)

Fiberboard Box

Tri-Wall (p. D-11)

Fiberboard Drums

\section{Test/Analysis Results}

Each of these packagings was subjected to this test prior to each of the three tests: free drop, compression, and penetration. As a result of the water spray, the addition of triple-wall support was required in many of the containers so that these packagings could withstand the compression test. This test also demonstrated the need for water-resistant tape as required in the Restrictions/Specifications section. As one would expect, the boxes were softened considerably; however, this didn't seem to make make mach difference in the drop or penetration tests.

Since one has to assume an inleakage of water, each shipper must address this potential inleakage of water and ensure there is no transport of radioactive materials out of the packaging by the following methods or their equivalent.

$a_{\text {Page numbers refer to MIM-3245. }}$

Two possible approaches are described that are acceptable with respect to addressing this potential inleakage and ensuring that there is no transport of radioactive materials out of the packaging.

(1) Securely enclose the radioactive contents within the box so that any inleaking water cannot come in contact with the radioactive material.

(2) Ensure that there is no loose or removable contamination which could be entrained in any liquid and that the radioactive material is not soluble in the liquid. Thus, even if the liquids come in contact with the radioactive material, there could be no transport from the package.

NOTE: These two approaches are presented in the Restrictions/Specifications section for each of the evaluated packagings. There are obviously other possible approaches; however, if an alternative approach is chosen, the basis for the choice must be supported and documented. The use of one of these altermatives or an equivalent method allows these fiberboard packagings to meet this requirement. 
WATER SPRAY TEST RESUITS FOR UF-6 CYLTNDERS

TABLE D-7

\section{Specific}

packaging

Models 1S, 2S, 5A, $8 \mathrm{~A}, 12 \mathrm{~A}, 12 \mathrm{~B}, 30 \mathrm{~A}, 30 \mathrm{~B}$, $48 \mathrm{G}, 48 \mathrm{H}, 48 \mathrm{HX}, 48 \mathrm{X}, 48 \mathrm{Y}$

\section{Test/Analysis Results}

The factors to be considered in evaluating compliance as mentioned previously were:

(1) The effect the water spray would have on the ability of the UF-6 cylinders to meet the other Spec 7A performance requirements;

(2) The potential for inleakage of water with the subsequent potential for transport of the radioactive contents out of the packagings.

The materials and method of construction make it obvious that a water spray (rain) would not have any significant effect on the structural integrity. This is well-substantiated by years of shipping thousands of these packagings through a wide variety of weather conditions. With respect to the second aspect, inleakage of water, since these cylinders have welded seams and threaded valves which are gas-leak tight, the inleakage of water is not credible. Thus, these packagings meet this requirement. 
WATER SPRAY TEST RESUIIS FOR IIQUIDS AND GASES

TABLE D-8

Specific

Packaging

Steel Drum

MS 24347-7

(p. $\mathrm{F}-1)^{\mathrm{a}}$

LASL-12B-62

Fiberboard Box

(p. F-6)

LINL

Steel Drums

with Gas cylinders

ORNL

Liquids and Solids (p. F-15)

Disposable container with Shielding

(pp. F-20 and 21)

- Liquids, Solids, or Gases

$a_{\text {Page numbers refer to }} \mathrm{MM}-3245$.

\section{Test/Analysis Results}

This test was not conducted on this packaging since the outer packaging component is a steel drum, and compliance is demonstrated as described on Page D-3.

The test was conducted prior to each of the three tests: 30-ft drop, compression, and penetration. Since the packaging successfully passed these three tests, this demonstrates the lack of significant effect with respect to structural aspects. Also, since the 2-in. inner container is air-leak tight, there is no potential for inleakage of water. Thus, this packaging meets this requirement.

The compliance of the outer packaging, Spec 17H 30-gal steel drum, has already been demonstrated as described on Page D-3.

The water spray was performed prior to each test, and the packaging successfully met all requirements. Since there is a sealed metal inner container, there is no potential for further inleakage of water.

The water spray was performed prior to each test, and the packaging successfully met all requirements. Since there is a sealed metal inner container, there is no potential for further inleakage of water. 
TABLE D-8 (continued)

Specific

packaging

\section{Wooden Box}

Returnable, Shielded

(p. F-26)

\section{Gas Cylinder}

Returnable - Hoke

(p. F-30)

\section{Gas Cylinder}

Returnable

J. I. Shephard

(p. F-36)

\section{Test/Analysis Results}

The water spray was performed prior to each test, and the packaging successfully met all requirements. The sealed inner metal containers preclude any potential for futher inleakage.

The water spray was performed prior to each test, and the packaging successfully met all requirements. The plastic box used as an overpack typically precludes any significant effect due to the water spray. Then, considering that the inner cylinders are gas-leak tight, there is no potential for further inleakage of water.

Considering the materials and method of construction and the fact that these cylinders are gas-leak tight, there is no potential for inleakage of water. 
WATER SPRAY TEST RESUITSS FOR MISCELIANEOUS PACKAGINGS

TABLE D-9

Specific

Packaging

LINL

Spec 55 (p. G-1)

ORNL

TRU Shipping Container

FEMA

Source Overpack

SNL

Tritium waste Package

\section{Test/Analysis Results}

This test was not conducted since, considering the materials and methods of of construction, it is obvious that this test would not adversely affect the ability of the package to meet the additional Spec $7 \mathrm{~A}$ requirements. In addition, since the package was demonstrated to be water-leak tight even after the 4-ft drop, there is no potential for inleakage of water.

This test was not conducted since, considering the materials and methods of of construction, it is obvious that this test would not adversely affect the ability of the package to meet the additional Spec 7A requirements. In addition, since the inner (source) containment has to meet the special Form [173.412(z)] criteria, the inleakage of water would not result in a potential transport of radioactive material from the package.

This test was not conducted since, considering the materials and methods of of construction, it is obvious that this test would not adversely affect the ability of the package to meet the additional Spec $7 \mathrm{~A}$ requirements. In addition, since the inner (source) containment has to meet the special form [173.412(z)] criteria, the inleakage of water would not result in a potential transport of radioactive material from the package.

The compliance of the outer packaging, Spec $17 \mathrm{H} 30$-gal steel drums, has already been demonstrated and discussed on Page D-3. 
(c) Free Drop Test.

The free-drop test consists of a fall onto the target in a manner that causes maximum damage to the safety features being tested; and

(1) For packages weighing 5,000 kilograms $(11,000 \mathrm{lb})$ or less, the distance of the fall measured from the lowest point of the packaging to the upper surface of the target shall not be less than 1.2 meters ( $4 \mathrm{ft}$ ).

(2) For packages weighing more than 5,000 kilograms $(11,0001 \mathrm{~b})$, the distance of the fall shall not be less than the distance specified in Table II, for the applicable packaging weight.
FREE DROP TEST

Major points.

(1) 4-ft drop

(2) Manner to cause maximm damage

\section{Comments}

(1) The orientation causing maximum damage may not be readily apparent. Typically, the following guidelines should be considered:

(a) Drums - side drop with bolt closure ring (BCR) at impact point;

- angle drop (approx. $45^{\circ}$ on BCR and on bottom at intersection of chime and side seam) :

(b) Boxes - Top (lid) corner near features, such as lifting rings and filters, if any exist;

(c) Approximate center of gravity over impact point.

(2) A quick release device is required to ensure no change in package orientation.

\section{Straightforwand}


comments

TABLE II - FREE FAIL DISTANCE FOR PACKAGING WETGHING MORE THAN 5,000 KG

\begin{tabular}{|c|c|c|c|}
\hline \multicolumn{2}{|c|}{ Packaqing Weight } & \multicolumn{2}{|c|}{$\begin{array}{l}\text { Free-Fall } \\
\text { Distance }\end{array}$} \\
\hline$(\mathrm{kg})$ & (1b) & (ft) & (m) \\
\hline $\begin{array}{l}>5,000-10,000 \\
>10,000-15,000 \\
>15,000\end{array}$ & $\begin{array}{l}>11,000-22,000 \\
>22,000-33,000 \\
>33,000\end{array}$ & $\begin{array}{l}3 \\
2 \\
1\end{array}$ & $\begin{array}{l}0.9 \\
0.6 \\
0.3\end{array}$ \\
\hline
\end{tabular}

(3) For Fissile Class II packagings, the free drop specified in subparagraph (1) or (2) of this paragraph shall be preceded by a free drop from a height of 0.3 meter (1 ft) on each corner. For cylindrical packagings, the 0.3-meter (1-ft) drop shall be onto each of the quarters of each rim.

(4) For fiberboand or wood rectangular packages not exceeding 50 kilograms (110 1b) in weight, a separate specimen of the proposed packaging shall be subjected to a free drop onto each corner from a height of 0.3 meters ( $1 \mathrm{ft}$ ).

(5) For fiberboard cylindrical packages weighing not more than 100 kilograms (220 1b), a separate specimen of the proposed packaging shall be subjected to a free drop onto each of the quarters of each rim from a height of 0.3 meters ( $1 \mathrm{ft}$ ).
Desigmer, tester, and evaluator to do and shipper responsibility to ensure.

For packagings to be used for Fissile class II shipments, further testing and evaluation per Paragraph 3 are required.

Designer, tester, evaluator to do and shipper responsibility to ensure.-

Designer, tester, evaluator to do and shipper responsibility to ensure. 
(6) The target shall have a flat, horizontal surface of such mass and rigidity that any increase in its resistance to displacement or deformation upon impact by the specimen would not significantly increase the damage of the specimen.
As a rule of thumb: An essentially nonyielding surface is one at least five times the mass of the impacting object.

Tester, evaluator to do and shipper responsibility to ensure. 
FOUR-FT FREE DROP TEST RESUITS FOR STEEL DRUMS

TABIE D-10

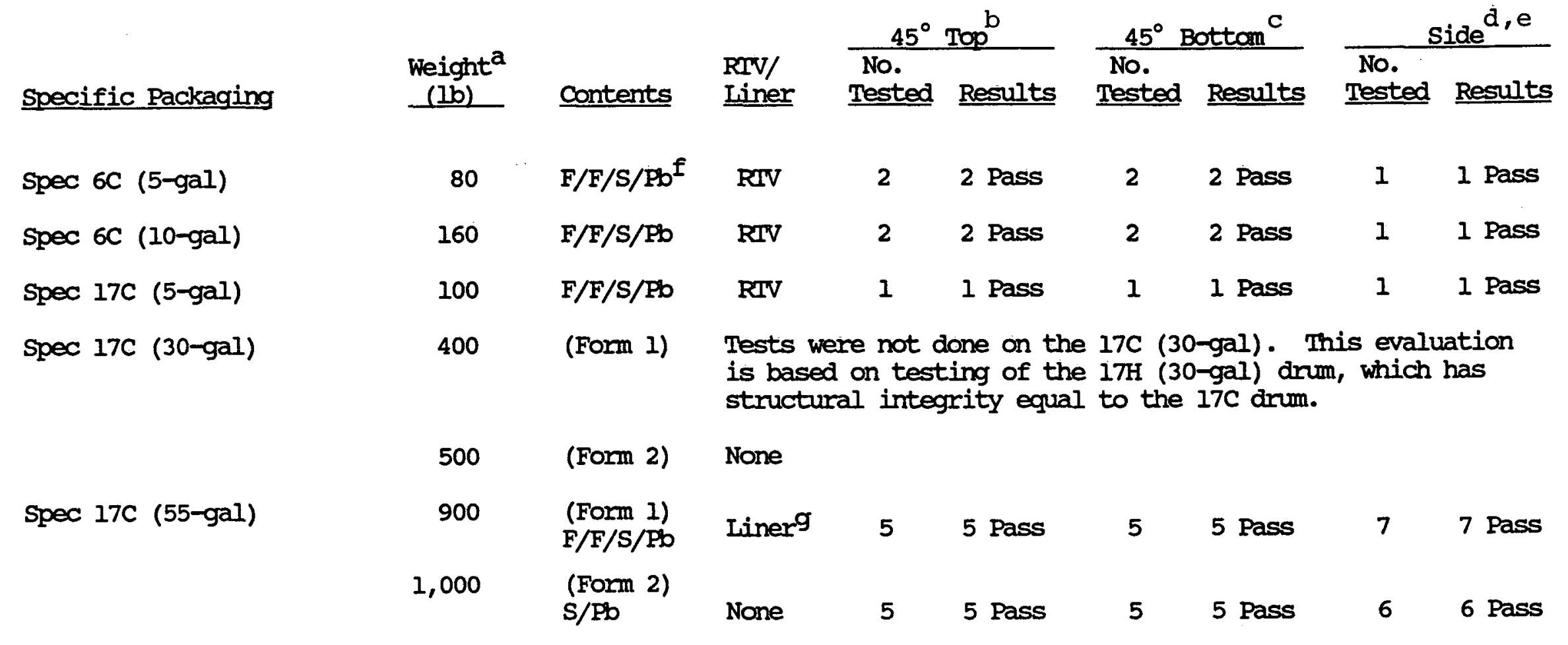

aris is the authorized gross weight. In each case, the actual test weights exceeded this value.

b Approximately a $45^{\circ}$ angle with the package impacting on the bolt of the bolt closure ring.

CApproximately a $45^{\circ}$ angle with the package impacting on the bottom chime.

doriented so that the bolt is at the point of impact.

$e_{4-f t}$ drops flat on the top and flat on the bottom were conducted on the $17 \mathrm{H}$ and $17 \mathrm{C} 55$-gal steel drums, but were not deemed necessary for other drums because of the almost total lack of effect.

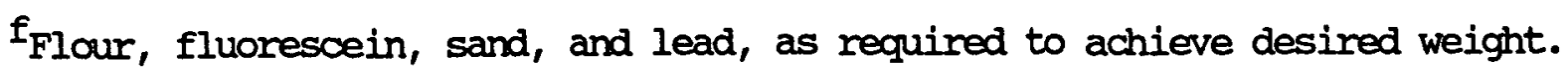

94-mil polyethylene bag, not the 90-mil HDPE liner discussed later. 
TABLE D-10 (continued)

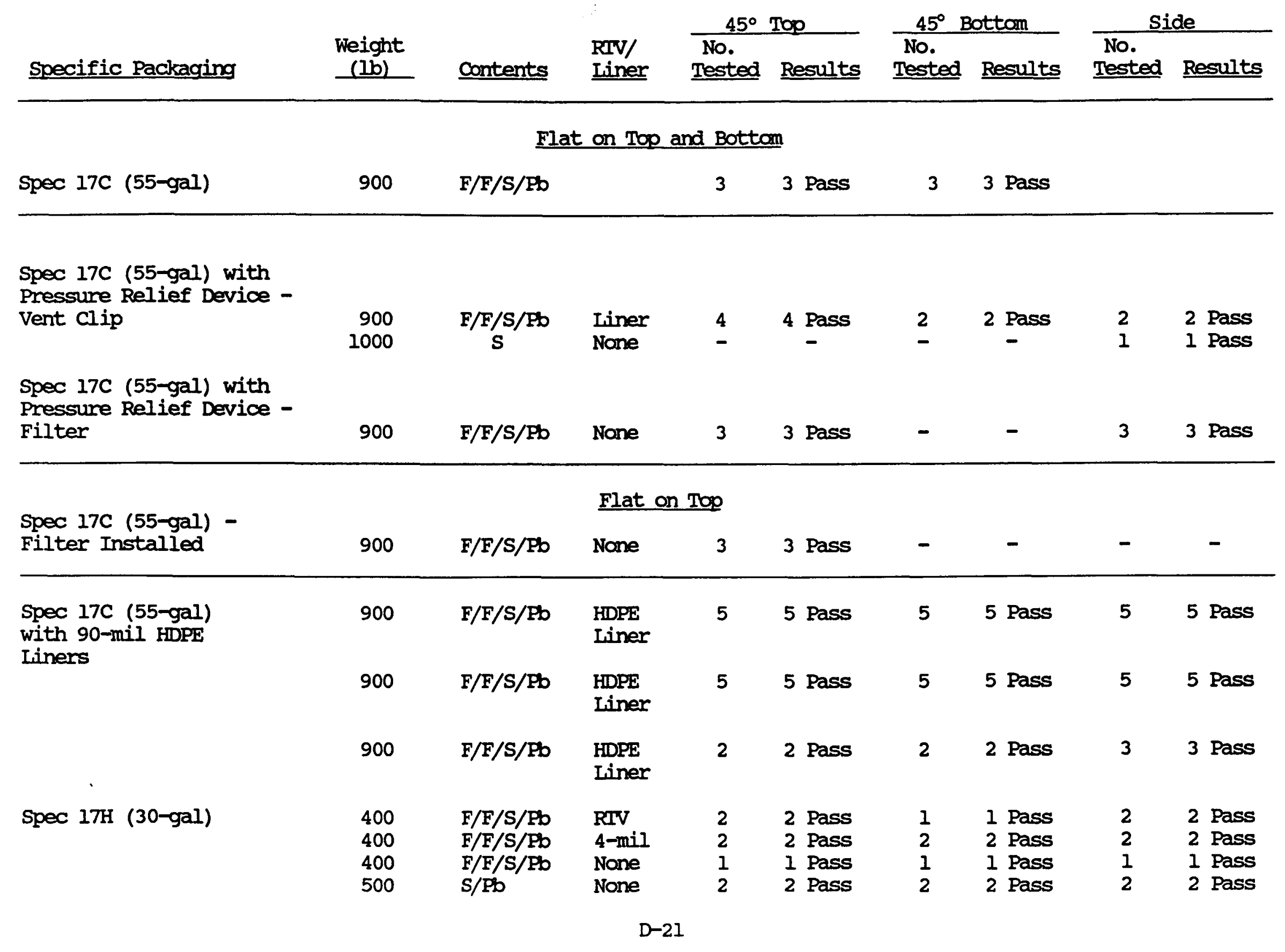


TABLE D-10 (continued)

\begin{tabular}{|c|c|c|c|c|c|c|}
\hline & & & & $45^{\circ}$ Top & $45^{\circ}$ Bottam & side \\
\hline Specific Packaging & $\begin{array}{l}\text { Weight } \\
\text { (lib) }\end{array}$ & Contents & $\begin{array}{l}\text { RTV/ } \\
\text { Liner }\end{array}$ & $\begin{array}{l}\text { No. } \\
\text { Tested Results }\end{array}$ & $\begin{array}{l}\text { No. } \\
\text { Tested Results }\end{array}$ & $\begin{array}{l}\text { No. } \\
\text { Tested Results }\end{array}$ \\
\hline
\end{tabular}

Spec 17H (55-gal)

$1,000 \quad S / P D$

None

$8 \quad 8$ Pass

$8 \quad 8$ Pass

$4 \quad 4$ Pass

\section{Flat on Top and Bottom}

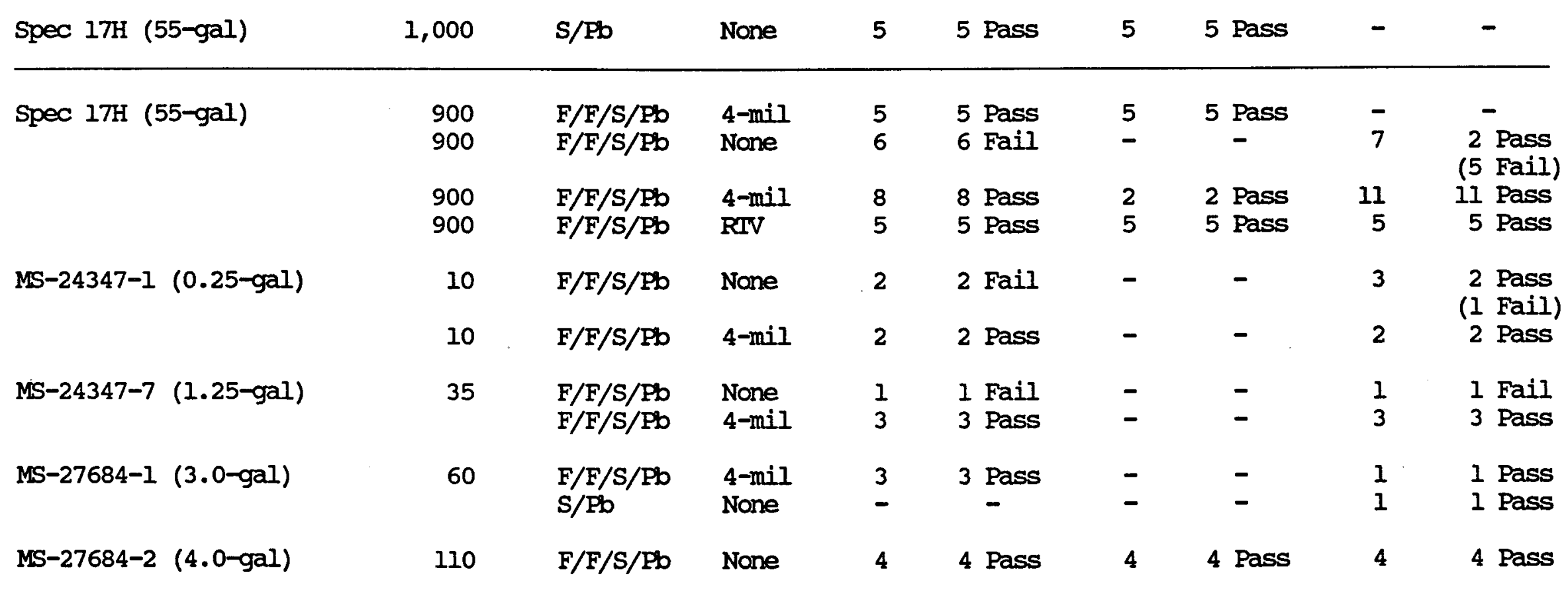


TABLE D-10 (continued)

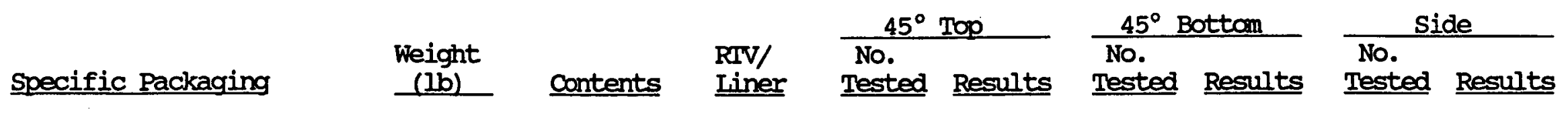

Flat on Top and Bottom

\begin{tabular}{|c|c|c|c|c|c|c|c|c|c|c|c|}
\hline MS-27684-2 & $(4.0-g a l)$ & & $\mathrm{F} / \mathrm{F} / \mathrm{S} / \mathrm{Pb}$ & None & 4 & 4 & Pass & 4 & 4 Pass & - & - \\
\hline MS-27684-3 & (6.0-gal) & 80 & $\begin{array}{l}\mathrm{F} / \mathrm{F} / \mathrm{S} / \mathrm{Pb} \\
\mathrm{S} / \mathrm{Pb}\end{array}$ & $\begin{array}{l}\text { 4-mil } \\
\text { None }\end{array}$ & 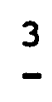 & 3 & $\begin{array}{l}\text { Pass } \\
-\end{array}$ & * & - & $\begin{array}{l}1 \\
1\end{array}$ & $\begin{array}{l}1 \text { Pass } \\
1 \text { Pass }\end{array}$ \\
\hline MS-27684-6 & (8.0-gal) & 80 & $F / F / S / P B$ & None & 3 & 3 & Pass & $\star$ & - & 2 & 2 Pass \\
\hline MS-27684-8 & (12.0-gal) & $\begin{array}{l}200 \\
200\end{array}$ & $\begin{array}{l}F / F / S / P b \\
S / P B\end{array}$ & $\begin{array}{l}\text { 4-mil } \\
\text { None }\end{array}$ & $\begin{array}{l}2 \\
1\end{array}$ & $\begin{array}{l}2 \\
1\end{array}$ & $\begin{array}{l}\text { Pass } \\
\text { Pass }\end{array}$ & * & - & $\begin{array}{l}1 \\
1\end{array}$ & $\begin{array}{l}1 \text { Pass } \\
1 \text { Pass }\end{array}$ \\
\hline MS-27683-7 & (30.0-gal) & $\begin{array}{l}400 \\
400\end{array}$ & $\begin{array}{l}\mathrm{F} / \mathrm{F} / \mathrm{S} / \mathrm{Pb} \\
\mathrm{S} / \mathrm{Fb}\end{array}$ & $\begin{array}{l}\text { 4-mil } \\
\text { None }\end{array}$ & $\begin{array}{l}2 \\
1\end{array}$ & $\begin{array}{l}2 \\
1\end{array}$ & $\begin{array}{l}\text { Pass } \\
\text { Pass }\end{array}$ & * & - & $\begin{array}{l}1 \\
1\end{array}$ & $\begin{array}{l}1 \text { Pass } \\
1 \text { Pass }\end{array}$ \\
\hline MS-27683-13 & (45-gal) & 500 & $\mathrm{~F} / \mathrm{F} / \mathrm{S} / \mathrm{Fb}$ & $\begin{array}{l}\text { 4-mil } \\
\text { Liner }\end{array}$ & 3 & 3 & Pass & * & - & 2 & 2 Pass \\
\hline & & & $\mathrm{F} / \mathrm{F} / \mathrm{S} / \mathrm{Pb}$ & None & - & & - & * & - & 1 & 1 Pass \\
\hline
\end{tabular}

*No tests were conducted since these were one-piece structures with no seals or chimes to test. 
TABLE D-11

General comments: The primary drop orientation was inverting the box (lid down) with a corner as the point of impact. When filters were used, they were typically placed in an end, and the corner chosen for the impact point was the corner closest to the filter location.

\section{Specific Packaging}

Manufacturer:

Capital Industries

$\begin{array}{llll}\text { S-0510-0823 } & 7,000 & \mathrm{~F} / \mathrm{F} / \mathrm{S}^{\mathrm{a}} & \text { Pass } \\ \mathrm{V}-0510-0823 & 7,000 & \mathrm{~F} / \mathrm{F} / \mathrm{S} & \text { Pass } \\ \text { S-0840-1440 } & 22,700 & \mathrm{~F} / \mathrm{F} / \mathrm{S} & \text { Pass } \\ \text { S-0730-1006 } & & & \\ & 10,400 & \mathrm{~F} / \mathrm{F} / \mathrm{S} & \text { Pass }\end{array}$

Weight

(lb)

contents

Results

Comments
Angle drop on top corner. No loss of contents or significant change in package gecmetry. Authorized for Form 1, 2, and 3 materials.

Angle drop on top cormer. No loss of contents or significant change in package geometry. Authorized for Form 1,2 , and 3 materials.

Angle drop on top corner. No loss of contents or significant change in package geometry. Authorized for Form 1, 2, and 3 materials.

Angle drop on top corner. No loss of contents or significant change in package geometry. Authorized for Form 1, 2, and 3 materials.

$a_{\text {Flour, fluorescein, and sand. }}$ 
TABLE D-11 (contimued)

\section{Specific Packaging \\ Manufacturer: \\ Capital Industries}

S-0730-0846

S-0480-0906

S-0450-0846
Weight

(lb)

Contents

Results

conments
8,700 Not Tested Pass

6,120 Not Tested

Pass

5,240 Not Tested
Evaluated by analysis and comparison (lid, lid reinforcing angle, bolt size, bolt spacing, container flange, and materials) to packaging S-0730-1006 which was tested and evaluated. All materials and methods of construction were equal to or better than the evaluated packaging, and the authorized gross weight was $1,700 \mathrm{lb}$ less than that for the evaluated packaging. Authorized for Form 1, 2 and 3 materials.

Evaluated by analysis and comparison (lid, lid reinforcing angle, bolt size, bolt spacing, container flange, and materials) to packaging s-0510-0823 which was tested and evaluated. All materials and methods of construction were equal to or better than the evaluated packaging, and the authorized gross weight was 820 lbs less than that for the evaluated packaging. Authorized for Form 1, 2 and 3 materials.

Evaluated by analysis and comparison (lid, lid reinforcing angle, bolt size, bolt spacing, container flange, and materials) to packaging s-0510-0823 which was tested and evaluated. All materials and methods of construction were equal to or better than the evaluated packaging, and the authorized gross weight was $1,760 \mathrm{lb}$ less than that for the evaluated packaging. Authorized for Form 1, 2 and 3 materials. 
Specific Packaging

Manufacturer:

Capital Industries

S-0240-0906

3,672 Not Tested

S-0480-1376

(lb)

Contents
Weight

Results

Comments

Pass

Evaluated by analysis and comparison (lid, lid reinforcing angle, bolt size, bolt spacing, container flange, and materials) to packaging s-0510-0823 which was tested and evaluated.

All materials and methods of construction were equal to or better than the evaluated packaging, and the authorized gross weight was $3,328 \mathrm{lb}$ less than that for the evaluated packaging. Authorized for Form 1,2 and 3 mateials.

Evaluated by analysis and comparison (lid, lid reinforcing angle, bolt size, bolt spacing, container flange, and materials) to packaging S-0730-1006 which was tested and evaluated. All materials and methods of construction were equal to or better than the evaluated packaging, and the authorized gross weight was $1,105 \mathrm{lb}$ less than that for the evaluated packaging. Authorized for Form 1,2 and 3 materials.

Container Products Corp. (CPC)

\footnotetext{
B-12-44-4-S/L FD

Drawing No. 01-3100-1-00

Rev. B
}

4,625 F/F/S Pass

Angle drop on top corner. Authorized for Form 1,2 , and 3 materials. 
TABIE D-11 (continued)

\section{Specific Packaging}

Mamufacturer:

Container Products corp. (CPC)

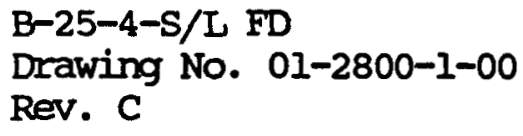

B-82-6-S/L FD

Drawing No. 01-2300-1-00 Rev. D

B-87-6-S/L FD

Drawing No. 04-1300-1-00

Rev. B
Weight

(lb)

contents

Results

Comments

Pass

4,820 Not Tested

Pass

Evaluated by analysis and comparison to tests of B-96-5 S/L FD which has identical lid seal characteristics. In addition, this package was tested using just sand with no loss of contents. Authorized for Form 1, 2, and 3 materials.

4,775 Not Tested Pass

Evaluated by analysis and comparison to tests of B-96-5 S/L FD which has identical lid seal characteristics. In addition, this package was tested using just sand with no loss of contents. Authorized for Form 1, 2, and 3 materials.

6,775 Not Tested Pass

Evaluated by analysis and comparison to tests of B-96-5 S/L FD which has identical lid seal characteristics. In addition, this package was tested using just sand with no loss of contents. Authorized for Form 1, 2, and 3 materials.

6,970 Not Tested Pass

Evaluated by analysis and comparison to tests of B-96-5 S/L FD which has identical lid seal characteristics. Authorized for Form 1, 2, and 3 materials. 


\section{Specific Packaging \\ Manufacturer: \\ Container Products Corp. (CPC)}

B-96-6-S/L FD

Drawing No. 04-1200-1-00

Rev. 0

\section{B-96-8-S/L FD}

Drawing No. 04-1200-2-00

Rev. 0

\section{B-96-5-S/L FD}

Drawing No. 01-2101-1-00 Rev. 0

B-96-5-S/L RA

Drawing No. 01-1901-1-00 Rev. 0

\section{B-96-5-RA B}

Drawing No. 01-2201-1-01

Rev. 0

$467-C-S / L$ FD

Drawing No. 01-3700-1-00

Rev. C

\section{Weight}

(lb) contents

Results

Camments

Pass

7,000 Not Tested

Evaluated by analysis and comparison to tests of B-96-8 S/L FD which has identical lid seal design. By analysis, the six side drive clips are comparable to the eight side drive clips for the $B-96-8 \mathrm{~S} / \mathrm{L}$ FD considering the difference of $2000 \mathrm{lb}$ in authorized gross weight. Authorized for Form 1, 2, and 3 materials.
9,100 F/F/S Pass

$6,050 \quad \mathrm{~F} / \mathrm{F} / \mathrm{S}$

Pass

$6,800 \quad$ Not Tested

Pass

6,500 Not Tested

4,000 Not Tested

Pass

Pass
Angle drop on top corner. Authorized for Form 1,2 , and 3 materials.

Angle drop on top corner. Authorized for Form 1,2 , and 3 materials.

Identical to B-96-5-S/L FD (except for strength members added to meet reduced pressure test) which was tested and passed. Authorized for Form 1, 2, and 3 materials. Identical to B-96-5-S/L FD (except there is no filter) which was tested and passed. Authorized for Form 1, 2, and 3 materials.
Evaluated by analysis and comparison to tests of B-96-5 S/L FD which has identical lid seal characteristics. In addition, tests have been completed using just sand with no loss of contents. Authorized for Form 1, 2, and 3 materials. 
TABLE D-Il (continued)

Specific Packaging

Mamufacturer:

Container Products Corp. (CPC)

B-96-5 FD B

Drawing No. 01-2301-1-01

Rev. 0
Weight

(lb)

contents

Results

Comments
RoGar Chemical and Nuclear Services

Model R-I

7,750

Not Tested

Pass

Model R-2
$6,500 \quad \mathrm{~F} / \mathrm{F} / \mathrm{S}$

(
Pass
Angle drop on top corner. Authorized for Form 1,2 , and 3 materials.
Evaluated by analysis and comparison (lids, lid reinforcing angle, bolt size, bolt spacing, container flange, materials of construction, etc.) to Model R-3. All materials and methods of construction were equal to or better than the test packaging, the dimensions were substantially less, and the authorized gross weight was $170 \mathrm{lb}$ less than that for the test packaging.

Evaluated by analysis and comparison (lids, lid reinforcing angle, bolt size, bolt spacing, container flange, materials of construction, etc.) to Model R-3. All materials and methods of construction were equal to or better than the test packaging, the dimensions were substantially less, and the authorized gross weight was $100 \mathrm{lb}$ less than that for the test packaging. 
TABLE D-Il (continued)

Specific Packaging

Manufacturer:

(lb)

Contents

Results

Comments

RoGar Chemical and Nuclear Services

Model R-3

$7,920 \quad F / F / S$

Pass

This package was dropped $4 \mathrm{ft}$ on a top (lid) corner. There was no loss of contents or significant change in package geometry. Authorized for Form 1, 2, and 3 materials.

Model R-4

$7,920 \quad$ Not Tested

Pass

Evaluated by analysis and comparison (lids, lid reinforcing angle, bolt size, bolt spacing, container flange, materials of construction, etc.) to Model R-3. All materials and methods of construction were equal to or better than the test packaging, the dimensions were substantially less, and the gross weight remained the same.

Rocky Flats SAND Box

Style I

7,000 Gravel and water

Pass

A number of tests were conducted at different orientations $\left(45^{\circ}\right.$ on top, $45^{\circ}$ on bottom, etc.) for each packaging. After each test, the packagings were successfully air-leak tested to $0.5 \mathrm{psi}$. The use of water and gravel was more conservative than the use of flour and fluorescein to simulate the contents. Authorized for Form 1, 2, and 3 materials. 
TABLE D-1I (continued)

\section{Specific Packaging}

Marufacturer:

Rocky Flats SAND BOX

Style 2

Style 3

Style 4
Weight

(1b)

Contents

Results

Comments
A number of tests were conducted at different orientations $\left(45^{\circ}\right.$ on top, $45^{\circ}$ on bottom, etc.) for each packaging. After each test, the packagings were suocessfully air-leak tested to $0.5 \mathrm{psi}$. The use of water and gravel was more conservative than the use of flour and fluorescein to simulate the contents. Authorized for Form 1, 2, and 3 materials.

A number of tests were conducted at different orientations $\left(45^{\circ}\right.$ on top, $45^{\circ}$ on bottorn, etc.) for each packaging. After each test, the packagings were successfully air-leak tested to $0.5 \mathrm{psi}$. The use of water and gravel was more conservative than the use of flour and fluorescein to simulate the contents. Authorized for Form 1, 2, and 3 materials.

A number of tests were conducted at different orientations $\left(45^{\circ}\right.$ on top, $45^{\circ}$ on bottom, etc.) for each packaging. After each test, the packagings were successfully air-leak tested to $0.5 \mathrm{psi}$. The use of water and gravel was more conservative than the use of flour and fluorescein to simulate the contents. Authorized for Form 1, 2, and 3 materials. 
TABLE D-11 (continued)

\begin{tabular}{|c|c|c|c|c|}
\hline cific Packaqing & $\begin{array}{l}\text { Weight } \\
\text { (1b) }\end{array}$ & contents & Results & conments \\
\hline
\end{tabular}

Mamufacturer:

\begin{tabular}{|c|c|c|c|c|}
\hline $\begin{array}{l}\text { Argonne } M-4 \\
\text { Bin }\end{array}$ & $3,000^{a}$ & $\begin{array}{l}\text { Four } 55 \text {-gal drums } \\
\text { filled with sand, } \\
\text { two 5-gal pails } \\
\text { and approximately } \\
300 \text { ib of loose } \\
\text { sand }\end{array}$ & Pass & $\begin{array}{l}\text { Dropped on one of the bottom cormers. Previ- } \\
\text { ous analysis had shown this orientation to be } \\
\text { most vulnerable to damage. After the drop, the } \\
\text { bin was filled with } 24 \text { in. of water, } 18 \text { in. } \\
\text { above the damage area. The bin was leak tight. } \\
\text { Authorized for Forms } 1,2 \text {, and } 3 \text { materials. }\end{array}$ \\
\hline
\end{tabular}

sand

Authorized for Forms 1, 2, and 3 materials.

ANL-West

$7 A-960$

$960 \quad$ Solid pieces of Pass

Dropped on top corner of lid. There was no loss of contents and no significant pathways created by which contents could escape. Authorized only for Form 3 materials.

The authorized gross weight is 3,000 1b; however, the actual gross weight for testing was 3,215 $1 \mathrm{~b}$. 
FOUR-FT FREE DROP TEST RESUIIS FOR ANL AND LUNL WOODEN BOXES

TABLE D-12

\begin{tabular}{|c|c|c|c|c|}
\hline Specific Packaging & $\begin{array}{l}\text { Weight } \\
\text { (Ib) }\end{array}$ & Contents & Results & Conments \\
\hline \multicolumn{5}{|l|}{ ANL-WEST } \\
\hline $\begin{array}{l}7 A-217 \\
7 A-375 \\
7 A-880 \\
7 A-995 \\
7 A-1315\end{array}$ & $\begin{array}{r}217 \\
375 \\
880 \\
995 \\
1,315\end{array}$ & $\begin{array}{l}\text { Solid materials } \\
\text { simulating Form } 3 \\
\text { materials were } \\
\text { used for all } \\
\text { tests }\end{array}$ & Pass & $\begin{array}{l}\text { Packagings were dropped on a top corner, which } \\
\text { included the lid. In all cases, the packaging } \\
\text { met the requirements for Form } 3 \text { materials. } \\
\text { Authorized for only Form } 3 \text { materials. }\end{array}$ \\
\hline $7 A-670$ & 670 & $\begin{array}{l}55-\text { gal drum } \\
\text { filled with soil } \\
\text { placed inside the } \\
\text { wooden box }\end{array}$ & Pass & $\begin{array}{l}\text { Packaging was dropped on a top corner, which } \\
\text { included the lid. In all cases, the packaging } \\
\text { met the requirement for Form } 3 \text { materials. } \\
\text { Authorized for only form } 3 \text { materials. }\end{array}$ \\
\hline
\end{tabular}

LUNL

Flush Panel

2,500

Drysorb 758 by weight;

Microsel-E 25\%

Pass

by weight

Packaging was dropped on a top corner, which included the lid. There was no release of contents and the packaging was authorized for Form 2 and 3 materials. 
FOUR-FT FREE DROP TEST RESUITS FOR WOODEN BOXES

TABLE D-13

General comments: All drops were conducted on a top corner of the lid. There was no loss of contents and the packagings were authorized for Form 2 and 3 materials.

\section{Specific Packaging \\ Mound Wooden Boxes - \\ Configuration $A$}

MA-1
MA-2
MA-3
MA-4
ound Wooden Boxes -

\section{configuration $\mathrm{B}$}

MB-1
MB-2
MB-3
MB-4
MB-5
MB-6

$$
\begin{aligned}
& \text { Weight } \\
& \text { (10) }
\end{aligned}
$$

Contents

No.

Tested

Results

\section{comments}

2 Pass

2 Pass

1 Pass

1 Pass

100

\section{$\mathrm{S} / \mathrm{PB}$}

F/F/S/PO

1 Pass
1 Pass

1 Pass
1 Pass

$150 \quad \mathrm{~F} / \mathrm{F} / \mathrm{S} / \mathrm{Fb}$

$150 \mathrm{~F} / \mathrm{F} / \mathrm{S} / \mathrm{Pb}$

2 Pass

2 Pass

2 Pass

$200 \quad F / F / S / P b$

2

150

$\mathrm{F} / \mathrm{F} / \mathrm{S} / \mathrm{Pb}$

2 Pass

150

$\mathrm{F} / \mathrm{F} / \mathrm{S} / \mathrm{Pb}$

2 Pass

200

F/F/S/PB

1 Pass

Authorized for only Form 2 and 3 materials.

Authorized for only Form 2 and 3 materials.

${ }^{a}$ Sand and lead.

$\mathrm{b}_{\text {Flour, fluorescein, sand, and lead. }}$ 
TABLE D-13 (continued)

\begin{tabular}{|c|c|c|c|c|c|}
\hline Specific Packaging & $\begin{array}{l}\text { Weight } \\
\text { (1b) }\end{array}$ & contents & $\begin{array}{l}\text { No. } \\
\text { Tested }\end{array}$ & Results & Comments \\
\hline
\end{tabular}

Mound Wooden Boxes Configuration C

MC-1
$M C-2$
$M C-3$
$M C-4$

$\begin{array}{llll}150 & \text { F/F/S/Pb } & 1 & 1 \text { Pass } \\ & \text { S } & 1 & 1 \text { Pass } \\ 300 & \text { F/F/S/PB } & 1 & 1 \text { Pass } \\ & \text { S/Pb } & 1 & 1 \text { Pass } \\ & \text { F/F/S/PB } & 1 & 1 \text { Pass } \\ 250 & \text { S/Pb } & 1 & 1 \text { Pass } \\ & \text { F/F/S/Pb } & 1 & 1 \text { Pass } \\ 100 & \text { S } & 1 & 1 \text { Pass } \\ & \text { F/F/S } & 1 & 1 \text { Pass }\end{array}$

Mound Wooden Boxes Configuration D
MD-1
MD-2
MD-3
MD-4
MD-5
MD-6

$\begin{array}{llll}200 & F / F / S / P b & 2 & 2 \text { Pass } \\ 300 & \text { F/F/S } / \text { Pb } & 1 & 1 \text { Pass } \\ 250 & \text { F/F/S } & 2 & 2 \text { Pass } \\ 250 & \text { F/F/S } & 2 & 2 \text { Pass } \\ 200 & \text { F/F/S/Pb } & 2 & 2 \text { Pass } \\ 200 & \text { F/F/S/Pb } & 2 & 2 \text { Pass }\end{array}$

Authorized for only Form 2 and 3 materials.

Authorized for only Form 2 and 3 materials. 
TABLE D-13 (contimued)

Specific Packaging

Weight

contents

No.

Tested

Results

Conments

Mound Wooden Boxes Configuration E

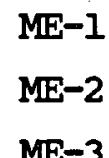

150

S

$150 \mathrm{~S}$

$150 \quad F / F / S$

1

1 Pass

2 Pass

11 Pass

\section{Y-12 B-Series}

Wooden Boxes
B-1
B-2
B-3
B-4
B-5
B-6
$B-7$
B-8

$\begin{array}{llll}400 & \mathrm{~S} / \mathrm{Pb} & 2 & 2 \text { Pass } \\ 400 & \mathrm{~S} / \mathrm{Pb} & 2 & 2 \text { Pass } \\ 400 & \mathrm{~S} / \mathrm{Pb} & 2 & 2 \text { Pass } \\ 400 & \mathrm{~S} / \mathrm{Pb} & 2 & 2 \text { Pass } \\ 400 & \mathrm{~S} / \mathrm{Pb} & 2 & 2 \text { Pass } \\ 400 & \mathrm{~S} / \mathrm{Pb} & 2 & 2 \text { Pass } \\ 400 & \mathrm{~S} / \mathrm{Pb} & 2 & 2 \text { Pass } \\ 400 & \mathrm{~S} / \mathrm{Pb} & 2 & 2 \text { Pass }\end{array}$

Authorized for only Form 2 and 3 materials.

Authorized for only Form 3 materials. 
TABLE D-13 (continued)

\section{Specific Packaging}

Y-12 Picture Frame Boxes

\section{Picture Frame}

$$
\begin{aligned}
& \text { PF-1 } \\
& \text { PF-2 } \\
& \text { PF-3 } \\
& \text { PF-4 } \\
& \text { PF-5 } \\
& \text { PF-6 } \\
& \text { PF-7 } \\
& \text { PF-8 }
\end{aligned}
$$

\section{Rocky Flats}

\section{RA Series}

Configuration 1

Configuration 2
Weight No.

(lb)

contents

Tested

Results

comments

$750 \quad \mathrm{~PB}$

$1,000 \quad \mathrm{~Pb}$

$500 \quad \mathrm{~Pb}$

$750 \quad \mathrm{~S} / \mathrm{Pb}$

$1,000 \quad \mathrm{~Pb}$

$750 \quad \mathbf{P b}$

$1,000 \quad$ Fo

Pbo

900 solid material 1

1 Pass

1 Pass

2 Pass

2 Pass

2 Pass

2 Pass

2 Pass

2 Pass

2 Pass

1,250 solid material

1 Pass

Authorized for only Form 3 materials. 
FOUR-FT FREE DROP TEST RESUITS FOR NL FAMILY OF BANDED WOODEN BOXES

TABIE D-14

General comments: All drops were conducted on a top comer of the lid. There was no loss of contents and the packagings were authorized for Form 3 materials.

Specific

$\mathrm{G}-4214$

$\mathrm{G}-4245$

G-4255

$G-4273$

G-4292
Weight (1b)

$\begin{aligned} 1,805 & \text { Pass } \\ 250 & \text { Pass } \\ 1,500 & \text { Pass } \\ 3,250 & \text { Pass } \\ 852 & \text { Pass }\end{aligned}$

\section{Orientation}

All drops were conducted on a top corner of Iid. In several instances these packagings survived drops of of $30 \mathrm{ft}$ ( 7.5 times the prescribed distance) with no release of contents.

\section{Comments}

Authorized for only Form 3 materials. 
FOUR-FT FREE DROP TEST RESULTS FOR FIBERBOARD BOXES

TABLE D-15

General comments. All drops were conducted on a top corner of the lid. There was no loss of contents and the packagings were authorized for Form 3 materials.

\section{Specific Packaging}

Weight

$$
\text { (lib) }
$$

Contents

12B-65 Fiberboand Boxes

1
2
3
4
5
6
7
8
9
10
11
12
13

IINL 12B-10 with inner metal $\operatorname{can}^{a}$

Tri-Wall Fiberboard Box

65
65
65
65
65
65
65
65
65
65
65
65
65

Po

Po

Po

S

$\mathbf{S}$

$\mathbf{S}$

$\mathrm{S}$

$\mathbf{S}$

S

$S$

S

$S$

$\mathrm{S}$

10

Inner metal

can filled

with rocks

350
No.

Tested Results

2 pass

3 pass

1 pass

2 pass

2 pass

1 pass

2 pass

2 pass

2 pass

2 pass

1 pass

2 pass

2 pass

3 pass

2

Sand in
plastic bags
Comments

Authorized for only Form 3 materials.

Authorized for only Form 3 materials.

Authorized for Form 1, 2, and 3 materials. Inner can was air-leak tested after each test.

2 pass Authorized for only Form 3 materials.

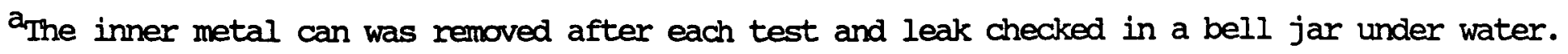


FOUR-FT FREE DROP TEST RESUITS FOR 21C FIBERBOARD DRUMS

TABLE D-16

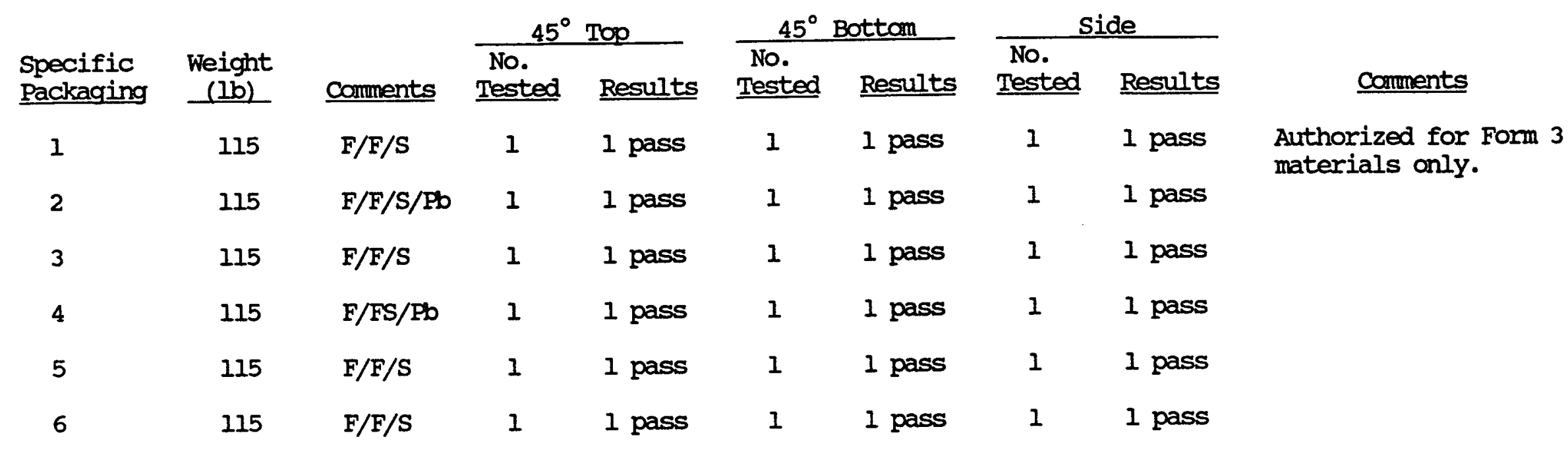

NOTE: Even though these packagings passed the drop test without release of the floor and fluorescein, they were authorized for only Form 3 materials since their performance in the penetration test was sporadic. 
FOUR-FT FREE DROP TEST RESUITS FOR UF 6 CYLTNDERS

\section{TABLE D-17}

\begin{tabular}{cc}
$\begin{array}{c}\text { Specific } \\
\text { Packaging }\end{array}$ & $\begin{array}{c}\text { Weight } \\
(1 \mathrm{lb})\end{array}$ \\
\cline { 2 - 2 } & \\
$1 \mathrm{~S}$ & 2 \\
$2 \mathrm{~S}$ & 9.5 \\
$5 \mathrm{~A}$ & 110 \\
$8 \mathrm{~A}$ & 375 \\
$12 \mathrm{~A}$ & 645 \\
$12 \mathrm{~B}$ & 650 \\
$30 \mathrm{~A}$ & 6,350 \\
$30 \mathrm{~B}$ & 6,420 \\
$48 \mathrm{G}$ & 30,600 \\
$48 \mathrm{H}$ & 30,150 \\
$48 \mathrm{HX}$ & 30,150 \\
$48 \mathrm{X}$ & 25,530 \\
$48 \mathrm{Y}$ & 32,760
\end{tabular}

\section{Orientation}

This category of packagings was evaluated based on numerous drop tests conducted on Models 5A, 8A, 12B, 30B, and $48 \mathrm{X}$ cylinders. These tests included the 4-ft drop (side and angle), the much more severe 30-ft drop (side and angle), and the 4-ft drop onto the bar (puncture test). In all of these tests, there was no loss of contents. When analyses were performed, data such as materials of construction, dimensions, authorized gross weight, and effects of testing were used to verify that the cylinders not tested meet the Spec 7A requirements.
\end{abstract}

\author{
corments \\ These packagings are authorized \\ for Form 1,2 , and 3 materials \\ (recognizing that Forms 2 and 3 \\ are not really appropriate).
}




\section{THIIRTY-FT FREE DROP TEST RESULTS FOR LIQUIDS AND GASES}

TABLE D-18

\section{Specific Packaging}

Steel Drum

MS-24347-7

(p. $\mathrm{F}-1$ )

IASL 12B-62

Fiberboard Box

IINL Steel Drums with

\section{Gas Cylinders}

(p. $F-11$ )

3 A 1800

3E 1800
Weight

(lb)

6

Contents

Water

Water

Air

Air

\section{Results/Comments}

$\begin{array}{ll}\text { Top }\left(45^{\circ}\right): & \text { No. Tested }-3 i \text { Results }-3 \text { pass } \\ \text { Flat on Top: } & \text { No. Tested }-1 ; \text { Results }-1 \text { pass } \\ \text { Bottom }\left(45^{\circ}\right): & \text { No. Tested }-3 \text { Results }-3 \text { pass } \\ \text { Side: } & \text { No. Tested }-2 ; \text { Results }-2 \text { pass }\end{array}$

Three 30-ft drops were done consecutively on the same package, then the inner containment vessel (glass bottle) was removed and inverted for $10 \mathrm{~min}$ to determine if there had been any loss of contents. After nine 30-ft drops, there was no evidence of leakage, and the package was evaluated as meeting all requirements.

One 30-foot drop was done on this packaging. The impact point was a top corner (package was inverted). After completion of the test, the inner containment vessel (glass ampule) was removed and inverted for $10 \mathrm{~min}$ to determine if there had been any loss of contents. There was no loss of contents. In addition, after an additional 30-ft drop, the 2-in. diameter inner shield container with the threaded cap and 0-ring seal was air-leak tested and passed. Thus, this packaging meets all requirements with any appropriate inner contaimment.

A 30-ft drop test was conducted on both configurations. After each drop test, it was determined that there had been no loss of contents (by comparison of pretest pressure to posttest pressure) from any of the seven test cylinders. Thus, there was no loss of contents and this packaging meets all requirements. 
TABLE D-18 (continued)

\section{Specific Packaging}

ORNL Fiberboard Box Liquids and Solids

(p. F-15)

ORNL Fiberboard BOX -

\section{Gases}

(p. F-20)

ORNL Fiberboard Box Liquids and Solids with Shielding

(p. F-2I)

ORNL Wooden Box -

Returnable, Shielded

(p. F-26)

ORNL Gas Cylinder

Returnable

(Hoke Cylinders)

HOH -50

HOXe-50

HOKr-50

HOH-150

HOXe-150

HOKr-150

$\mathrm{HOH}-300$

$\mathrm{HOKr}-300$

HOH -500

HOKr -500
Weight

Two 30-ft drops were conducted; one with the entire packaging assembly and one with just the stainless steel clad lead shield by itself (without the wooden box). The second drop indicated that this inner assembly could withstand the 30-ft drop test by itself. After both tests, the glass inner container was removed and examined. There was no loss of contents (leakage of water), and this packaging meets all requirements.

Thirty-ft drop tests were conducted on the $1000 \mathrm{~mL}$ (not currently used) and $500 \mathrm{~mL}$ gas shipping cylinders. The test packages were dropped with the valve cover down. There was no loss of contents, and these packagings meet this requirement. These two tests subjected the packaging to maximm stress, so, after consideration of material of construction, thickness of materials, package weights, etc., the analysis demonstrated that all listed packagings meet all requirements. 
TABLE D-18 (contimued)

\section{Specific packaging}

Weight

(lb)

contents

ORNL Gas Cylinder

Returnable

(J. L. Shepard)

Cylinder 1

Cylinder 2

cylinder 3

24

40

60

\section{Results/Comments}

A 30-ft drop test was conducted on J. L. Shepard Model 394-500-L gas shipping cylinder. The cylinder landed on its top. Helium leak testing before and after the testing demonstrated that there was no loss of contents and this packaging meets this requirement. Since this packaging would be subject to the greatest stress, all smaller packagings also meet all requirements. 
FOUR-FT FREE DROP TEST RESUITSS FOR MISCELIANEOUS PACKAGINGS

TABLE D-19

Specific

packaging

LINLOId Spec 55

ORNL TRU Shipping

container

FEMA Source Over

Pack

SNL Tritium Waste

Package
Weight

50

3,700

200

(2)

\section{comments}

Two of these packagings were filled with a water/fluorescein solution, sealed, and dropped on a lid edge. There was no loss of contents, even with these conservative contents. Thus, this packaging meets all requirement.

Since this packaging is certified only for Special Form [49 CFR 173.403(z)] contents, this test has little meaning from a loss of contents standpoint. However, the test was conducted on the top edge with no significant effect on the packaging. Thus, the packaging plus the Special Form contents meet all requirements.

Since this packaging is authorized only for Special Form [49 CFR 173.403(z)] contents, this test has little meaning from a loss of contents standpoint. However, the test was conducted on the top edge with no significant effect on the packaging. Thus, the packaging plus the Special Form contents meet all requirements.

200 The inner container was dropped $6 \mathrm{ft}$ on a chime and $4 \mathrm{ft}$ on a protected valve, and the entire package was dropped $4 \mathrm{ft}$ on the top bolt closure ring, all with no loss of contents. The packaging meets all requirements. 


\section{CORNER FREE DROP TEST RESULTS FOR WOODEN BOXES}

TABLE D-20

General comments: Eight 1-ft drops were conducted (one on each cormer). There was no loss of contents or other effects on contairment integrity. The slight dimensional changes are shown in the last column.

Specific Packaging

Mound Wooden Boxes Configuration A

MA-1
MA-2
MA-3
MA-4
Mound Wooden Boxes -

\section{MB-1 \\ $\mathrm{MB}-2$ \\ $\mathrm{MB}-3$ \\ MB-4 \\ MB-5 \\ MB-6}

Mound Wooden Boxes Configuration C

$$
\begin{aligned}
& M C-1 \\
& M C-2 \\
& M C-3 \\
& M C-4 \\
& M C-5
\end{aligned}
$$

40
100

\section{$\mathrm{S} / \mathrm{Pb}$}

S/Pb

$\mathrm{S} / \mathrm{Pb}$

$S / P D$
No.

Tested

1

1 Pass

1 Pass

1 Pass
Comments

0.25 -in. indent $0.25-i n$. indent $0.375-$ in. indent 0.25-in. indent
0.25 in. indent 0.375 -in. indent 0.375 -in. indent 0.375 -in. indent 0.375-in. indent 0.375 -in. indent

F/F/S/Pb
F/F/S/Pb
F/F/S/Pb
F/F/S/Pb
F/F/S/Pb
F/F/S/Pb

$\mathrm{S} / \mathrm{PB}$

$S$

$\mathrm{S} / \mathrm{Pb}$

$S / P B$

$\mathrm{S}$
1 Pass

1 Pass

1 Pass

1 Pass

1 Pass

1 Pass

\author{
0.5-in. indent \\ 0.25 -in. indent \\ 0.5 -in. indent \\ 0.25 -in. indent \\ 0.25-in. indent
}


TABLE D-20 (contimued)

Specific Packaging

Mound Wooden Boxes -

\section{Configuration D}

$M D-1$
$M D-2$
$M D-3$
$M D-4$
$M D-5$
$M D-6$

Mound Wooden Boxes -

\section{Configuration E}

$\mathrm{ME}-1$
$\mathrm{ME}-2$
$\mathrm{ME}-3$

150

150

150

200

200

250

250

200

200

$\mathrm{F} / \mathrm{F} / \mathrm{S} / \mathrm{Pb}$

$\mathrm{F} / \mathrm{F} / \mathrm{S} / \mathrm{Pb}$

$F / F / S$

$\mathrm{F} / \mathrm{F} / \mathrm{S}$

$\mathrm{F} / \mathrm{F} / \mathrm{S} / \mathrm{Pb}$

$F / F / S / F b$

Y-12 Series B

Wooden Boxes

$B-1$
$B-2$
$B-6$

400

400

400

$\mathrm{S} / \mathrm{Pb}$

S/PB

$\mathrm{S} / \mathrm{Pb}$
No.

Tested

Results

Comments

$0.25-$ in. indent 0.25 -in. indent 0.25-in. indent $0.375-$ in. indent $0.25-i n$. indent 0.25-in. indent

0.25 -in. indent 0.25 -in. indent Pass, based on testing of similar packagings.

11 Pass

Not Tested

0.55 -in. indent

1 Pass

0.25 -in. indent

0.125 -in. indent 
CORNER FREE DROP TEST RESULTSS FOR FIBERBOARD BOXES

TABIE D-21

General comments: Eight l-ft drops were conducted (one on each cormer). There was no loss of contents or other effects on contairment integrity. The slight dimensional changes are shown in the last column.

\begin{tabular}{cll} 
Specific Packaging & $\begin{array}{c}\text { Weight } \\
(1 \mathrm{~b})\end{array}$ & Conte \\
\cline { 2 - 3 }$\frac{12 \mathrm{~B}-65}{1}$ & 65 & $\mathrm{~Pb}$ \\
2 & & \\
& & \\
3 & & \\
4 & 65 & $\mathrm{~S} / \mathrm{Pb}$ \\
5 & 65 & $\mathrm{~S}$ \\
6 & 65 & $\mathrm{~Pb}$ \\
7 & 65 & $\mathrm{~S}$ \\
8 & 65 & $\mathrm{~S}$ \\
9 & 65 & $\mathrm{~S}$ \\
10 & 65 & $\mathrm{~S}$ \\
11 & 65 & $\mathrm{~S}$ \\
12 & 65 & $\mathrm{~S}$ \\
13 & 65 & $\mathrm{~S}$ \\
& 65 & $\mathrm{~S} / \mathrm{Pb}$
\end{tabular}

$\underline{\text { INNL 12B-10 }}$

contents

Pb

$\mathbf{S}$

$\mathbf{S}$

$\mathrm{S} / \mathrm{PBO}$

$\begin{array}{ll}\begin{array}{l}\text { No. } \\ \text { Tested }\end{array} & \\ 2 & 2 \text { pass } \\ \text { Not Tested } & \end{array}$

1 pass

2 pass

2 pass

2 pass

2 pass

2 pass

1 pass

2 pass

2 pass

2 pass

2 pass

Not Tested

\section{Comments}

0.25-in. indent Pass, based on testing of similar packagings.

0.25-in. indent

0.25-in. indent

0.25 -in. indent

$0.25 \mathrm{in.} \mathrm{indent}$

0.25-in. indent

0.25 -in. indent

0.25 -in. indent

0.25 -in. indent

0.25 -in. indent

0.25 -in. indent

0.25 -in. indent

Pass, based on testing of similar packagings. 
CORNER FREE DROP TEST RESUITS FOR 21C FIBERBOARD DRUMS

TABLE D-22

General conments: Eight 1-ft drops were conducted (one on each of the quarters of each rim). There was no loss of contents or other effects on containment integrity. The slight dimensional changes are shown in the last column.

$\begin{array}{cccccc}\text { Specific Packaging } & \begin{array}{c}\text { Weight } \\ (1 \mathrm{~b})\end{array} & \begin{array}{c}\text { Contents } \\ \text { No. }\end{array} & \begin{array}{c}\text { Tested } \\ \text { Results }\end{array} & \begin{array}{c}\text { Conments } \\ 0.25 \text {-in. indent }\end{array} \\ 2 & 115 & \text { F/F/S/Fb } & 1 & 1 \text { pass } & 0.125 \text {-in. indent } \\ 3 & 115 & \text { F/F/S/Fb } & 1 & 1 \text { pass } & 0.25 \text {-in. indent } \\ 4 & 115 & \text { F/F/S/Fb } & 1 & 1 \text { pass } & 0.25 \text {-in. indent } \\ 5 & 115 & \text { F/F/S/PD } & 1 & 1 \text { pass } & 0.25 \text {-in. indent } \\ 6 & 115 & \text { F/F/S } & 1 & 1 \text { pass } & 0.25 \text {-in. indent }\end{array}$


COMPRESSION TEST

(d) Compression Test

The compression test shall

last for a period of at least $24 \mathrm{hr}$ and consist of a

compressive load equivalent to the greater of the following:

(1) Five times the weight of the actual package; or

(2) 1300 kilograms per square meter $\left(265 \mathrm{lb} / \mathrm{ft}^{2}\right)$ multiplied by the vertically projected area of the package. The compressive load shall be applied uniformly to two opposite sides of the packaging specimen, one of which must be the base on which the package would normally stand.
Major Points

(1) 5 times actual weight

(2) $265 \mathrm{lb} / \mathrm{ft}^{2}$ times the area of package

\section{comments}

(1) Be alert. For packages with a large top surface area, the $265 \mathrm{lb} / \mathrm{ft}^{2}$ can quickly become very large.

(2) Any decreases in distances to package surfaces should be documented for use in evaluating the "No significant dose rate increase" requirement.

Tester and evaluator to do and shipper responsibility to ensure. 
COMPRESSION TEST RESULTS FOR STEEL DRUMS

TABLE D-23

\begin{tabular}{|c|c|c|c|c|c|c|}
\hline $\begin{array}{l}\text { Specific } \\
\text { Packaging }\end{array}$ & $\begin{array}{l}\text { Authorized } \\
\text { Gross } \\
\text { Weight } \\
\text { (10) }\end{array}$ & $\begin{array}{l}\text { Compression } \\
\text { Test Weight } \\
\text { (lb) }\end{array}$ & $\begin{array}{l}\text { Test } \\
\text { Duration } \\
\text { (hr) }\end{array}$ & $\begin{array}{l}\text { Test/A } \\
\text { Data an } \\
\text { No. } \\
\text { Tested }\end{array}$ & $\begin{array}{l}\text { alysis } \\
\text { Results } \\
\text { Results }\end{array}$ & Comments \\
\hline Spec 6C 5-gal & 80 & 500 & $>24$ & 1 & 1 Pass & No detectable effect. \\
\hline Spec 6C 10-gal & 160 & 928 & $>24$ & 1 & 1 Pass & No detectable effect. \\
\hline Spec 17C 5-gal & 100 & 520 & $>24$ & 1 & 1 Pass & No detectable effect. \\
\hline Spec 17C 30-gal & 500 & Not Tested ${ }^{a}$ & & & & Pass, based on testing of $17 \mathrm{H} 30$-gal drum. \\
\hline Spec 17C 55-gal & 1,000 & Not Testeab & & & & Pass, based on testing of $17 \mathrm{H} 55-\mathrm{gal}$ drm ${ }^{c}$. \\
\hline $\begin{array}{l}\text { Spec } 17 \mathrm{C} 55-\mathrm{gal} \\
\text { with pressure } \\
\text { relief devices }\end{array}$ & 1,000 & Not TestedC & & & & Pass, based on testing of $17 \mathrm{H} 55-\mathrm{gal}$ drum $\mathrm{c}$. \\
\hline $\begin{array}{l}\text { Spec 17C 55-gal } \\
\text { with HDPE Iiner }\end{array}$ & 1,000 & Not Tested & & & & Pass, based on testing of $17 \mathrm{H} 55-\mathrm{gal}$ drum \\
\hline Spec 17H 30-gal & 500 & 2,700 & $>24$ & 1 & 1 Pass & No detectable effect. \\
\hline Spec $17 \mathrm{H} 55-$ gal & 1,000 & 5,100 & $>74$ & 1 & 1 Pass & No detectable effect. \\
\hline \multicolumn{7}{|c|}{ 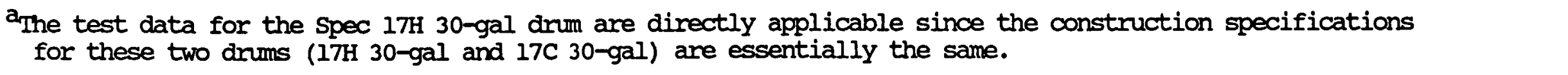 } \\
\hline
\end{tabular}


TABLE D-23 (continued)

\begin{tabular}{|c|c|c|c|c|c|c|}
\hline $\begin{array}{l}\text { Specific } \\
\text { Packaging }\end{array}$ & $\begin{array}{l}\text { Authorized } \\
\text { Gross } \\
\text { Weight } \\
\text { (1b) }\end{array}$ & $\begin{array}{l}\text { Compression } \\
\text { Test Weight } \\
\text { (1b) }\end{array}$ & $\begin{array}{c}\text { Test } \\
\text { Duration } \\
(\mathrm{hr}) \\
\end{array}$ & $\begin{array}{l}\text { Test/A } \\
\text { Data an } \\
\text { No. } \\
\text { Tested }\end{array}$ & $\begin{array}{l}\text { alysis } \\
\text { Results } \\
\text { Results }\end{array}$ & Comments \\
\hline MS 24347-1 & 10 & 100 & 48 & 1 & 1 Pass & No detectable effect. \\
\hline MS $24347-7$ & 35 & 200 & 48 & 1 & 1 Pass & No detectable effect. \\
\hline MS 27684-1 & 60 & 300 & $>24$ & 1 & 1 Pass & No detectable effect. \\
\hline MS-27684-2 & 110 & Not Tested & & & & $\begin{array}{l}\text { Pass, based on comparison to test data on } \\
\text { comparable drums. }\end{array}$ \\
\hline MS-27684-3 & 80 & 401 & $>24$ & 1 & 1 Pass & No detectable effect. \\
\hline MS $-27684-6$ & 80 & 500 & $>24$ & 1 & 1 Pass & No detectable effect. \\
\hline MS-27684-8 & 200 & 1,000 & $>24$ & 1 & 1 Pass & No detectable effect. \\
\hline MS-27683-7 & 400 & 2,072 & $>24$ & 1 & 1 Pass & No detectable effect. \\
\hline MS-27683-13 & 500 & 2,752 & $>24$ & 1 & 1 Pass & No detectable effect. \\
\hline MS-27683-21 & 800 & 5,500 & $>24$ & 1 & 1 Pass & No detectable effect. \\
\hline
\end{tabular}


COMPRESSION TEST RESULTS FOR STEEL BOXES

TABLE D-24

$\begin{array}{lcccc} & \text { Authorized } & & \text { Test/Analysis } \\ \text { Specific } & \text { Gross } & \text { Compression } & \text { Test } & \text { Data and Results } \\ \text { Packaging } & \text { Weight } & \text { Test Weight Duration } & \text { No. } \\ \text { (lb) } & \text { (lb) } & \text { (hr) } & \text { Tested Results }\end{array}$

Capital Industries

$\begin{array}{cccccc}\text { S-0510-0823 } & 7,000 & 35,000 & >24 & 1 & 1 \text { Pas } \\ \text { V-0510-0823 } & 7,000 & 35,000 & >24 & 1 & 1 \text { Pas } \\ \text { S-0450-0844 } & 5,240 & \text { Not Tested } & - & & \end{array}$

S-0730-0846

8,700

Not Tested

S-0240-0906

3,672

Not Tested

S-0480-0906

6,120

Not Tested

\section{Comments}

No detectable effect.

No detectable effect.

Pass, based on testing of Model S-0510-0823. This model passed with a load of $2500 \mathrm{lb} /$ corrogation. Model S-0450-0844 would require a test of $1871 \mathrm{lb} /$ corrogation which would be expected to pass.

Pass, based on testing of Model S-0730-1006. This model passed with a load of $2167 \mathrm{lb} /$ corrgation. Model s-0730-0846 would require a test of $2175 \mathrm{lb} /$ corrogation which would be expected to pass.

Pass, based on testing of Model S-0510-0823. This model passed with a load of $2500 \mathrm{lb} /$ corrogation. Model S-0240-0906 would require a test of 1353 lb/corrogation which would be expected to pass.

Pass, based on testing of Model V-0510-0823. This model passed with a load of $2500 \mathrm{lb} /$ corrogation. Model S-0480-0906 would require a test of $1913 \mathrm{lb} /$ corrogation which would be expected to pass. 
TABLE D-24 (continued)

\begin{tabular}{|c|c|c|c|c|}
\hline & $\begin{array}{l}\text { Authorized } \\
\text { Gross }\end{array}$ & Compression & Test & $\begin{array}{l}\text { Test/Analysis } \\
\text { Data and Results }\end{array}$ \\
\hline $\begin{array}{l}\text { Specific } \\
\text { Packaging }\end{array}$ & $\begin{array}{c}\text { Weight } \\
\text { (lb) }\end{array}$ & $\begin{array}{l}\text { Test Weight } \\
\text { (lb) }\end{array}$ & $\begin{array}{c}\text { Duration } \\
\text { (hr) }\end{array}$ & $\begin{array}{l}\text { No. } \\
\text { Tested }\end{array}$ \\
\hline
\end{tabular}

Capital Industries

$\begin{array}{cccc}\text { S-0730-0906 } & 10,400 & 52,000 & >24 \\ \text { S-0840-1440 } & 22,700 & 124,184 & >24 \\ \text { S-0480-1376 } & - & \text { Not Tested } & -\end{array}$

Container Products corp.

\begin{tabular}{|c|c|c|c|}
\hline$B-96-5-S / I-F D$ & 6,050 & 30,250 & $>24$ \\
\hline$B-96-5-S / L-R A$ & 6,801 & Not Tested & - \\
\hline$B-96-5-S / L-R A$ & 6,500 & Not Tested & - \\
\hline $\begin{array}{l}467-C-S / I-F D \\
\text { TRU Waste } \\
\text { Container }\end{array}$ & 4,000 & 20,000 & $>24$ \\
\hline B-12-44-4-S/I-FD & 4,625 & Not Tested & - \\
\hline
\end{tabular}

$\begin{array}{ll}1 & 1 \text { Pass } \\ 1 & 1 \text { Pass }\end{array}$

Pass, based on testing of Model S-0730-1006. This model passed with a load of $2167 \mathrm{lb} /$ corrgation. Model s-0480-1376 would require a test of $1936 \mathrm{lb} /$ corrogation which would be expected to pass.

\section{Comments}

No detectable effect.

No detectable effect.

11 Pass No detectable effect.

Pass, based on testing of a comparable container, B-96-5-S/L-FD, which met this requirement.

Pass, based on testing of a comparable container, B-96-5-S/L-FD, which met this requirement.

$1 \quad 1$ Pass No detectable effect.
Pass, based on testing of a comparable container, B-25-4-S/I-FD, which met this requirement. 
TABLE D-24 (contimued)

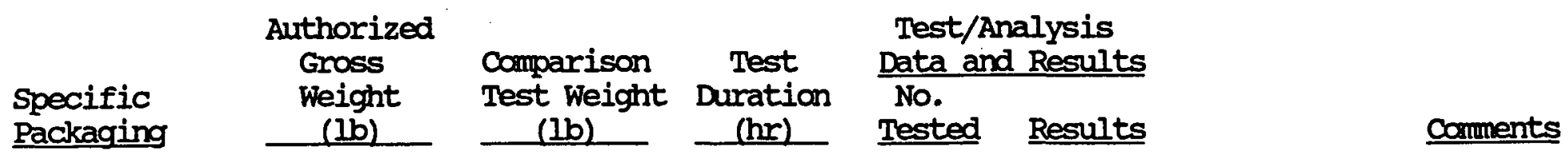

Container Prochucts Corp.

$\begin{array}{lllllll}\text { B-25-4-S/L-FD } & 4,820 & 25,000 & >24 & 1 & 1 \text { Pass } & \text { No detectable effect. } \\ \text { B-52-4-S/I-FD } & 4,775 & 29,000 & >24 & 1 & 1 \text { Pass } & \text { No detectable effect. } \\ \text { B-82-6-S/I-FD } & 6,775 & 35,000 & >24 & 1 & 1 \text { Pass } & \text { No dectectable effect. }\end{array}$

B-87-6-S/I-FD 6,970 Not Tested

Pass, based on testing of a comparable container, B-96-6-S/I-FD, which met this requirement.

$\begin{array}{lllllll}\text { B-96-6-S/L-FD } & 7,005 & 40,020 & >24 & 1 & 1 \text { Pass } & \text { No detectable effect. } \\ \text { B-96-8-S/L-FD } & 9,100 & 47,000 & >24 & 1 & 1 \text { Pass } & \text { No detectable effect. }\end{array}$

\section{Rocky Flats SAND BOX}

$\begin{array}{lllllll}\text { Style 1 } & 7,000 & 36,760 & >24 & 2 & 2 \text { Pass } & \text { No detectable effect. } \\ \text { Style 2 } & 6,000 & 32,000 & >24 & 3 & 3 \text { Pass } & \text { No detectable effect. } \\ \text { Style 3 } & 6,000 & 32,000 & >24 & 1 & 1 \text { Pass } & \text { No detectable effect. } \\ \text { Style 4 } & 6,000 & 32,000 & >24 & 2 & 2 \text { Pass } & \text { No detectable effect. }\end{array}$




\section{TABLE D-24 (continued)}

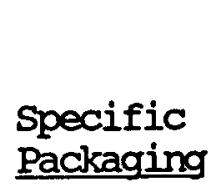

Argonne

M-4 Bin

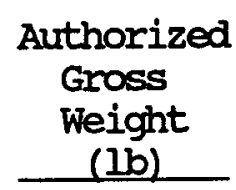

Authorized

Teight

3,000

Not Tested

Comparison

(1b)

Test

Duration

\section{Test/Analysis}

Data and Results

No.

(hr)

Tested Results

Comments

Pass, based on testing of the M-III steel bin with a compression load of $40,000 \mathrm{lb}$. The M-4 is of equal or better structural strength and would be expected to meet this requirement.

\section{ANI-West}

Steel Box
4,800

$>24$
1

1 Pass
No detectable effect. 
COMPRESSION TTEST RESULTS FOR WOODEN BOXES

TABLE D-25

\begin{tabular}{|c|c|c|c|c|c|c|}
\hline $\begin{array}{l}\text { Specific } \\
\text { Packaging }\end{array}$ & $\begin{array}{l}\text { Authorized } \\
\text { Gross } \\
\text { Weight } \\
\text { (lib) }\end{array}$ & $\begin{array}{c}\text { Compression } \\
\text { Test Weight } \\
\text { (1b) } \\
\end{array}$ & $\begin{array}{l}\text { Test } \\
\text { Duration } \\
\text { (hr) }\end{array}$ & $\begin{array}{l}\text { Test/A } \\
\text { Data an } \\
\text { No. } \\
\text { Tested }\end{array}$ & $\begin{array}{l}\text { alysis } \\
\text { Results } \\
\text { Results }\end{array}$ & Conments \\
\hline $\begin{array}{c}\text { ANL-West } \\
7 A-217 \\
7 A-375 \\
7 A-880 \\
7 A-995 \\
7 A-1315 \\
7 A-670\end{array}$ & $\begin{array}{r}217 \\
375 \\
880 \\
995 \\
1,315 \\
670\end{array}$ & $\begin{array}{l}1,085 \\
4,000 \\
5,168 \\
6,308 \\
7,000 \\
4,000\end{array}$ & $\begin{array}{l}24 \\
24 \\
24 \\
24 \\
24 \\
24\end{array}$ & $\begin{array}{l}1 \\
1 \\
1 \\
1 \\
1 \\
1\end{array}$ & $\begin{array}{ll}1 & \text { Pass } \\
1 & \text { Pass } \\
1 & \text { Pass } \\
1 & \text { Pass } \\
1 & \text { Pass } \\
1 & \text { Pass }\end{array}$ & $\begin{array}{l}\text { No detectable effect. } \\
\text { No detectable effect. } \\
\text { No detectable effect. } \\
\text { No detectable effect. } \\
\text { No detectable effect. } \\
\text { No detectable effect. }\end{array}$ \\
\hline $\begin{array}{l}\text { IINL Flush } \\
\text { Panel }\end{array}$ & 2,500 & 25,000 & $>24$ & 1 & 1 Pass & No detectable effect. \\
\hline \multicolumn{7}{|c|}{$\begin{array}{l}\text { Mound Wooden Boxes - } \\
\text { Configuration A }\end{array}$} \\
\hline $\begin{array}{l}\mathrm{MA}-1 \\
\mathrm{MA}-2 \\
\mathrm{MA}-3 \\
\mathrm{MA}-4\end{array}$ & $\begin{array}{r}40 \\
100 \\
100 \\
100\end{array}$ & $\begin{array}{l}265 \\
500 \\
500 \\
500\end{array}$ & $\begin{array}{l}>24 \\
>24 \\
>24 \\
>24\end{array}$ & $\begin{array}{l}1 \\
1 \\
1 \\
1\end{array}$ & $\begin{array}{l}1 \text { Pass } \\
1 \text { Pass } \\
1 \text { Pass } \\
1 \text { Pass }\end{array}$ & $\begin{array}{l}\text { No detectable effect. } \\
\text { No detectable effect. } \\
\text { No detectable effect. } \\
\text { No detectable effect. }\end{array}$ \\
\hline \multicolumn{7}{|c|}{$\begin{array}{l}\text { Mound wooden Boxes - } \\
\text { Configuration B }\end{array}$} \\
\hline $\mathrm{MB}-1$ & 150 & Not Tested & & & & $\begin{array}{l}\text { Pass, based on shown testing of boxes of } \\
\text { similar materials and construction methods at } \\
\text { weights in excess of those actually required. }\end{array}$ \\
\hline $\mathrm{MB}-2$ & 150 & 1,500 & $>24$ & 1 & 1 Pass & No detectable effect. \\
\hline
\end{tabular}


TABLE D-25 (continued)

\section{Specific \\ Packaging}

MB-3

MB-4

150

MB-5

150

MB-6

200

Mound Wooden Boxes -

\section{Configuration $C$}

MC-1
$M C-2$
$M C-3$
$M C-4$
$M C-5$
Oound Wooden Boxes -

MD-1
Test/Analysis Data and Results

No.

Tested Results
Test (hr)

Not Tested

Not Tested

Not Tested

1,116
1

1 Pass

\section{Comments}

Pass, based on testing of boxes of similar materials and construction methods at weights in excess of those actually required.

Pass, based on testing of boxes of similar materials and construction methods at weights in excess of those actually required.

Pass, based on testing of boxes of similar materials and construction methods at weights in excess of those actually required.

No detectable effect.

No detectable effect.

No detectable effect.

No detectable effect.

No detectable effect.

No detectable effect.
Pass, based on testing of boxes of similar materials and construction methods at weights in excess of those actually required. 
TABLE D-25 (continued)
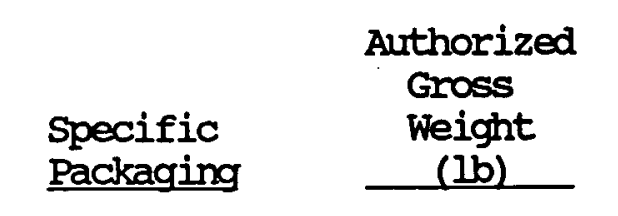

MD-2

MD-3

300

250

250

200

MD-5

MD-6

200

Not Tested

Mound Wooden Boxes -

Configuration E

ME-1

Not Tested

ME-2

150

150

Not Tested

1,351

Not Tested

$\mathrm{ME}-3$

Compression
Test Weight
$\begin{gathered}\text { Duration } \\ \text { (lib) }\end{gathered}$

Test/Analysis

Data and Results

No.

Tested Results

1

1 Pass

$>24$

1

1 Pass

\section{1}

1

1 Pass

1 Pass

\section{comments}

No detectable effect.

Pass, based on testing of boxes of similar materials and construction methods at weights in excess of those actually required.

No detectable effect.

Pass, based on testing of boxes of similar materials and construction methods at weights in excess of those actually required.

Pass, based on testing of boxes of similar materials and construction methods at weights in excess of those actually required.

Pass, based on testing of boxes of similar materials and construction methods at weights in excess of those actually required.

No detectable effect.

No detectable effect. 
TABLE D-25 (contimued)

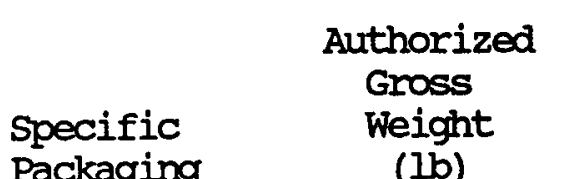

Packaging

To Family of Banded

Wooden Boxes

$G-4214$
$G-4245$
$G-4255$
$G-4273$

Y-12 Series B

Wooden Boxes

$$
\begin{aligned}
& \mathrm{B}-1 \\
& \mathrm{~B}-2 \\
& \mathrm{~B}-3 \\
& \mathrm{~B}-4 \\
& \mathrm{~B}-5 \\
& \mathrm{~B}-6 \\
& \mathrm{~B}-7 \\
& \mathrm{~B}-8
\end{aligned}
$$

1,805
250
1,500
3,250
852

Test/Analysis

Data and Results

No.

Test Weight Duration (lb)
Tested Results

\section{Comments}

Y-12 Picture Frame Wooden Boxes

$\mathrm{PF}-1$

PF-2

$>24$
$>24$
$>24$
$>24$
$>24$

1

10,000

1,000

7,500

18,000

4,500
1 Pass

1 Pass

1 Pass

1 Pass

1 Pass

No detectable effect.

No detectable effect.

No detectable effect.

No detectable effect.

No detectable effect.

No detectable effect. No detectable effect. No detectable effect. No detectable effect. No detectable effect. No detectable effect. No detectable effect. No detectable effect.

Pass, based on testing of boxes of similar materials and construction methods at weights in excess of those

No detectable effect. 
TABLE D-25 (contimued)

\begin{tabular}{|c|c|c|c|c|c|c|}
\hline $\begin{array}{l}\text { Specific } \\
\text { Packaging }\end{array}$ & $\begin{array}{l}\text { Authorized } \\
\text { Gross } \\
\text { Weight } \\
\text { (1b) }\end{array}$ & $\begin{array}{l}\text { Compression } \\
\text { Test Weight } \\
\text { (lb) } \\
\end{array}$ & $\begin{array}{l}\text { Test } \\
\text { Duration } \\
\text { (hr) }\end{array}$ & $\begin{array}{l}\text { Test/A } \\
\text { Data an } \\
\text { No. } \\
\text { Tested }\end{array}$ & $\begin{array}{l}\text { alysis } \\
\text { Results } \\
\text { Results }\end{array}$ & Comments \\
\hline $\mathrm{PF}-3$ & 1,000 & Not Tested & & & & $\begin{array}{l}\text { Pass, based on testing of boxes of similar } \\
\text { materials and construction methods at weights } \\
\text { in excess of those actually required. }\end{array}$ \\
\hline $\mathrm{PF}-4$ & 500 & Not Tested & & & & $\begin{array}{l}\text { Pass, based on testing of boxes of similar } \\
\text { materials and construction methods at weights } \\
\text { in excess of those actually required. }\end{array}$ \\
\hline $\mathrm{PF}-5$ & 750 & 3,770 & $>24$ & 1 & 1 Pass & No detectable effect. \\
\hline $\mathrm{PF}-6$ & 1,000 & 5,100 & $>69$ & 1 & 1 Pass & No detectable effect. \\
\hline $\mathrm{PF}-7$ & 750 & Not Tested & & & & $\begin{array}{l}\text { Pass, based on testing of boxes of similar } \\
\text { materials and construction methods at weights } \\
\text { in excess of those actually required. }\end{array}$ \\
\hline $\mathrm{PF}-8$ & 1,000 & 5,100 & 47 & 1 & 1 Pass & No detectable effect. \\
\hline \multicolumn{7}{|c|}{$\begin{array}{l}\text { Pocky Flats } \\
\text { A Series of wooden Boxes }\end{array}$} \\
\hline Configuration 1 & 900 & 4,541 & 24 & 1 & 1 Pass & No detectable effect. \\
\hline Configuration 2 & 1,250 & 6,664 & 24 & 1 & 1 Pass & No detectable effect. \\
\hline
\end{tabular}


COMPRESSION TEST RESULTS FOR FIBERBOARD PACKAGINGS

TABLE D-26

\section{Specific \\ Packaging \\ 12B-65 Fiberboand}

Authorized

Boxes

1

Compression $\begin{gathered}\text { Test } \\ \text { Test Weight Duration } \\ \text { (1b) }\end{gathered}$
(hr)

Test/Analysis Data and Results

No.

Tested Results
Comments
Pass, based on testing of boxes of similar materials and construction methods at weights in excess of those actually required.

Pass, based on testing of boxes of similar materials and construction methods at weights in excess of those actually required.

Pass, based on testing of boxes of similar materials and construction methods at weights in excess of those actually required.

11 Pass

No detectable effect.

Pass, based on testing of boxes of similar materials and construction methods at weights in excess of those actually required.

1 I Pass No detectable effect. 
TABLE D-26 (contimued)

\begin{tabular}{|c|c|c|c|c|c|c|}
\hline $\begin{array}{l}\text { Specific } \\
\text { Packaging }\end{array}$ & $\begin{array}{l}\text { Authorized } \\
\text { Gross } \\
\text { Weight } \\
\text { (1b) }\end{array}$ & $\begin{array}{l}\text { Compression } \\
\text { Test Weight } \\
\text { (lb) }\end{array}$ & $\begin{array}{l}\text { Test } \\
\text { Duration } \\
\text { (hr) }\end{array}$ & $\begin{array}{l}\text { Test/Ar } \\
\text { Data anc } \\
\text { No. } \\
\text { Tested }\end{array}$ & $\begin{array}{l}\text { alysis } \\
\text { Results } \\
\text { Results }\end{array}$ & Conments \\
\hline 7 & 65 & 325 & $>24$ & 1 & 1 Pass & No detectable effect. \\
\hline 8 & 65 & 328 & $>24$ & 1 & 1 Pass & No detectable effect. \\
\hline 9 & 65 & 328 & $>24$ & 1 & 1 Pass & No detectable effect. \\
\hline 10 & 65 & 325 & $>24$ & 1 & 1 Pass & No detectable effect. \\
\hline 11 & 65 & 328 & $>24$ & 1 & 1 Pass & No detectable effect. \\
\hline 12 & 65 & Not Tested & & & & $\begin{array}{l}\text { Pass, based on testing of boxes of similar } \\
\text { materials and construction methods at weights } \\
\text { in excess of those actually required. }\end{array}$ \\
\hline 13 & 65 & Not Tested & & & & $\begin{array}{l}\text { Pass, based on testing of boxes of similar } \\
\text { materials and construction methods at weights } \\
\text { in excess of those actually required. }\end{array}$ \\
\hline $\begin{array}{l}\sqrt{L} 12 \mathrm{~B}-10 \\
\text { th inner } \\
\text { cal can }\end{array}$ & 10 & 100 & $>24$ & 1 & 1 Pass & No detectable effect. \\
\hline $\begin{array}{l}\text { ri-Wall } \\
\text { iberboard Box }\end{array}$ & 350 & 2,510 & $>24$ & 2 & 2 Pass & $\begin{array}{l}\text { Box was compressed } 0.5 \text { in. in the middle as a } \\
\text { result of this test. }\end{array}$ \\
\hline
\end{tabular}




\section{TABLE D-26 (contimued)}

\begin{tabular}{|c|c|c|c|c|c|c|}
\hline $\begin{array}{l}\text { Specific } \\
\text { Packaging }\end{array}$ & $\begin{array}{l}\text { Authorized } \\
\text { Gross } \\
\text { Weight } \\
\text { (1b) }\end{array}$ & $\begin{array}{l}\text { Compression } \\
\text { Test Weight } \\
\text { (lb) }\end{array}$ & $\begin{array}{c}\text { Test } \\
\text { Duration } \\
\text { (hr) }\end{array}$ & $\begin{array}{l}\text { Test/I } \\
\text { Data ar } \\
\text { No. } \\
\text { Tested }\end{array}$ & $\begin{array}{l}\text { lysis } \\
\text { Results }\end{array}$ & Conments \\
\hline Fiberboard & & & & & & \\
\hline $\begin{array}{l}1 \\
2 \\
3 \\
4 \\
5 \\
6\end{array}$ & $\begin{array}{l}115 \\
115 \\
115 \\
115 \\
115 \\
115\end{array}$ & $\begin{array}{l}603 \\
600 \\
601 \\
603 \\
603 \\
601\end{array}$ & $\begin{array}{l}>24 \\
>24 \\
>24 \\
>24 \\
>24 \\
>24\end{array}$ & $\begin{array}{l}1 \\
1 \\
1 \\
1 \\
1 \\
1\end{array}$ & $\begin{array}{ll}1 & \text { Pass } \\
1 & \text { Pass } \\
1 & \text { Pass } \\
1 & \text { Pass } \\
1 & \text { Pass } \\
1 & \text { Pass }\end{array}$ & $\begin{array}{l}\text { No detectable effect. } \\
\text { No detectable effect. } \\
\text { No detectable effect. } \\
\text { No detectable effect. } \\
\text { No detectable effect. } \\
\text { No detectable effect. }\end{array}$ \\
\hline
\end{tabular}


COMPRESSION TEST RESULTS FOR UF-6 CYLTNDERS

\section{TABLE D-27}

Calculated No. of Packages Required for Stress Leading

Packaging

is

2S

$5 \mathrm{~A}$

$8 A$

$12 \mathrm{~A}$

$12 B$

$30 \mathrm{~A}$

$30 \mathrm{~B}$

$48 \mathrm{G}$

$48 \mathrm{H}$

$48 \mathrm{HX}$

$48 \mathrm{X}$

$48 Y$ to Failure $>100$

21

15

$>100$

$>100$

12

12

9

9

12

12

9
Results

Pass

Pass

Pass

Pass

Pass

Pass

Pass

Pass

Pass

Pass

Pass

Pass

Pass

\section{Comments}

Two methods of analysis were used to evaluate the containers:

(1) A linear elastic stress and buckeling analysis using the shell of revoluation program BOSOR; and

(2) A linear elastic buckeling analysis and a nonlinear elasticplastic collapses analysis using the finite element program NASTRAN. 
COMPRESSION TEST RESULTS FOR IIQUIDS AND GASES

\begin{tabular}{|c|c|c|c|c|c|c|}
\hline \multicolumn{7}{|c|}{ TABIE D-28 } \\
\hline $\begin{array}{l}\text { Specific } \\
\text { Packaging }\end{array}$ & $\begin{array}{l}\text { Authorized } \\
\text { Gross } \\
\text { Weight } \\
\text { (1b) }\end{array}$ & $\begin{array}{l}\text { Compression } \\
\text { Test Weight } \\
\text { (lb) }\end{array}$ & $\begin{array}{l}\text { Test } \\
\text { Duration } \\
\text { (hr) }\end{array}$ & $\begin{array}{l}\text { Test/A } \\
\text { Data an } \\
\text { No. } \\
\text { Tested }\end{array}$ & $\begin{array}{l}\text { alysis } \\
\text { Results } \\
\text { Results }\end{array}$ & Comments \\
\hline $\begin{array}{l}\text { Steel Drum } \\
\text { MS-24347-7 } \\
(\text { p. F-l })^{a}\end{array}$ & 10 & Not Tested & & & & $\begin{array}{l}\text { Pass, see Page D-52 of this addendum for test } \\
\text { results on this drum. }\end{array}$ \\
\hline $\begin{array}{l}\text { LASL 12B-62 } \\
\text { Fiberboard Box }\end{array}$ & 62 & 328 & $>24$ & 1 & 1 Pass & No detectable effect. \\
\hline $\begin{array}{l}\text { IINL Steel Drums } \\
\text { with Gas Cylinders } \\
\text { (p. F-l1) }\end{array}$ & & Not Tested & & & & $\begin{array}{l}\text { Pass, see Page } D-51 \text { of this addendum for test } \\
\text { results on } 17 \mathrm{H} 30-\text { gal steel drums. }\end{array}$ \\
\hline $\begin{array}{l}\text { ORNL Fiberboard } \\
\text { BOx - Liquids } \\
\text { and Solids } \\
\text { (p. F-15) }\end{array}$ & 33 & 165 & $>24$ & 1 & 1 Pass & $\begin{array}{l}\text { Deformation of up to } 1 \text { in. on all four sides } \\
\text { and less than } 0.5 \mathrm{in.} \text { on the top end button. }\end{array}$ \\
\hline $\begin{array}{l}\text { ORNL Fiberboard } \\
\text { BOX - Gases } \\
\text { (p. F-20) }\end{array}$ & 33 & 165 & $>24$ & 1 & 1 Pass & $\begin{array}{l}\text { Deformation of up to } 1 \text { in. on all four sides } \\
\text { and less than } 0.5 \mathrm{in.} \text { on the top end button. }\end{array}$ \\
\hline
\end{tabular}

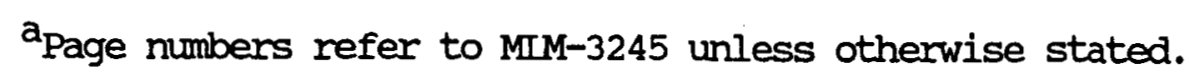


TABLE D-28 (contimed)

\begin{tabular}{|c|c|c|}
\hline $\begin{array}{l}\text { Specific } \\
\text { Packaging }\end{array}$ & $\begin{array}{l}\text { Authorized } \\
\text { Gross } \\
\text { Weight } \\
\text { (1b) }\end{array}$ & $\begin{array}{c}\text { Compression } \\
\text { Test Weight } \\
\text { (1b) }\end{array}$ \\
\hline $\begin{array}{l}\text { ORNL Fiberboard } \\
\text { Box - Iiquids } \\
\text { and solids with } \\
\text { Shielding } \\
\text { (p. F-2l) }\end{array}$ & 33 & 165 \\
\hline $\begin{array}{l}\text { ORNL Wooden Box - } \\
\text { Returnable, } \\
\text { Shielded } \\
\text { (p. F-26) }\end{array}$ & 212 & 1,040 \\
\hline $\begin{array}{l}\text { ORNL Gas Cylinder } \\
\text { Returnable } \\
\text { (Hoke Cylinders) }\end{array}$ & 212 & 1,060 \\
\hline HOH-50 & 9 & Not Tested \\
\hline HOXe -50 & 15 & Not Tested \\
\hline HOKr -50 & 15 & Not Tested \\
\hline $\mathrm{HOH}-150$ & 11 & Not Tested \\
\hline HOXe-150 & 35 & Not Tested \\
\hline HOKr -150 & 35 & Not Tested \\
\hline
\end{tabular}

Test/Analysis Data and Results No. Tested Results

$>24 \quad 1 \quad 1$ Pass

Deformation of up to $1 \mathrm{in.}$ on all four sides and less than $0.5 \mathrm{in}$. On the top end button.

Tests on a slightly smaller packaging at a slightly less compressive load demonstrated that this packaging would be expected to meet this requirement.

$>24$

11 Pass

No damage to the packaging.

Pass, based on comparison to test data on heaviest cylinder, HOKr-500, shown below.

Pass, based on comparison to test data on heaviest cylinder, $\mathrm{HOKx}-500$, shown below.

Pass, based on comparison to test data on heaviest cylinder, HOKr-500, shown below.

Pass, based on comparison to test data on heaviest cylinder, HOKr-500, shown below.

Pass, based on comparison to test data on heaviest cylinder, HOKr-500, shown below.

Pass, based on comparison to test data on heaviest cylinder, HOKr-500, shown below. 


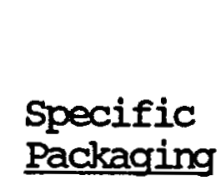

HOH -300

HOKr -300

HOH -500

HOKr-500

\section{Authorized} Gross

Weight (1b)

\section{2}

36

15

50

285 (Ib)
Test/Analysis

Compression Test Data and Results

Test Weight Duration

(hr)

Not Tested

Not Tested

Not Tested

24

No.

Tested Results
Pass, based on comparison to test data on heaviest cylinder, HOKr-500, shown below.

Pass, based on comparison to test data on heaviest cylinder, HOKr-500, shown below.

Pass, based on comparison to test data on heaviest cylinder, HOKr-500, shown below.

No damage to the packaging.

Tests were also conducted with a 1,000 mL container in which a compressive load of $580 \mathrm{lb}$ was applied for $24 \mathrm{hr}$. There was no damage to the package. Since these cylinders are all identical in construction except for size and weight, the testing of the two heaviest packagings represents the worst possible cases. Thus, all of the above cylinders would pass this test.

Evaluated based on letter describing testing conducted by ORNL, subject "J. L. Shepard Gas Cylinder," D. M. Ferren/D. A. Edling, April 30, 1985.
ORNL Gas Cylinder Returnable

(J. L. Shepard)

Cylinder 1

Cylinder 2

cylinder 3 
COMPRESSION TEST RESUIISS FOR MISCEHIANEOUS PACKAGINGS

TABLE D-29

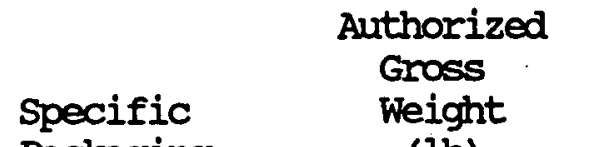

Packaqing

IINL Old Spec 55

ORNL TRU Shipping

Container

FEMA Source over

Pack

SNL Tritium Waste

Package
Compression

(1b)

$$
\text { (1b) }
$$

300

Not Tested

3,700

200

200

Not Tested
Test

Duration

(hr)

$>24$

$>24$
Test/Analysis

Data and Results

No.

Tested Results

11 Pass

No detectable effect.

Analysis demonstrates that even 50,000 1b, a severe over-test, would not have a significant effect.

$1 \quad 1$ Pass

No detectable effect.

Pass, see Page D-5I of this document for test data on the $17 \mathrm{H} 30$-gal drum. 
PENETRATION TEST

\section{(e) Penetration Test.}

For the penetration test the packaging specimen shall be placed on a rigid, flat, horizontal surface that will not move while the test is being performed. The test shall consist of:

(1) A bar 3.2 centimeters (1.25 in.) in diameter with with a hemispherical end, weighing 6 kilogram (13.2 1b) being dropped with its longitudinal axis vertical, onto the center of the weakest part of the packaging specimen, so that, if it penetrates far enough, it will hit the containment system. The bar must not be deformed by the test; and

(2) The distance of the fall of the bar measured from its lower end to the upper surface of the packaging specimen shall not be less than 1 meter $(3.3 \mathrm{ft})$.
Major points.

(1) 13-16 bar

(2) $1 \mathrm{~m}(3.3 \mathrm{ft})$

(3) Most vulnerable point

\section{Comments}

Penetration of the outer packaging(s) is not necessarily a cause for failure. The question is, "Did the test result in a loss of contents?" For outer packaging components not meeting this requirement, one could specify an inner component(s) that will or design protective devices to ensure that the bar cannot reach the primary containment system.

Tester and evaluator to do and shipper responsibility to ensure. 
PENEIRATION TEST RESUITS FOR STEEEL DRUMS

TABLE D-30

Specific

packaging

Spec 6C (5-gal)

Spec 6C (10-gal)

Spec 17C (5-gal)

Spec 17C (30-gal)

Spec 17C (55-gal)

Spec 17C (55-gal) with Pressure Relief Device Nuc-fil filter

\begin{tabular}{l} 
No. Tested \\
\hline 1 \\
1 \\
1 \\
1 \\
1 \\
1 \\
Not Tested \\
Not Tested \\
Not Tested
\end{tabular}

3

Not Tested
Test/Analysis Results

Iocation

Results

Iid at center

side at seam

Lid near closure ring

\section{Lid at center}

side at seam

Iid near closure

ring

$$
\text { ring }
$$

1 Pass

1 Pass

1 Pass

1 Pass

1 Pass

1 Pass center of filter 3 pass

\section{Comments}

0.5 -in. dent

1-in. dent

0.25 -in. dent

0.5-in. dent

$0.75-$ in. dent

0.5-in. dent

Pass, based on test data shown for comparable or lesser gauge steels.

Pass, based on test data shown for comparable or lesser gauge steels.

Pass, based on test data shown for comparable or lesser gauge steels.

Air flow was established after each test with flour/fluorescein as contents. There was no visible evidence of loss of contents, and no loss of contents was detected under a black light. 
TABLE D-30 (contimued)

\section{Specific}

packaging

Spec 17C (55-gal)

with 90-mil HDPE Liners

Spec $17 \mathrm{H}(30$-gal)

Spec 17H (55-gal)

MS24347-1 (0.25-gal)

MS24347-7 (1.25-gal)

MS27684-I (3.0-gal)

MS27684-2 (4.0-gal)

MS27684-3 (6.0-gal)

$\begin{array}{ll}\text { Test/Analysis Results } \\ \text { No. Tested } & \text { Iocation }\end{array}$

Not Tested

1

1

1

1

1

1

1

1

1

1

$1 \quad$ Iid at middle

1

Side at seam

Not Tested

$\begin{array}{lll}1 & \text { Lid at middle } & \text { I Pass } \\ 1 & \text { Side at seam } & \text { I Pass }\end{array}$

Iid near closure 1 Pass

ring

Iid at middle

1 Pass

1 Pass

Iid at middle

Side at seam

Iid near closure

1 Pass

1 Pass

1 Pass

1 Pass

1 Pass
Comments

Pass. Data shown and discussed below apply here and demonstrate compliance.

0.125 -in. dent

0.125 -in. dent

0.055-in. dent

0.125 -in. dent

0.125 -in. dent

0.055-in. dent

0.75-in. dent

1.25-in. dent

0.5 -in. dent

1.25-in. dent

0.125 -in. dent

$0.75-$ in. dent

1-in. dent

Pass, based on test data shown for drums of lesser gauge and size.

1-in. dent

0.5 -in. dent 


\section{TABLE D-30 (continued)}

Specific

packaging

MS27684-6 (8.0-gal)

MS27684-8 (12.0-gal)

MS27683-7 (30.0-gal)

MS27683-13 (45-gal)

MS27683-21 (85-gal)
Test/Analysis Results

\begin{tabular}{|c|c|c|}
\hline No. Tested & Location & Results \\
\hline 1 & Iid at middle & 1 Pass \\
\hline 1 & Side at seam & 1 Pass \\
\hline 1 & Iid at middle & 1 Pass \\
\hline 1 & Side at seam & 1 Pass \\
\hline 1 & Iid at middle & 1 Pas \\
\hline 1 & Side at seam & 1 Pas \\
\hline $\begin{array}{l}1 \\
1\end{array}$ & $\begin{array}{l}\text { Iid at middle } \\
\text { Side at seam }\end{array}$ & 1 Pas \\
\hline
\end{tabular}

Not Tested

\section{Comments}

$0.125-i n$. dent

i-in. dent

1-in. dent

$0.562-i n$. dent

1-in. dent

0.562-in. dent

$0.125-$ in. dent

$0.125-i n$. dent

Pass, based on test data shown for drums of lesser gauge and size. 
PENETRATION TEST RESULTS FOR STEELL BOXES

TABLE D-31

Specific

Packaging

Capital Industries

$S-0510-0823$
$V-0510-0823$
$S-0840-1440$
$S-0730-1006$
$S-0730-0846$

s-0730-0846

S-0480-0906

\begin{tabular}{ccc}
\multicolumn{3}{c}{ Test/Analysis Results } \\
\hline No. Tested & Iocation & Resul \\
& & \\
1 & Middle top & Pass \\
1 & Center of filter & Pass \\
1 & Middle top & Pass \\
1 & Middle top & Pass \\
Not Tested & & Pass
\end{tabular}

Not Tested

\section{Comments}

In all cases below, including the filter test, the only effect was a minor dent. This is expected based on materials of construction and comparative testing of lesser gauge materials.

Evaluated by analysis and comparison (lid, lid reinforcing angle, bolt size, bolt spacing, container flange, and materials) to packaging S-0730-1006 which was tested and evaluated. All materials and methods of construction were equal to or better than those of the tested packaging.

Evaluated by analysis and comparison (lid, lid reinforcing angle, bolt size, bolt spacing, container flange, and materials) to packaging s-0510-0823 which was tested and evaluated. All materials and methods of construction were equal to or better than those of the tested packaging. 
TABLE D-31 (contimued)

Specific

Packaging

\section{Capital Industries}

S-0450-0846

S-0240-0906

S-0480-1376

$\frac{\text { Test/Analysis Results }}{\text { No. Tested }}$

Not Tested

Not Tested

Not Tested
Results

Pass

Evaluated by analysis and comparison (lid, lid reinforcing angle, bolt size, bolt spacing, container flange, and materials) to packaging S-0580-0823 which was tested and evaluated.

All materials and methods of construction were qual to or better than those of the tested packaging.

Pass

Evaluated by analysis and comparison (lid, lid reinforcing angle, bolt size, bolt spacing, container flange, and materials) to packaging S-0580-0823 which was tested and evaluated.

All materials and methods of construction were equal to or better than those of the tested packaging.

Evaluated by analysis and comparison (lid, lid reinforcing angle, bolt size, bolt spacing, container flange, and materials) to packaging 5-0730-1006 which was tested and evaluated. All materials and methods of construction were equal to or better than those of the tested packaging. 
TABLE D-31 (continued)

Specific

Packaging

Container Products

\section{Corp. (CPC)}

B-12-44-4-S/L FD

Drawing No. 01-3100-1-00

Rev. B

B-25-4-S/L FD

Drawing No. 01-2800-1-00 Rev. C

B-52-4-S/L FD

Drawing No. 04-1000-1-00

Rev. F

B-82-6-S/L FD

Drawing No. 01-2300-1-00

Rev. D

B-87-6-S/L FD

Drawing No. 04-1300-1-00

Rev. B

B-96-6-S/L FD

Drawing No. 04-1200-1-00

Rev. 0

B-96-8-S/L FD

Drawing No. 04-1200-2-00

Rev. 0

\begin{tabular}{lll}
\multicolumn{3}{c}{ Test/Analysis Results } \\
No. Tested & Iocation
\end{tabular}

Pass

Not Tested

1

Top cover

Pass

1

Top cover

Pass

1

Top cover

Pass

Pass

Not Tested

1

Top cover

Pass

1

Top cover

\section{Comments}

Evaluated by analysis and comparison to packsaging $B-25-4-S / L$ FD whose top is constructed of materials of equal thickness.

only effect was a minor dent.

only effect was a minor dent.

only effect was a minor dent.

Evaluated by analysis and comparison to packaging B-96-6-S/L FD whose top is constructed of materials of equal thickness.

Only effect was a minor dent.

Only effect was a minor dent. 
TABLE D-31 (contimued)

Specific

Packaging

Container Products

Corp. (CPC)

B-96-5-S/L FD

Drawing No. 01-2101-1-00

Rev. 0

B-96-5-S/L RA

Drawing No. 01-1901-1-00

Rev. 0

B-96-5-RA-B

Drawing No. 01-2201-1-01

Rev. 0

467-C-S/L FD

Drawing No. 01-3700-1-00

Rev. C

RoGar Chemical and Nuclear Services

Model $R-1$

\begin{tabular}{ll}
\multicolumn{3}{c}{ Test/Analysis Results } \\
No. Tested Iocation
\end{tabular}

1

Top

Pass

Pass

Not Tested

Not Tested

Pass

1

Top cover

Pass

Not Tested
Pass

\section{comments}

only effect was a minor dent.

Evaluated by analysis and comparison to packaging B-96-5-S/L, FD whose top is constructed of materials of equal thickness.

Evaluated by analysis and comparison to packaging B-96-5-S/L FD whose top is constructed of materials of equal thickness.

only effect was a minor dent.
Evaluated by analysis and comparison (lid, lid reinforcing angle, bolt size, bolt spacing, container flange, and materials of construction) to test package (Model R-3). All materials and methods of construction were equal to or better than those of the tested packaging. 
TABLE D-31 (continued)

Specific

Packaging

RoGar Chemical and Nuclear

\section{Services}

Model R-2

Not Tested

Model R-3

Model R-4

\section{Rocky Flats SAND BOX}

Style 1

Style 2
Pass

No. Tested
Not Tested

Test/Analysis Results

Iocation Results

1

1

Not Tested
Top cover

Center of filter
Pass

Pass

Pass

$\begin{array}{ll}\text { Top } & 1 \text { Pass } \\ \text { Side } & 1 \text { Pass } \\ \text { Filter } & 1 \text { Pass } \\ \text { Top } & 1 \text { Pass } \\ \text { Side } & 1 \text { Pass } \\ \text { Filter } & 1 \text { Pass }\end{array}$

Comments

Evaluated by analysis and comparison (lid, lid reinforcing angle, bolt size, bolt spacing, container flange, and materials of construction) to test package (Model R-3). All materials and methods of construction were equal to or better than those of the tested packaging.

The only effect was a minor dent.

The only effect was a minor dent.

Evaluated by analysis and comparison ( 1 id, lid reinforcing angle, bolt size, bolt spacing, container flange, and materials of construction) to test package (Model R-3). All materials and methods of construction were equal to or better than those of the tested packaging.

other than a minor dent, there was no damage in any instance.

other than a minor dent, there was no damage in any instance. 
TABIE D-31 (continued)

Specific packaging

Rocky Flats SAND Box

Style 3

Style 4

\section{Argonne M-4}

Bin

ANL-West

7A-960

No.

$\begin{array}{lll}1 & \text { Top } & 1 \text { Pass } \\ 1 & \text { Side } & 1 \text { Pass } \\ 1 & \text { Filter } & 1 \text { Pass }\end{array}$

1 Pass

1 Pass

1 Pass

Pass

I Pass
Top

Side

Top

Side

Filter

Side

Side

Top
1 Pass

1 Pass

Results

Other than a minor dent, there was no damage in any instance.

Other than a minor dent, there was no damage in any instance.

Other than a minor dent, there was no damage in any instance.

1 Pass
Other than a minor dent, there was no damage in any instance. 
PENETRATION TEST RESUITS FOR WOODEN BOXES

TABLE D-32

Specific

packaging

ANL-West

$7 A-217$

$7 A-375$

$7 \mathrm{~A}-880$

$7 \mathrm{~A}-995$

$7 \mathrm{~A}-1315$

$7 A-670$

\section{IINL}

Flush Panel

Mound - Configuration A

$M A-1$

$\mathrm{MA}-2$

MA-3

$M A-4$
Test/Analysis Results

No. Tested Iocation Results

1 Pass

1 Pass

1 Pass

1 Pass

1 Pass

1 Pass

Top

Top

Top

1 Pass

1

Top

Side

Top

Side

Top

Side

Top

Side
1 Pass

1 Pass

1 Pass

1 Pass

1 Pass

1 Pass

1 Pass

1 Pass

\section{Conments}

Only effect was a minor dent in each case.

Only effect was a minor dent.

Only effect was a minor dent in each case.

Only effect was a minor dent in each case.

only effect was a minor dent in each case.

Only effect was a minor dent in each case. 
TABIE D-32 (continued)

Specific

Packaging

Mound - configuration B

$M B-1$

MB-2

MB-3

MB-4

MB-5

MB-6

Mound - Configuration C

MC-1

$\frac{\text { Test/Analysis Results }}{\text { No. Tested }}$ Iocation

Not Tested

1

1

Bottom
Side

Not Tested

Not Tested

Not Tested

1

1

Top

Side

1 Pass

1 Pass

1 Pass

1 Pass
Pass, based on testing of boxes of similar materials and construction methods at weights in excess of those actually required.

only effect was a minor dent in each case. The bottom was chosen because it was still wet at the time.

Pass, based on testing of boxes of similar materials and construction methods at weights in excess of those actually required.

Pass, based on testing of boxes of similar materials and construction methods at weights in excess of those actually required.

Pass, based on testing of boxes of similar materials and construction methods at weights in excess of those actually required.

only effect was a minor dent in each case.

1 Pass

1 Pass

only effect was a minor dent in each case. 
TABLE D-32 (continued)

Specific

packaging

Mound - Configuration C

MC-2

MC-3

MC-4

$M C-5$

Mound - Configuration D

MD-1

MD-2

MD-3

MD-4

MD-5

MD-6

\begin{tabular}{lll}
\multicolumn{3}{c}{ Test/Analysis Results } \\
No. Tested & Iocation
\end{tabular}

1 Pass

1 Pass

1 Pass

1 Pass

1

side

Top

Side

1 Pass

Top

Side

1 Pass

Top

Side

1 Pass

1 Pass

Only effect was a minor dent in each case.

Only effect was a minor dent in each case.

only effect was a minor dent in each case.

Only effect was a minor dent in each case.

Not Tested

Not Tested

Not Tested

Not Tested

Not Tested

Not Tested

Pass, based on testing of boxes of similar materials and construction methods.

Pass, based on testing of boxes of similar materials and construction methods.

Pass, based on testing of boxes of similar materials and construction methods.

Pass, based on testing of boxes of similar materials and construction methods.

Pass, based on testing of boxes of similar materials and construction methods.

Pass, based on testing of boxes of similar materials and construction methods. 
TABLE D-32 (continued)

Specific

Packaging

\section{Mound - Configuration E}

$\mathrm{ME}-1$

ME-2

ME-3

NLO Family of Banded Wooden Boxes

\section{G-4214}

G-4245

G-4255

$G-4273$

G-4292

\begin{tabular}{lll}
\multicolumn{3}{c}{ Test/Analysis Results } \\
No. Tested & Iocation
\end{tabular}

1 Pass

1 Pass

1 Pass

1 Pass

Side

1 Pass

Top

Side

1 Pass
Only effect was a minor dent in each case.

Only effect was a minor dent in each case.

Only effect was a minor dent in each case.
1

1

1

1

1
Top

Top

Top

Top

Top
1 Pass

1 Pass

1 Pass

1 Pass

1 Pass

Only effect was a minor dent in each case.

Only effect was a minor dent in each case.

Only effect was a minor dent in each case.

Only effect was a minor dent in each case.

Only effect was a minor dent in each case. 
TABLE D-32 (continued)

Specific

packaging

\section{Y-12 Series B}

B-l

B-2

B-3

B-4

B-5

B-6

B-7

B-8
Test/Analysis Results

No. Tested Iocation Results

1 Pass

1 Pass

1 Pass

1 Pass

1 Pass

1 Pass

1 Pass

1 Pass

1 Pass

1 Pass

side

Top

Side

1 Pass

1 Pass

Top

Side

1 Pass

1

Top

Side
1 Pass

1 Pass

1 Pass
All packages were water spray tested before testing. Only effect of the penetration test was a minor dent in each case.

All packages were water spray tested before testing. Only effect of the penetration test was a minor dent in each case.

All packages were water spray tested before testing. Only effect of the penetration test was a minor dent in each case.

All packages were water spray tested before testing. Only effect of the penetration test was a minor dent in each case.

All packages were water spray tested before testing. Only effect of the penetration test was a minor dent in each case.

All packages were water spray tested before testing. Only effect of the penetration test was a minor dent in each case.

All packages were water spray tested before testing. Only effect of the penetration test was a minor dent in each case.

All packages were water spray tested before testing. Only effect of the penetration test was a minor dent in each case. 
TABLE D-32 (continued)

Specific

packaging

\section{Y-12 Picture Frame}

$\mathrm{PF}-1$

$\mathrm{PF}-2$

$\mathrm{PF}-3$

$\mathrm{PF}-4$

$\mathrm{PF}-5$

PF-6

$\mathrm{PF}-7$

PF-8

Rocky Flats RA Series

Configuration 1

configuration 2

\begin{tabular}{lll}
\multicolumn{3}{c}{ Test/Analysis Results } \\
No. Tested & Location
\end{tabular}

1 Pass

1

1

\begin{abstract}
Top center
Top edge
\end{abstract}

1 Pass

Not Tested

Not Tested

Not Tested

$\begin{array}{ll}\text { Top center } & 1 \text { Pass } \\ \text { Top edge } & 1 \text { Pass } \\ \text { Top center } & 1 \text { Pass } \\ \text { Top edge } & 1 \text { Pass }\end{array}$

Not Tested

Not Tested

\section{Comments}

Only effect was a minor dent in each case.

Pass, based on testing of boxes of similar materials and construction methods.

Pass, based on testing of boxes of similar materials and construction methods.

Pass, based on testing of boxes of similar materials and construction methods.

only effect was a minor dent in each case.

Only effect was a minor dent in each case.

Pass, based on testing of boxes of similar materials and construction methods.

Pass, based on testing of boxes of similar materials and construction methods.

only effect was a minor dent in each case. 
PENEIRATION TEST RESULTSS FOR FIBERBOARD PACKAGTNGS

TABLE D-33

Specific

Packaging

\section{B-65 Fiberboand Boxes}

1

2

3

5

$\frac{\text { Test/Analysis Results }}{\text { No. Tested Location }}$

Pass - No Penetration

Pass - No Penetration

Pass - No Penetration

Pass - No Penetration

Not Tested

Pass - Penetration

Pass - Penetration

Pass - No Penetration

Pass - No Penetration

Pass - Penetration

Pass - Penetration

Pass - No Penetration

Pass - Penetration

Pass - Penetration

Pass - Penetration

$1 \quad$ Side

$1 \quad$ Top

1 Side
Pass - No Penetration

Pass - No Penetration

\section{Comments}

Only effect was a minor dent in each case.

Pass, based on testing of boxes of similar materials and construction methods.

only effect was a minor dent.

only effect was a minor dent.

only effect was a minor dent. 
TABLE D-33 (contimued)

\section{Specific}

Packaging

12B-65 Fiberboard Boxes

11

12

13

12B-10 with inner

metal can

Tri-Wall

Fiberboand Box
Test/Analysis Results

No. Tested Iocation Results

\section{Comments}

Pass, based on testing of boxes of similar materials and construction methods.

Bar made 0.5-in. dent in inner can in in each case. A leak check (air) of the can in each case demonstrated continued leak tightness. 
TABLE D-33 (continued)

Specific

packaging

\section{C Fiberboard}

Drums

1

2

3

4

5

6
Test/Analysis Results

No. Tested Iocation Results

Comments
Top Pass - No Penetration

Side Pass - No Penetration

Top Pass - No Penetration

Side Pass - No Penetration

Top Pass - No Penetration

Side Pass - No Penetration

Top Pass - No Penetration

Side Pass - Penetration

Top Pass - No Penetration

Side Pass - Penetration

Top Pass - No Penetration

Side Pass - No Penetration 
PENEIRATION TEST RESUIIS FOR UF-6 CYLTNDERS

TABIE D-34

Specific

Packaging

Model No.

is

25

$5 A$

8A

$12 \mathrm{~A}$

12B

$30 \mathrm{~A}$

$30 \mathrm{~B}$

$48 G$

$48 \mathrm{H}$

48HX

$48 X$

$48 Y$

$\frac{\text { Test/Analysis Results }}{\text { No. Tested Location }}$

Comments

Evaluated based on the materials and material thicknesses and by camparison to test data shown for much lesser thicknesses. This test would not have any effect

(as verified by testing) on the sides of these cylinders. Testing was also conducted to demonstrate that this test, when conducted on the valve assembly/ assembly cover, would also have no effect. Thus, all these cylinders meet this requirement. 
PENETRATION TEST RESUITS FOR IIQUIDS AND GASES

TABLE D-35

Specific

Packaging

Steel Drum

MS-24347-7

(p. $\mathrm{F}-1)^{\mathrm{a}}$

IASL 12B-62 Fiberboard

Box

IINL Steel Drums with

Gas Cylinders

(p. F-1I)

ORNL Fiberboard Box Liquids and solids

(p. F-15)

ORNL Fiberboard BOx -

Gases (p. F-20)

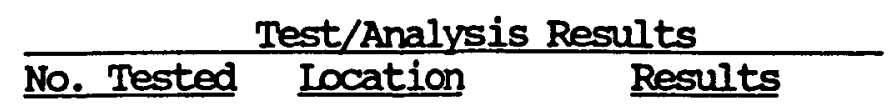

1

1

Top

Side

Pass - Penetration

Pass - Penetration

1

Top
(center)

1 Pass

1

Top

\section{Comments}

Pass, based on test data shown on page D-72.

The bar did not contact the inner container in either case.

Pass, based on test data shown on Page D-72.

A nompenetrating deformation of the wet cardboand box and a $0.55-i n$. deep by $0.75-i n$. diameter indentation in the top of the inner metal can.

A nompenetrating deformation of the wet cardboard box and a $0.55-i n$. deep by $0.75-i n$. diameter indentation in the top of the inner metal can.

$a_{\text {All page numbers refer to MIM-3245. }}$ 
TABLE D-35 (contimued)

Specific

packaging

ORNL Fiberboard BOX Iiquids and Solids (p. F-21)

ORNL Wooden BOX Returnable, Shielded (p. F-26)

ORNL Gas Cylinder

Returnable

(Hoke Cylinders)
HOH -50
HOXe -50
HOK $x-50$
HOH-150
HOXe-150
HOKr-150
HOH -300
HOKr-300
HOH -500
HPKr -500

ORNL Gas Cylinder

Returnable

(J. L. Shepard)

Cylinder 1

Cylinder 2

Cylinder 3

Test/Analysis Results
No. Tested Location

1

Top (center)

1 Pass

1

Top (center)

1 Pass

1

Top

(center of protective valve cap)

\section{comments}

A nompenetrating deformation of the wet cardboard box and a 0.55-in. deep by 0.75-in. diameter indentation in the top of the imer metal can.

Minor, nompenetrating dent.

This test was conducted on the HOKr 1000-mL cylinder (which is not listed), but the results can be used to evaluate the smaller packagings.
Pass
Evaluated based on testing conducted by ORNL, letter dated April 30, 1985, D. M. Ferren/D. A. Edling. 
PENETRATION TEST' RL,UITS FOR MISCELLANEOUS PACKAGINGS

TABLE D-36

Specific

packaging

IINL old Spec 55

ORNL TRU Shipping

Container

FEMA Source over

Pack

SNL Tritium Waste

Package
Test/Analysis Results

\begin{tabular}{|c|c|c|}
\hline No. Tested & Iocation & Results \\
\hline 2 & Iid bolts & 2 Pass \\
\hline $\begin{array}{l}1 \\
1\end{array}$ & $\begin{array}{l}\text { Top } \\
\text { Side }\end{array}$ & $\begin{array}{l}1 \text { Pass } \\
1 \text { Pass }\end{array}$ \\
\hline 1 & Top & 1 Pass \\
\hline
\end{tabular}

Pass, based on test data shown on Page D-72. 